ANL- $-90 / 29$

DE91 013284

ANL-90/29

ARGONNE NATIONAL LABORATORY

9700 South Cass Avenue

Argonne, Illinois 60439

GUIDELINES TO ACHIEVE SEALS WITH MINIMAL LEAK RATES FOR HWR-NPR COOLANT SYSTEM COMPONENTS

by

P. A. Finn

Chemical Technology Division

March 1991

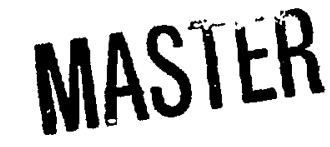

Work supported by the U.S. Department of Energy, Office of New Production Reactors, under Contract W-31-109-Eng-38. 
1. INTRODUCTION

2. EXECUTIVE SUMMARY

3. CRUCIAL SEALS FOR HWR-NPR ………....................................................... 5

3.1 Flange for Reactor Head ......................................................................... 5

3.2 Elastomer Seals for Control Rods/Safety Rods/Fuel Tubes .............................. 5

3.3 Isolation Valves ....................................................................................... 5

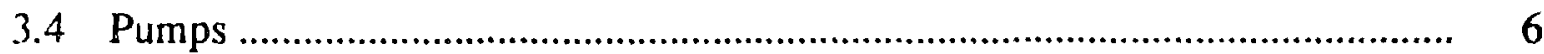

4. SEAL REQUIREMENTS IN THE HWR-NPR .................................................. 6

4.1 Leak Rate ............................................................................................... 6

4.2 Aging Effects .................................................................................... 9

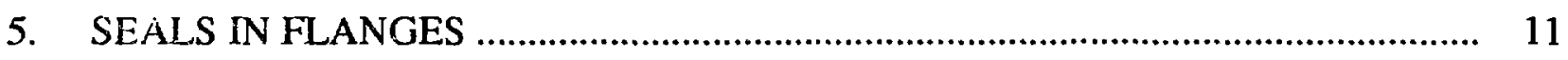

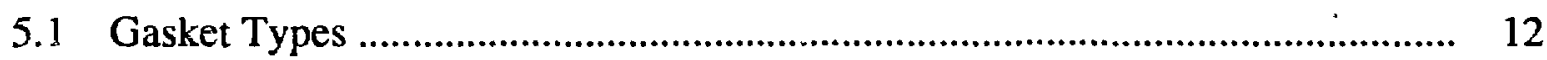

5.2 Design Procedure for Flanges ............................................................... 17

5.3 Bolt Design .......................................................................................... 22

54 Surface Finish ................................................................................ 24

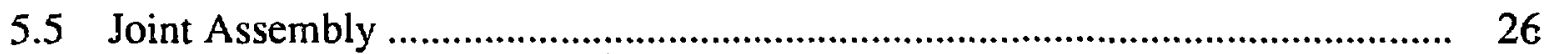

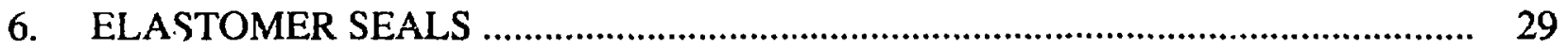

6.1 Long Term Deformation ............................................................................. 30

6.2 Characterization of Ethylene Propylene ……................................................... 32

6.3 Engineering Design of Elastomers .................................................................... 36

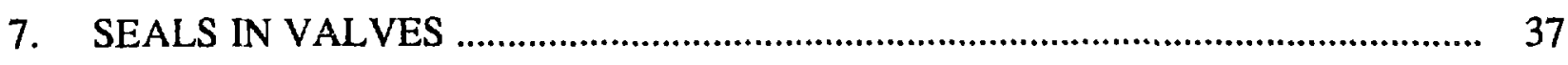

7.1 Bellows Valves ....................................................................................... 38

7.2 Packed Valves ............................................................................................. 39

7.2.1 Live-Loading .......................................................................................... 39 
7.2.2 Expanded Graphite Packing ............................................................ 43

7.2.3 Valve Redesign ................................................................................... 48

7.3 Other Valve Developments ............................................................................ 48

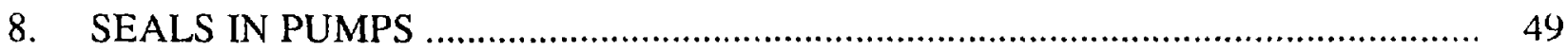

8.1 Centrifugal Pumps ................................................................................ 49

8.2 Canned Yumps ....................................................................................... 51

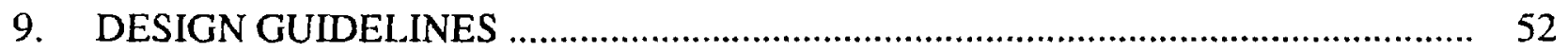

9.1 Flange Seals ........................................................................................ 52

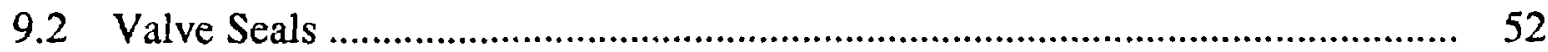

9.3 Pump Seals .......................................................................................... 53

9.4 Manufacturing Requirements ........................................................................ 53

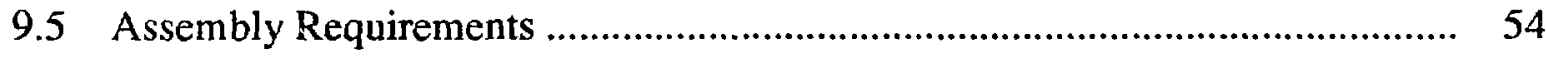

9.6 Maintenance Requirements .......................................................................... 54

10. RECOMMENDED RESEARCH AND DEVELOPMENT …............................. 55

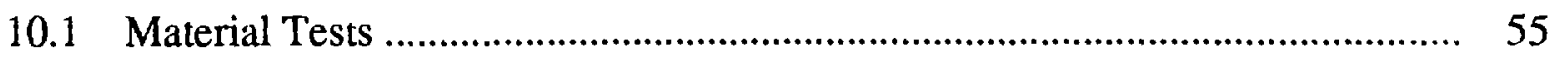

10.2 Quality Control Tests ............................................................................... 55

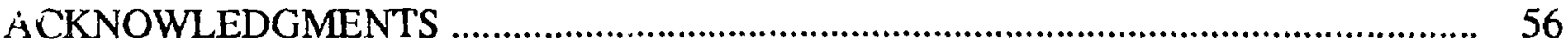

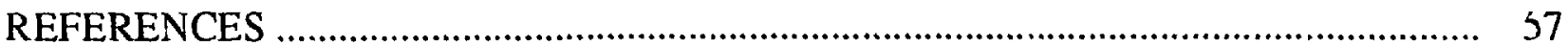




\section{LIST OF FIGURES}

No.

1. Effect of Pressure, Temperature, and Leak Diameter on Water Leak Rate Calculated from Helium Leak Rate of $10^{-6} \mathrm{~cm}^{3}(\mathrm{STP}) / \mathrm{s}$

2. Three Types of Weld Joints: Omega, Canopy, and Lip

3. Generic Example of Results of Part A and Part B Tests for Spiral Wound Gaskets

4. Data for Part A Tests for Lines of Constant Gasket Stress

5. Stress Versus Leak Tightness and Gasket Deflection for 304 Stainless Steel Spiral Wound Gaskets with Graphite Filler

6. Gasket Leak Rate Chart for Given Gasket Type 22

7. Bolt Relaxation Curves for Different Pretreatments

8. Peak-to-Valley Distribution of a Highly Compressed Abraded Surface

9. Effect of Defect Distribution on Flow across Seal

10. Variation of Seal Leakage with Seal Compression for Different Machining Processes

11. Load on Individual Bolts after Three Tightenings with Calibrated Torque Wrenches, with an Extensometer, and after Two Years Operation

12. Arrhenius Plots Comparing Compression Set to Two Other Techniques for Silicone Rubber and Low Compression Set Fluorocarbon

13. Change in Compression Set for Ethylene Propylene Copolymer in Air as Function of Time and Temperature

14. Change in Compression Set for Ethylene Propylene Copolymer in Pressurized Water as Function of $\mathrm{O}_{2}$ Content and Time 


\section{LIST OF FIGURES (contd)}

No.

15. Distribution of Axial and Radial Forces within a Valve Stuffing Box

16. Force-Displacement Relationship for the Gland Loading System

17. Characteristic Load-Deflection Curves for Belleville Springs

18. Belleville Spring Stacking Arrangements .

19. Graphite Wedge Packing Arrangement in Valves

20. Initial Consolidation and In-Service Consolidation of Graphite Wedge Packing

21. Gland Pressure Versus System Pressure for Graphite Wedge Packing 


\section{LIST OF TABLES}

No.

1. Fffect of the Leak Diameter on a Component's Water Leak

Rate at $0.5 \mathrm{MPa}$ and $100^{\circ} \mathrm{C}$

2. Causes of Failures in Reactor Systems ................................................................ 10

3. Type of Service Interruption Caused by System Failure …...................................... 10

4. Cause of Reactor System and Valve Failure Due to Aging .................................... 11

5. Cause of System and Pump Failure Due to Aging .................................................. 11

6. Room-Temperature Properties of GTA Graphite Sheets ........................................... 15

7. Effect of Increase in Graphite Sheet Density on Physical Properties

8. Mechanical Properties of Graphite Sheet after Irradiation ........................................ 16

9. Conditions for which Compression Was $\geq 50 \%$ for Ethylene Propylene in AECL Tests

10. Water Leak Rates and Compression Set for

Ethylene Propylene Compared to Other Elastomers

11. Compression Set and Tritiun Off-gas Rate for Ethylene Propylene and Other Elastomers

12. Dynamic Leakage for Graphite Packing in BWR and PWR Modified Valves After 1500 Stroke Cycles

13. Cross Sections for Graphite Packings Tested by Rockwell

14. Designer Actions to Achieve Valves with Low Leak Rates 


\title{
GUIDELINES TO ACHIEVE SEALS WITH MINIMAL LEAK \\ RATES FOR HWR-NPR COOLANT SYSTEM COMPONENTS
}

by

P. A. Finn

\begin{abstract}
Seal design practices that are acceptable in pressurized-water and boilingwater reactors in the United States are not usable for the Heavy Water Reactor-New Production Reactor (HWR-NPR) because of the stringent requirement on tritium control for the atmosphere within its containment building. To maintain an atmosphere in which workers do not need protective equipment, the components of the coolant system must have a cumulative leak rate less than $0.00026 \mathrm{~L} / \mathrm{s}$.

Existing technology for seal systems was reviewed with regard to flange, elastomer, valve, and pump design. A technology data base for the designers of the HWR-NPR coolant system was derived from operating experience and seal development work on reactors in the United States, Canada, and Europe. This data base was then used to generate guidelines for the design of seals and/or joints for the HWR-NPR coolant system. Also discussed are needed additional research and development, as well as the necessary component qualification tests for an effective quality control program.
\end{abstract}

\section{INTRODUCTION}

The objective of this effort was to develop guidelines for designing seals with minimal leak rates for the coolant system components in the Heavy Water Reactor-New Production Reactor (HWR-NPR). Seal practices which are acceptable in pressurized-water and boilingwater reactors in the United States are not acceptable for the HWR-NPR. The nuclear power industry accepts water leak rates of the order of $0.0065 \mathrm{~L} / \mathrm{s}$ from unknown sources and up to $0.065 \mathrm{~L} / \mathrm{s}$ from known sources to their containment building. An upper limit is $0.65 \mathrm{~L} / \mathrm{s}$, the maximum that the recirculation pumps can handle. With a leak rate of $0.065 \mathrm{~L} / \mathrm{s}$ being acceptable, the relative humidity within the containment buildings of commercial reactors is often $100 \%$.

The Heavy Water Reactor-New Production Reactor has stringent requirements on tritium control. At a water leak rate of $0.0065 \mathrm{~L} / \mathrm{s}$ (ten times more stringent than the commercial power industry), the atmospheric tritium concentration within containment can rise to $40 \mu \mathrm{Ci} / \mathrm{m}^{3}$ in $10 \mathrm{~min}$ in a volume of $10^{5} \mathrm{~m}^{3}$, at a heavy water tritium concentration of $1 \mathrm{Ci} / \mathrm{L}$. This room concentration exists even if high-efficiency driers are in operation since economics would limit the maximum flow rate to the driers to $<10$ vol\%/min for volumes of $10^{4}$ to $10^{5} \mathrm{~m}^{3}$. For an 
unprotected worker, this tritium concentration results in a dose rate of $5 \mathrm{mrem} / \mathrm{h}$, or a dose of $0.5 \mathrm{rem}$ in $100 \mathrm{~h}$. This dose is the annual goal for each worker at the HWR-NPR. Since the dose from gamma radiation has not been included, this is a lower limit on the dose that the worker would receive under these conditions.

The leak rate to the containment building which is acceptable for the coolant components of the HWR-NPR must meet three requirements: (1) the tritium concentration within containment is acceptable for workers, (2) the yearly heavy water losses from containment are minimized, and (3) reasonably sized air cleanup systems and deuterated water upgrade systems are adequate to achieve the first two requirements.

Regulatory requirements and/or maintenance requiruments have driven the development of new seal materials and/or concepts within the United States. Environmental Protection Agency (EPA) requirements have resulted in the replacement of asbestos valve packings and gaskets with expanded graphite materials. For retrofits with expanded graphite materials, the designs of flanges and valves are not optimized since the properties of expanded graphite are significantly different from asbestos. Thus, flange or valve hardware built to operate with asbestos cannot achieve the optimum leak rate possible with expanded graphite. A new valve and/or joint design is therefore needed to achieve the lower leak rate that is possible.

In the United States published information on seal modifications which result in low leak rates is often not incorporated into specifications and/or designs for new systems because of a lack of knowledge, conservativeness in specifying new product lines, or a perceived capital cost disadvantage. Failure to incorporate existing technology (American, European, Canadian) into design practices for seal components results in high operating costs in the commercial nuclear power industry, both for replacement electrical power during repairs and for the extra worker time needed to minimize individual dose during repairs.

For the HWR-NPR, the specification of seal systems which have cumulative leak rates of $0.00026 \mathrm{~L} / \mathrm{s}$ (30 times lower than any commercial specification), would be highly desirable. To specify these seal systems, existing technology was reviewed in four categories: (1) flange design, (2) elastomer design, (3) valve design, and (4) pump design. The collected data base was derived from operating experience and seal development work for commercial reactors in the United States, Canada, and Europe. Groups which have sponsored or generated sustained programs are the Electric Power Research Institute (EPRI), Atomic Energy of Canada, Limited (AECL), and the British Hydromechanical Research Association (BHRA) in Europe. Major changes in the specifications for joints or seals have arisen from their work and should be incorporated into the specifications for the coolant components of the HWR-NPR.

Our work can serve as a basis for guidelines to design a coolant system which can achieve the leak-rate requirement of the HWR-NPR design. Areas needing research and development are summarized. Qualification and verification tests for components are specified. Capital costs which might be incurred by following the recommendations of this study would be offset by the lower operating costs incurred over 40 years of HWR-NPR operation. 


\section{EXECUTIVE SUMMARY}

The state of the art in seal development was determined by reviewing the relevant literature for the design of flanges, elastomer seals, valves, and pumps. The collected data base includes data obtained from operating experience and seal development efforts for commercial reactors in the United States, Canada, and Europe. Guidelines to direct the design of effective seals for the coolant system in the HWR-NPR were derived from this information. These guidelines are especially important in designing the flange seal on the reactor head; the dynamic seals for the fuel tubes, control rods, and safety rods which pass through the reactor head; the isolation valves; and the reactor pumps. The guidelines are divided into the following categories: engineering design, manufacturing requirements, assembly requirements, maintenance requirements, material tests, and quality control tests.

\section{Engineering Design}

Common practices for the design of bolted flanges, elastomer seals, valves, and pumps should be reassessed.

The ASME formulas used to compute the sealing load for a flange are not justified, as shown by work sponsored by the BHRA. An alternative system should be used to specify compression loads for flange seals using a spiral-wound gasket with an expanded-graphite filler.

For large diameter seals in critical locations, a finite element analysis is required to determine the rotation in the joint, which is a function of the internal pressure and the structural stiffness of the flange. The seal should be modeled full size, since deformation characteristics and contact stress are influenced by a seal's cross section.

The valve designer has several choices for the HWR-NPR plant. First, the number of valves can be minimized within the constraints of system maintenance. Second, bellows valves or welds can be used if fatigue is not a problem or if loss of access is allowed. Third, valves using die-formed expanded-graphite packing with live-loading can be incorporated. For the latter, packing and spring combinations have to be tested so that spring stacks can be designed to assure a sustained high gland load on the packing. This option probably will require the design of new valves.

For centrifugal pumps, ethylene propylene seals with a curved-back U-cup design should be used in shaft seals to minimize the effects of power blackouts on the degradation of the shaft seal.

\section{Manufacturing Requirements}

Two factors are important in manufacturing: the consistent availability of a qualified component and the consistent production of that component to specification. Certificates of conformance or compliance would be advisable to ensure that the required material is supplied. These certificates would include the manufacturing history, especially important for bolts, and would document the exclusion of deleterious materials (chloride or sulfur containing). 
The tolerances needed on a flange or valve body to achieve a given leak rate must be specified. The effects of post-machining stress relaxation or the influence of other structural components need to be considered in the flange design to achieve a seal with a low leak rate. Surface waviness and changes in tolerances increase with physical size, and distortions can occur due to the weight-carrying capacity of a component like a flange.

\section{Assembly Requirements}

Special tools may be required for assembly or disassembly of flanges, valves, and/or pumps. These tools need to be specified and designed if so required. For example, an ultrasonic extensometer should be specified for the assembly of bolted flanges.

\section{Maintenance Requirements}

Achieving seals that are reliable and maintainable requires considerable effort, including the collection of failure rate data for each component and the determination of failure modes, corrective maintenance times, and preventive maintenance times. Design decisions based on analysis of failure modes can improve reliability and maintainability. Physical changes in equipment, systems, or procedures can improve reliability, as can clearly stated specifications for the equipment and factual evidence that the specifications are met.

Maintenance requirements should inciude not only physical maintenance but also the specification of maintenance records on each component throughout its lifetime.

\section{Material Tests}

A rigorous characterization of the properties of spiral-wound graphite-filled gaskets, ethylene propylene, and expanded-graphite packing material is needed since these properties serve as a basis for designer's calculations.

For spiral-wound gaskets, the leak behavior has to be measured using the technique developed under the sponsorship of BHRA. The properties of the elastomer (EPDM) have to be well characterized. The response to load of graphite packing and Belleville springs, as a function of time, needs to be ineasured so that the lifetime of these components can be estimated.

\section{Quality Control Tests}

A quality control program is needed for the design, manufacture, installation, and assembly of all coolant component seals and/or joints. Specifications must be set for the components to ensure that they achieve the minimal leak rate. Then the components have to be qualified in defined tests to ensure long-term leakage performance. In addition, procedures for the installation and assembly of these components within containment have to be documented. The four types of quality control tests necessary for all components are qualification, validation, compliance, and development tests. 


\section{CRUCIAL SEALS FOR HWR-NPR}

The HWR-NPR coolant systems will require several crucial seals: a flange for the reactor head, static elastomer seals for the fuel rods, dynamic elastomer seals for the control and safety rods, isolation valves, and reactor pumps.

\subsection{Flange for Reactor Head}

The design of the flange seal on the reactor head is a major design challenge. To achieve a design which has both the strength and the flexibility needed, the best experience on flanged joint design and assembly has to be incorporated into the HWR-NPR design effort. Each feature of this seal (the design and manufacture of the flange faces, the type of gasket, the type of bolt, the method of assembly) influences the effectiveness of the seal. Therefore, we have examined each of these areas to provide for the designer information pertinent to the goal of an effective seal.

\subsection{Elastomer Seals for Control Rods/Safety Rods/Fuel Tubes}

The current control rods for Savannah River Site reactors are in open standpipes. Tritiated water vaporizes from these standpipes to the reactor building. For the HWR-NPR, the control rods will have a sealed drive system, and multiple rods will be interlinked.

Since these control rods have to constantly change position within the reactor core, a flexible but leak-tight seal is required at the reactor and air interface. The design of this seal should incorporate current data on elastomers which have the greatest resistance to tritium embrittlement or the loss of their compressibility. In addition, live-loaded seals, which provide a constant compression force, may be an effective way to improve the control rod's seal.

The HWR-NPR design of the fuel rod has as its greatest challenge, the refueling

operation. For pressurized-water reactors (PWRs) refueling is done under water, ${ }^{1,2}$ but there are hardware malfunctions, many of which cause leaks. Improvements in hardware have been recommended for both $\mathrm{PWRs}^{3}$ and boiling-water reactors (BWRs) ${ }^{4}$ to address the fueling operations.

\subsection{Isolation Valves}

The HWR-NPR design has attempted to minimize the problem of leaking valves by eliminating most valves within the containment building. However, there is one set of valves which cannot be eliminated, the isolation valves. These valves have a crucial function; therefore, their design requires the incorporation of the best input from existing data. These data include specifications for live-loading and expanded graphite packing. These data have been summarized for the designer's benefit. 


\subsection{Pumps}

Two types of pumps have been proposed for the main coolant system, centrifugal pumps and canned motor pumps. Available information for each of these systems has been reviewed. For centrifugal pumps, information relevant to the seals on the shaft has been examined, especially the behavior of this system during off-normal conditions.

Recommendations are made on desirable elastomer seals to use on the pump shaft. For canned motor pumps, in which blockage of the coolant channels is a problem, the needed information for corrosion behavior of the internal graphitar bearing is mentioned.

\section{SEAL REQUIREMENTS IN HWR-NPR}

Specifications for seals have to conform to the low leak rate requirements for the HWRNPR. At an early stage in the development of the design, the ability to meet these specifications must be assured.

The leak rate to containment which is acceptable for the coolant components of the HWRNPR must meet three requirements: (1) the yearly heavy water losses from containment are minimized, (2) the tritium concentration within containment is acceptable for workers, and (3) reasonably sized air cleanup systems and deuterated water upgrade systems can achieve the first two requirements.

The influence of various parameters on seal leakage and permeation must be considered. The parameters include system pressure, system temperature, fluid properties, seal materials, seal dimensions, geometric shape of seal, surface condition, and the effects of aging.

\subsection{Leak Rate}

Leakage $\left(Q_{p}\right)$ is a function of the ratio of the contact pressure $\left(P_{c}\right)$ to material yield shear stress ( $k$ ) or to material elastic modulus $(E)$, for plastic or elastic deflections. An increase in the contact pressure results in a reduction in leakage:

$$
Q_{p}=f\left(P_{c} / 2 k\right) \text { or } Q_{p}=f\left(P_{c} / E\right)
$$

where $\mathrm{f}$ indicates a functional relationship.

Water losses from a seal are due to permeability or defects in the seal. For elastomers, the lower leak rate limit is the permeation rate. Several workers have measured permeability for elastomers. ${ }^{5-8}$ The upper limit for water losses for elastomer, graphite, or metal seals is due to defects in the seal material. Defects in seal materials can increase over time due to corrosion or wear effects.

Several calculational techniques based on fluid flow theory have been developed for

estimating component leakage..$^{9-15}$ One technique is based on characterizing coolant leakage from a component by means of the helium leak rate for that component. ${ }^{9}$ A common difficulty for this technique is the selection of parameters to characterize the components in terms of the 
leak rate. The most direct technique assumes that the helium leak rate is known, based on quality assurance acceptance standards or leak rate measurements at a known temperature and pressure. Component leakage can then be characterized by determining the dimensions of the leak path which would produce such a leak rate under the given conditions of temperature and pressure.

The determination of the leak-path dimensions is determined as a function of molecular or laminar flow. For laminar flow, the Poiseuille equation is used:

$$
\mathrm{Q}_{1}=\pi(\mathrm{D} / 2)^{4}\left(\mathrm{P}_{\mathrm{a}} / 8 \mu \mathrm{L}\right)\left(\mathrm{P}_{1}-\mathrm{P}_{2}\right)
$$

where $Q_{1}$ is the volumetric leak rate, $P_{1}$ is the upstream pressure, $P_{2}$ is the downstream pressure, $P_{a}$ is the average of the two pressures, $D$ is the leak path diameter, $L$ is the leak path length, and $\mu$ is the fluid viscosity. For molecular flow, the Knudsen equation is used:

$$
\mathrm{Q}_{\mathrm{m}}=(2 \pi \mathrm{RT} / \mathrm{M})^{0.5}\left(\mathrm{D}^{3} / 6 \mathrm{~L}\right)\left(\mathrm{P}_{1}-\mathrm{P}_{2}\right)
$$

where $\mathrm{R}$ is the gas law constant, $\mathrm{T}$ is the absolute temperature, and $\mathrm{M}$ is the molecular weight of the fluid. If liquid laminar flow is assumed, the leak-path dimensions are used to calculate water leakage:

$$
\mathrm{Q}_{\mathrm{L}}=\pi(\mathrm{D} / 2)^{4}\left(\mathrm{P}_{1}-\mathrm{P}_{2}\right) / 8 \mu \mathrm{L}
$$

To apply this technique, it is necessary to specify an appropriate helium leak rate. A leak-tightness standard, equivalent to a helium leak rate of $10^{-6} \mathrm{~cm}^{3}(\mathrm{STP}) / \mathrm{s}$, is proposed for each manufactured component at its beginning-of-life for the HWR-NPR since components with this leak rate would meet the water leak rate requirements for the containment building. This leaktightness standard can be used to estimate the chronic leakage at the beginning-of-life from components of the water coolant systems. Because these components will have different leak rates, some of which may represent a significant increase above the leak-tightness standard during operation, we assumed that $10 \%$ of the population have a leak rate two orders of magnitude higher than the standard, e.g., $10^{-4} \mathrm{~cm}^{3}(\mathrm{STP}) / \mathrm{s}$.

Amesz ${ }^{9}$ derived the following equation for water leakage:

$$
\mathrm{Q}_{\mathrm{H} 2 \mathrm{O}}=\frac{9.5 \mathrm{Q}_{\mathrm{He}} \mu_{\mathrm{He}}\left(\text { density }_{\mathrm{H} 2 \mathrm{O}}\right)\left(\mathrm{P}_{\mathrm{H} 2 \mathrm{O}}-1\right)}{\mu_{\mathrm{H} 2 \mathrm{O}} \mathrm{P}_{\mathrm{He}}\left(\mathrm{P}_{\mathrm{He}}+31\left(\mu_{\mathrm{He}}(\mathrm{D})\right)\left(\mathrm{T}_{\mathrm{He}} / \mathrm{M}_{\mathrm{He}}\right)^{0.5}\right.}
$$

where the leakage is in $\mathrm{g} / \mathrm{h}$, the viscosity in $\mathrm{cP}$, density in $\mathrm{g} / \mathrm{cm}^{3}$, pressure in atm, leak diameter in $\mu \mathrm{m}$, and helium leakage in "lusec" (1.315 $\left.\times 10^{-3} \mathrm{~atm} \mathrm{~cm}^{3} / \mathrm{s}\right)$.

We calculated the component leak rates using $E_{4} .5$ and assumed a helium leak rate of $10^{-6} \mathrm{~cm}^{3}(\mathrm{STP}) / \mathrm{s}$ and a water pressure of $0.5 \mathrm{MPa}$ to account for the effect of transients. The results of these calculations for the effect of pressure, temperature, and leak diameter on leak rate are shown in Fig. 1. For the case of $100^{\circ} \mathrm{C}$ and $0.5 \mathrm{MPa}$, the water leak rate is listed in Table 1 as a function of leak diameter assumed. Also listed in Table 1 is the total tritium release if the 
Component Water Leak Rate Equivalent to Helium Leak Rate of $10^{-6} \mathrm{~cm}^{3} / \mathrm{s}$

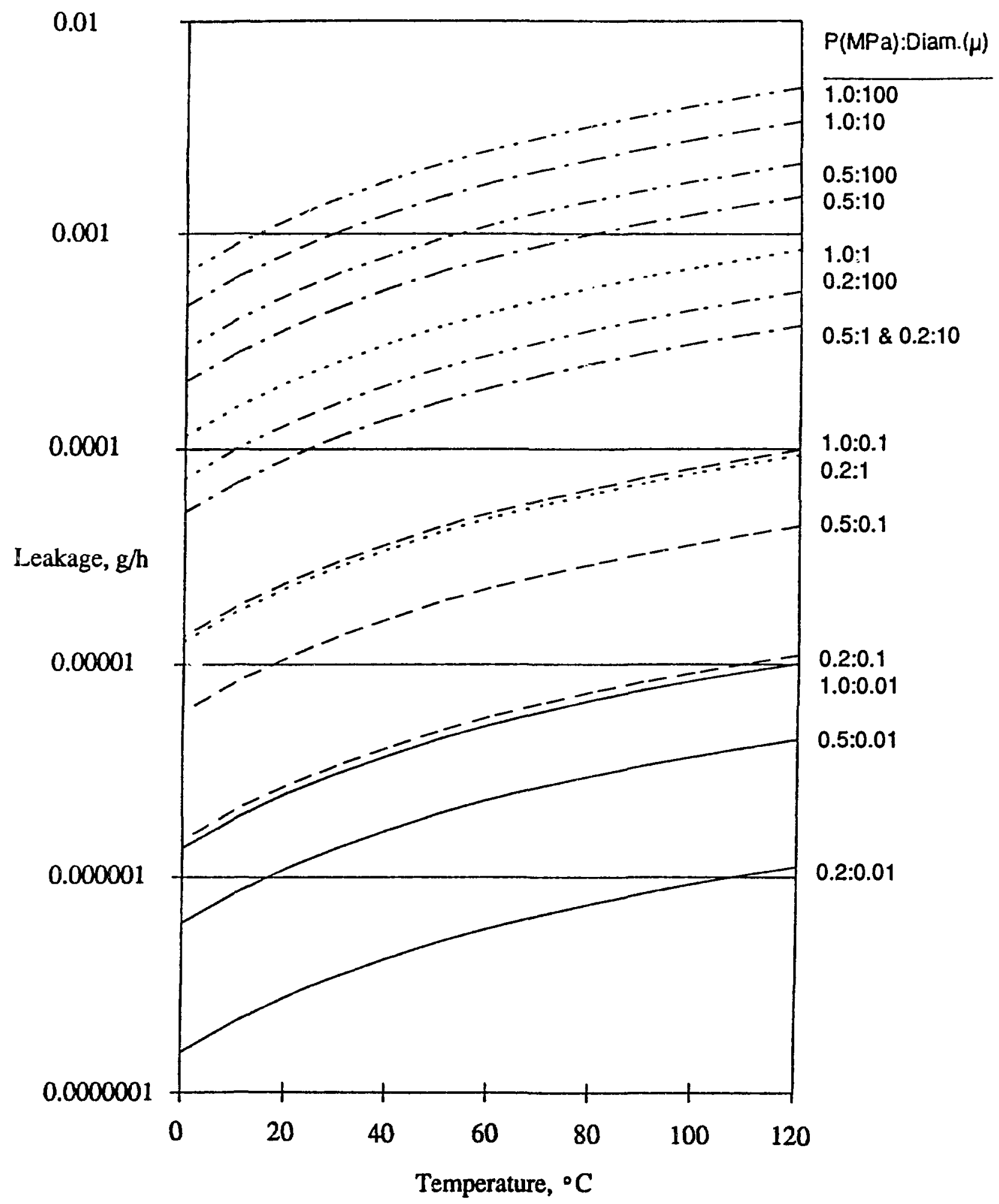

Fig. 1. Effect of Pressure, Temperature, and Leak Diameter on Water Leak Rate Calcuiated from Helium Leak Rate of $10^{-6} \mathrm{~cm}^{3}(\mathrm{STP}) / \mathrm{s}$ 
tritium concentration in the coolant water is $1 \mathrm{Ci} / \mathrm{L}$. The last column in Table 1 is the room tritium concentration for the optimum case, since some percentage of the components during opcration will have a leak rate greater than $10^{-6} \mathrm{~cm}^{3} / \mathrm{s}$. An increase in the equivalent helium leak rate (ordinate of Fig. 1) by a factor of ten would increase the leak rate by a factor of ten. Thus, for a helium leak rate of $10^{-4} \mathrm{~cm}^{3} / \mathrm{s}$ at $0.5 \mathrm{MPa}$ and $100^{\circ} \mathrm{C}$, the equivalent water leak rate for a $10 \mu \mathrm{m}$ diameter hole is $200 \mathrm{mg} / \mathrm{h}$ for one component. If $40(10 \%)$ of the components have this leak rate, the room tritium concentration is $19.2 \mu \mathrm{Ci} / \mathrm{m}^{3}$. The benefit of air processing to remove tritium from the atmosphere has been ignored for this example.

Table 1. Effect of Leak Diameter on a Component's Water Leak Rate at $0.5 \mathrm{MPa}$ and $100^{\circ} \mathrm{C}$ (Optimum Case)

\begin{tabular}{llrc}
$\begin{array}{c}\text { Diamcler, } \\
\mu \mathrm{m}\end{array}$ & $\begin{array}{c}\mathrm{H}_{2} \mathrm{O} \text { Leak } \\
\text { Rate, } \\
\mathrm{mg} / \mathrm{h}\end{array}$ & $\begin{array}{c}\text { Tritium } \\
\text { Release Rate, } \\
\mu \mathrm{Ci} / \mathrm{d}\end{array}$ & $\begin{array}{c}\text { Tritium } \\
\text { Concentration, } \\
\mu \mathrm{Ci} / \mathrm{m}^{3}\end{array}$ \\
\hline 0.01 & 0.005 & 48 & 0.0048 \\
0.1 & 0.05 & 480 & 0.048 \\
1 & 0.3 & 2880 & 0.288 \\
10 & 2 & 19200 & 1.92 \\
100 & 3 & 28800 & 2.88 \\
\hline
\end{tabular}

${ }^{a}$ Equivalent to a helium leak rate of $10^{-6} \mathrm{~cm}^{3}(\mathrm{STP}) / \mathrm{s}$.

${ }^{b}$ Conservative estimate since there will be $>400$ fuel assemblies, control rods, and safely rods.

'Volume assumed to be $10^{4} \mathrm{~m}^{3}$.

Although seals and joints at the beginning-of-life can have leak rates which would not require extensive air processing within containment, the leak rate during operation is the more important parameter. To minimize the leak rate during the 30-40 years of operation of HWR-NPR, one must first optimize the design of each seal, and then ensure that the assembly, operation and the maintenance of each seal is done in accordance with qualified procedures.

The seals also have to survive conditions during an accident or a transient. (A "transient" is an off-normal event which may not require shutdown of the reactor. An "accident" is an off-normal event which requires reactor shutdown and major recovery efforts.) For example, a fuel/target tube could melt during a transient, which would increase the tritium content in the coolant. In an accident, major amounts of $\mathrm{D}_{2}$ and $\mathrm{T}_{2}$ could be released because of radiolysis of the coolant, metal/water interactions, or $\mathrm{T}_{2}$ releases from target tubes. To protect from catastrophic failures, backup systems to minimize leakage may be provided on equipment. These backups include welds on bolted flange joints and on valve bodies and water collection systems for centrifugal pumps. The presence of these backups not only adds complexity to the coolant components, but also complicates their maintenance, reduces access within containment, and increases space requirements within containment.

\subsection{Aging Effects}

The effects of aging are difficult to assess since they can be due to material degradation, creep, and/or stress relaxation. The only study to address this issue was a two-year 
effor ${ }^{16}$ which examined the relative impact that aging has on componem failures in light-water reactors. (The source material in this study was the records in the coding structure of the Nuclear Plant Aging Research Program sponsored by the U.S. NRC.) The records were classified into five generic failure categories: (1) aging, (2) design and installation error, (3) testing and maintenance activities, (4) human-related actions, and (5) other (unknown or unclassified) failures. The study had to contend with several problems: (1) service ages were uncertain, (2) plant-specific effects were masked, and (3) $50 \%$ of the data records indicated unknown failures, which were classified as "other" since the caluses were never determined.

Aging was found to cause $32 \%$ of all failures. The systems and components affected by aging included the pumps in component cooling systems and the valves in the containment isolation system. Also, normally operating fluid systems, like the component cooling water, tended to exhibit slightly higher proportions of aging-related failures than stand-by systems.

The causes of the failures for different reactor systems are summarized in Table 2. In Table 3, the consequences of the failures in different systems are summarized as a loss of system function, degraded operation, loss of redundancy, loss of a subsystem, and none. Loss of function accounted for $2 \%$ of the service interruptions for any reactor system.

Table 2. Causes of Failures in Reactor Systems

\begin{tabular}{lcccccc}
\hline & Failures, & \multicolumn{5}{c}{ Percent } \\
\cline { 3 - 7 } System & No. & Design & Aging & Maint. & Human & Other \\
\hline Auxiliary Feedwater & 829 & 10 & 30 & 10 & 1 & 49 \\
Component Cooling $\mathrm{H}_{2} \mathrm{O}$ & 976 & 5 & 48 & 8 & 1 & 38 \\
Containment Fan & 318 & 7 & 26 & 10 & 1 & 56 \\
Containment Isolation & 926 & 3 & 45 & 5 & 1 & 45 \\
Main Feedwater & 827 & 10 & 38 & 5 & 1 & 45 \\
Reactor Bldg. Cooling & 65 & 8 & 28 & 10 & 8 & 46 \\
Reactor Coolant & 1012 & 15 & 28 & 5 & 1 & 52 \\
Residual Heat Removal & 1968 & 12 & 26 & 8 & 1 & 55 \\
Service $\mathrm{H}_{2} \mathrm{O}$ & 1272 & 8 & 45 & 8 & 1 & 40 \\
\hline
\end{tabular}

Table 3. Type of Service Interruption Caused by System Failure

\begin{tabular}{lccccc}
\hline & \multicolumn{5}{c}{ Percent } \\
\cline { 2 - 6 } Reactor System & $\begin{array}{c}\text { Lose } \\
\text { Function }\end{array}$ & Degrade & $\begin{array}{c}\text { Lose } \\
\text { Redun. }\end{array}$ & $\begin{array}{c}\text { Lose } \\
\text { Subsys. }\end{array}$ & None \\
\hline Auxiliary Fcedwater & 1 & 19 & 18 & 32 & 32 \\
Component Cooling $\mathrm{H}_{2} \mathrm{O}$ & 1 & 15 & 13 & 35 & 38 \\
Containment Fan & 2 & 15 & 25 & 25 & 35 \\
Containment Isolation & 0 & 25 & 15 & 30 & 34 \\
Main Feedwater & 2 & 20 & 5 & 18 & 52 \\
Reactor Bldg. Cooling & 0 & 20 & 12 & 32 & 25 \\
Reactor Coolant & 2 & 23 & 13 & 23 & 40 \\
Residual Heat Removal & 1 & 18 & 15 & 24 & 45 \\
Service $\mathrm{H}_{2} \mathrm{O}$ & 0 & 17 & 19 & 35 & 30 \\
\hline
\end{tabular}


Tables 4 and 5 present data on valve and pump failures. These tables show the percent of component failures due to aging, and the percent that these component-aging failures are represented in reactor system failures. A valve is considered failed when it does not meet any of the performance requirements in its technical specification. In the study, the confidence intervals for the valve data are small (20\%), which indicates that aging in valves is independent of the reactor system in which they reside. This indicates that there is a need to examine valve design.

Table 4. Cause of Reactor System and Valve Failure Due to Aging

\begin{tabular}{lccc}
\hline Reactor Systems & $\begin{array}{c}\text { Valve Failure } \\
\text { due to Age, } \%\end{array}$ & $\begin{array}{c}\text { Total Valve } \\
\text { Failures, No. }\end{array}$ & $\begin{array}{c}\text { System Failure } \\
\text { due to Valve Age, \% }\end{array}$ \\
\hline Auxiliary Fcedwater & $46-58$ & 267 & 17 \\
Component Cooling $\mathrm{H}_{2} \mathrm{O}$ & $51-62$ & 276 & 16 \\
Containment Fan & $13-35$ & 65 & 5 \\
Containment Isolation & $52-63$ & 451 & 28 \\
Main Feedwater & $47-58$ & 334 & 22 \\
Reactor Bldg. Cooling & $28-89$ & 10 & 10 \\
Reactor Coolant & $42-60$ & 118 & 7 \\
Residual Heat Removal & $46-55$ & 484 & 12 \\
Scrvice $\mathrm{H}_{2} \mathrm{O}$ & $51-60$ & 362 & 16 \\
\hline
\end{tabular}

Table 5. Cause of System and Pump Failure Due to Aging

\begin{tabular}{lccc}
\hline Reactor Systems & $\begin{array}{c}\text { Pump Failure } \\
\text { due to Age, } \%\end{array}$ & $\begin{array}{c}\text { Total Pump } \\
\text { Failures, No. }\end{array}$ & $\begin{array}{c}\text { Systern Failure due } \\
\text { to Pump Age, \% }\end{array}$ \\
\hline Auxiliary Feedwater & 28 & 110 & 4 \\
Component Cooling $\mathrm{H}_{2} \mathrm{O}$ & 75 & 183 & 14 \\
Containment Fan & 68 & 3 & 1 \\
Main Feedwater & 48 & 49 & 4 \\
Reactor Coolant & 35 & 93 & 4 \\
Residual Heat Removal & 48 & 86 & 3 \\
Service $\mathrm{H}_{2} \mathrm{O}$ & 58 & 248 & 12 \\
\hline
\end{tabular}

\section{SEALS IN FLANGES}

Seal development for flanges (bolted joints) does not require the development of a special material but the integration of design and assembly factors to ensure that sufficient clanning force is exerted to form an acceptable seal. If any factor is ignored, the seal may have a high leak rate in a short operating time. Some of the factors to be considered in seal development are material property data for gaskets, bolts, and flanges; engineering design data for flarges, which are used to calculate the clamping force required for a given flange stiffness; quaiity control during the manufacture of joint components, especially the finish on the flange surface; and quality control during the assembly of the joint to achieve the desired clamping force and maintain it during the joint's lifetime. The designer of leak-tight flange joints, especially large flange joints, must stipulate for each joint (1) the properties of the gasket, ${ }^{17-29}(2)$ the design 
method, ${ }^{30-42}(3)$ the correct bolts, ${ }^{43-44}$ (4) the surface finish, ${ }^{45}$ and (5) the assembly procedure to ensure that the required assembly stress is achieved. ${ }^{46-54}$

A flanged joint has several elements: the flanges, the bolts, the gasket, and the wall of the pipe or vessel. To prevent leakage, a certain level of contact stress must be maintained between the gasket and the flanges. This contact stress will vary with time due to stress relaxation in the gasket, changes in the fluid pressure and temperature with associated flange distorions, and creep in highly stressed regions of the bolts and the flanges. The net effect is a decrease in the gasket contact stress and less-effective joint seals. Tu maintain the necessary contact stress, elastic strain energy has to be stored in the joint system. This storage is usually in the bolt stretch, the elastic compression of the gasket, and the flange deflection. The bolts are usually the main source of stored energy but a significant amount is incorporated in metallic spiral wound types of gaskets.

Over the last ien years, there has been a major effort in the development of spiral wound gaskets, understanding the relationship between joint loading stress and the leak rate, and the improvement of joint assembly techniques. The major work in these areas is summarized in the following sections.

\subsection{Gasket Types}

The desired characteristics ${ }^{45}$ in a gasket are the following: the surface layers should be plastic; the internal structure should be elastic; stress relaxation should be low; under compression, time dependent creep should be low and unaffected by temperature changes; the material should not be porous in the compressed state; the physical properties of the material should not be degraded by the fluid; the material should not easily tear or rupture; and the material should be readily available.

The gasket which meets these requirements for the HWR-NPR is a spiral-wound gasket with an expanded graphite filler and inner and outer stainless steel retainers. These gaskets have a large tolerance for flange surface irregularities; ${ }^{28}$ have very good flexibility, which compensates for modest flange separation; have excellent operational characteristics; are usable at high temperature and high pressure; and are highly resistant to radiation. The main disadvantage of this gasket is that a medium bolt load is required. This type of gasket has been developed in the U.S., ${ }^{18,21}$ England, ${ }^{19-20}$ and France. ${ }^{24-26}$ One variety is being used at Savannah River $^{27}$ as replacements for asbestos gaskets.

Workers at Oak Ridge National Laboratory ${ }^{28}$ determined the advantages and disadvantages of other types of gaskets: metal welds, elastcmer O-rings, Belleville spring type gasketed joints, solid metal gaskets with a thick cross section, and hollow metallic O-rings. These advantages and disadvantages are summarized below.

Three types of weld joints are shown in Fig. 2: omega (circular around joint area), canopy (arc), lip (small weld at an edge). A canopy or omega weld uses two welds to seal the joint. A weld joint provides a leak-tight seal. However, weld joints require the use of a design 


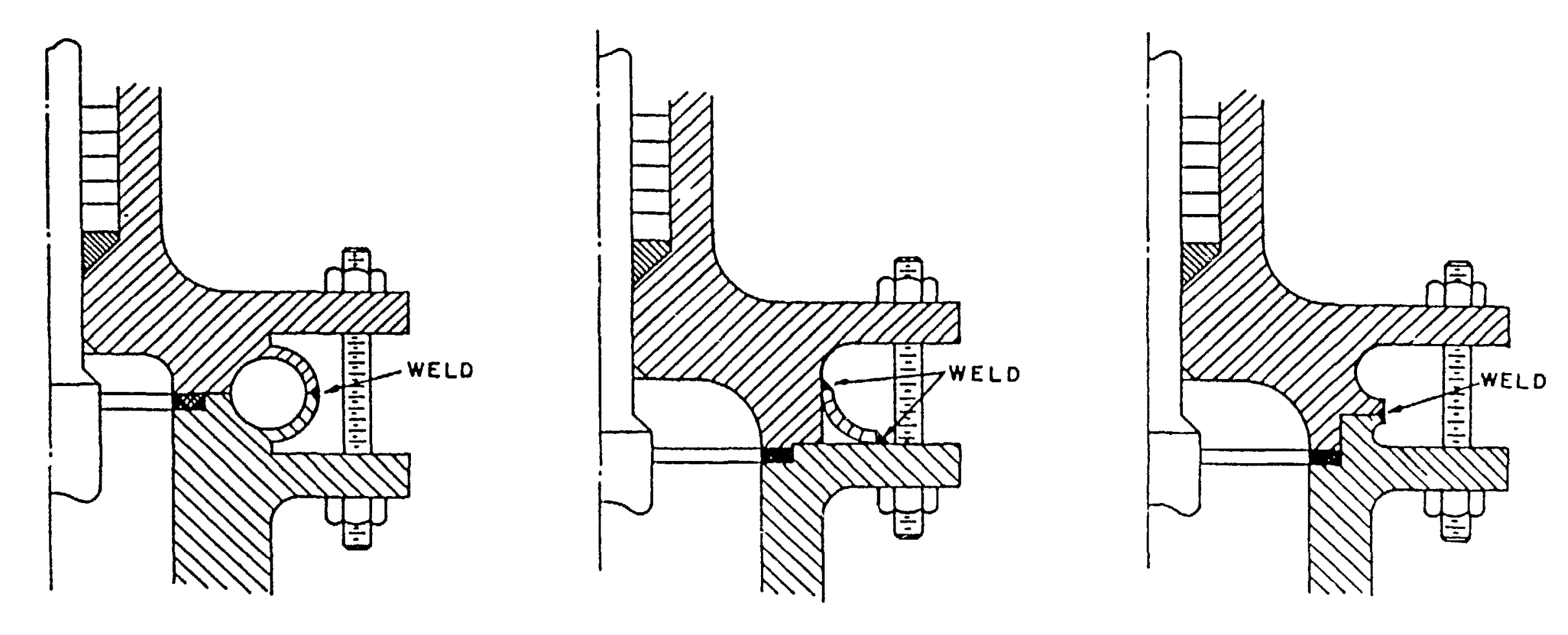


which allows replacement of the weld five times; require qualification of the welding procedure and the welder and the testing of full-size mockups; have no strength loading; are expensive; require routine inspections; have defects which can increase permeability comparable to other seals; can have internal leakage; and are severely affected by neutron irradiation ${ }^{29}$ and tritium retention, both of which cause a buildup of helium.

The perceived advantage of elastomer gaskets is that a low bolt load is required. However, elastomers have a low temperature limit; are not tolerant of radiation; have properties which change rapidly over time, especially in a tritium environment; and may have their formulation changed or discontinued.

Belleville systems are reusable by replacing an internal gasket, are light-weight joints, are usable at high temperature and high pressure, and are resistant to radiation. Their disadvantages are that critical tolerances and critical alignments are needed.

Solid metal gaskets are usable at high temperature and high pressure, are resistant to radiation and extreme temperature shock, and require low or moderate bolt loads. Their disadvantages are that fine tolerances and metal hardness are required and self-welding to the flange can occur.

Hollow metal O-ring are usable at high temperature and high pressure, are resistant to radiation, and require a low bolt load. However, stress relaxation of the metal can impair the seal, and large diameter O-rings are difficult to install.

The material which is the best substitute for asbestos in gaskets and valve packing is expanded graphite. The physical form and the properties of expanded graphite are presented.

Expanded graphite is a distinctive material with unique properties ${ }^{17-21}$ that make it a valuable material for packings and gaskets. Expanded graphite is a mechanical interlocking of worm-like expanded flakes with considerable closed porosity. Its compressibility can be changed by densification. Die-formed expanded graphite has a density of $1.4-1.6 \mathrm{Mg} / \mathrm{m}^{3}$ (60-70\% theoretical density). The material has a high heat resistance and a negligible relaxation to sealing stress. As a filler in spiral-wound gaskets, this material requires inner support rings to prevent radial deformation of the inner windings during compression.

The manufacturing process for producing expanded graphite involves multiple steps. A mineral, like limestone containing 5\% natural graphite, is treated to produce graphite flakes. Then, these flakes which are $99 \%$ graphite are separated to get a distribution which is $80 \%$ 80 -mesh size particles. The $1 \%$ impurity is usually silica or mica based materials. This natural flake graphite is treated with concentrated nitric and sulfuric acid to form a bisulfate compound which enters the graphite structure, a process known as intercalation. The treated flake is then washed thoroughly, which leaves large quantities of water within the graphite structure (5-15\%), together with small amounts of sulfate species (3-5\%) after it is dried. (The amount of sulfur left in the material can be minimized by using an intercalation method which does not employ sulfuric acid.) 
The intercalated graphite flake is then gently heated to force the remaining water to vaporize and push the graphite layers apart to give an expanded or exfoliated graphite. The degree of exfoliation achieved is closely related to the intercalation method used and the heating conditions. By heating the flakes to $1000^{\circ} \mathrm{C}$ in one second, a well exfoliated graphite is produced. Since graphite oxidizes at temperatures $>500^{\circ} \mathrm{C}$, the exfoliated graphite has to be rapidly cooled. Weight losses to oxidation are 5-10\%, and water losses are up to $15 \%$.

The degree of exfoliation is measured by the bulk density, which can be as low as $2-3 \mathrm{~kg} / \mathrm{m}^{3}$. This low density material appears worm-like since the expansion takes place only in the "c" direction of the flake. By applying pressure to this worm-like matenal, the graphite is consolidated to form a coherent flexible structure in the form of sheet. These sheets can have a tensile strength of 6-10 MPa. The ultimate strength depends on the control employed during the intercalation process and the exfoliation process. The properties of the graphite sheet can be markedly improved by altering the purity of the starting flake, the source of the flake, the flake size, the reaction time in the acid, and the washing/drying process.

Some of the properties of expanded graphite, under the trade name Graphoil, have been measured by Union Carbide, ${ }^{18}$ which had the original patents on this material. Some of these properties are shown in Table 6 for Union Carbide's GTA grade sheets. Since these sheets have a density of $1.1 \mathrm{Mg} / \mathrm{m}^{3}$, Table 7 shows the qualitative effect of an increase in the expanded graphite's density on its physical properties.

Table 6. Room-Temperature Properties of GTA ${ }^{\mathrm{a}}$ Graphite Sheets

\begin{tabular}{|c|c|c|}
\hline Propeny & Quantity & ASTM Method \\
\hline Bulk Density, $\mathrm{Mg} / \mathrm{m}^{3}$ & 1.1 & C-559 \\
\hline Tensile Strength, MPa & 5.2 & F-152 \\
\hline Young's Modulus, GPa & 1.4 & -- \\
\hline Compressive Strength, $\mathrm{MPa}$ & 165 & C-695 \\
\hline Gas Permeability (Darcy's) & $<10^{-5}$ & C-577 \\
\hline Friction Static Coef. & $0.05-0.2$ & --- \\
\hline Specific Heat, $\mathrm{J} / \mathrm{kg} \cdot \mathrm{K}$ & 711 & $---b$ \\
\hline \multicolumn{2}{|l|}{ Thermal Conductivity, $\mathrm{W} /(\mathrm{m} \cdot \mathrm{K})$} & Fitch Method \\
\hline Length \& Width & 140 & \\
\hline Thickness & 5 & \\
\hline \multicolumn{2}{|c|}{ Coef. Lin. Therm. Exp., $10^{-6} \mathrm{~m} / \mathrm{m} /{ }^{\circ} \mathrm{C}$} & $\cdots$ \\
\hline Length \& Width & 0.4 & \\
\hline Thickness & 27 & \\
\hline \multicolumn{2}{|l|}{ Electr. Resistivity, $10^{-6} \mathrm{ohm} \cdot \mathrm{m}$} & C-611 \\
\hline Length \& Width & 8 & \\
\hline Thickness at $0.69 \mathrm{MPa}$ & 15 & \\
\hline Carbon Content (min), wt\% & 99.5 & C-571 \\
\hline Ash Content (max), wt \% & 0.5 & C-561 \\
\hline Sulfur Content (max), ppm & 700 & C-816 \\
\hline Leachable $\mathrm{Cl} / \mathrm{F}(\max ), \mathrm{ppm}$ & $50 / 50$ & --- \\
\hline
\end{tabular}

${ }^{a}$ Standard sheet produced by Union Carbide. Other sheets available with density of $1.4 \mathrm{Mg} / \mathrm{m}^{3}$.

'Specific heat from Union Carbide's Carbon and Graphite Handbook. 
Table 7. Effect of increase in Graphitc Sheat Density on Physical Properties

\begin{tabular}{ll}
\hline Property & Effect \\
\hline Tensile Strength & Increase \\
Young's Modulus & Increase \\
Compressibility & Decrease \\
Gas Permeability & Decrease \\
Thermal Conduclivity & Increase \\
Electrical Resistance & Decrease \\
Recovery & Increase \\
Flexibility & Decrease \\
Hardness & Increase \\
Abrasion Resistance & Increase \\
Oxidation Rate & Decrease \\
\hline
\end{tabular}

The ririction coefficient of flexible graphite was measured in a shear test by Union Carbide. ${ }^{18}$ On a metal surface with a 63 RMS finish and a preload of $34.5 \mathrm{MPa}$ for $30 \mathrm{~min}$, the friction coefficient was 0.2. ing the same test fixture with the residual graphite embedded into the metal surface, the friction coefficient was reduced to 0.09 when the preload of $34.5 \mathrm{MPa}$ was held for five days. In a test with graphite sheet held against stainless steel with a $0.055 \mathrm{MPa}$ load, the friction coefficient was 0.05 .

The properties of graphite are as follows: (1) low coefficient of friction (0.1), (2) self-lubricating, (3) no binders, resins, fillers, (4) impermeable to gases and liquids, (5) flexible yet no cold or hot flow characteristics, (6) corrosion resistant, (7) resistant to temperature changes, (8) high degree of anisotropy for electrical and thermal conductivity, (9) capable of

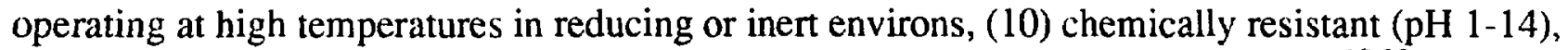
(11) nuclear grade with leachable chloride $<50 \mathrm{ppm}$, and (12) resistant to radiation. ${ }^{18,22}$

The change in mechanical properties of expanded graphite sheet after $170 \mathrm{Mrad}$ of gamma irradiation is shown in Table 8. Exposure to $170 \mathrm{Mrad}$ is equivalent to 100 years of exposure in the nuclear reactor environment, an environment in which properties of all materials undergo degradation. Therefore, the percent changes in the mechanical properties of the graphite sheet (Table 8) are not statistically significant.

Table 8. Mechanical Properties of Graphite Sheet alter Irradiation ${ }^{\mathrm{a}}$

\begin{tabular}{lcccc}
\hline Properiy & Control & Irradiated & \% Change & ASTM Test \\
\hline $\begin{array}{l}\text { Ultimate Tensilc } \\
\text { Strength, } \mathrm{kPa}\end{array}$ & 5030 & 5720 & +14 & F152-72 \\
$\begin{array}{l}\text { Elongation at } \\
\text { Fracture, \% }\end{array}$ & 1.8 & 1.3 & -28 & F152-72 \\
$\begin{array}{l}\text { Creep Relaxation } \\
\text { (Room Temp.), } \%\end{array}$ & 4 & 5 & +25 & F38-80 \\
Compressibility, \% & 51.7 & 51.3 & -0.8 & F36-81 \\
Recovery, \% & 22.9 & 23.1 & +0.9 & $-\cdots$ \\
\hline
\end{tabular}

After $170 \mathrm{Mrad}$ gamma exposure from cobalt source in air. All specimens at $100^{\circ} \mathrm{C}$ for $24 \mathrm{~h}$. 'Specimens under load for $1 \mathrm{~h}$. 


\subsection{Design Procedure for Flanges}

A bolted joint functions as an elastic clamp. The behavior of this bolted clamp is complex in that the relative stiffness of the gasket, the flange, and the bolts are all important. The most widely used design procedure for joints is a long-established ASviE code method (ASME 1985/Appendix S). However, this procedure focuses on bolt stresses, not gasket leakage, and uses two arbitrary gasket factors, $y$ and $\mathrm{m}$, to size bolting. The factor $\mathrm{y}$ is defined as the minimum gasket seating stress needed during pretightening to ensure proper gasket seating to close gasket porosity and ensure conformity with the flange face. This is not the required assembly stress to seal the joint. The factor $m$ is defined as the stress over twice the effective gasket area divided by the internal pressure which must be maintained during operation conditions. Gasket stresses associated with tabulated values of $y$ and $m$ are for bolt sizing purposes only and are not sufficient to prevent leakage. The values tabulated in the ASME code are related by

$$
y=180(2 m-1)^{2}
$$

Leakage is only reduced progressively with gasket stress. Thus, there is always some level of leakage. What a designer needs to know is what leak rate is acceptable, and then design the joint so that an appropriate stress can be applied to achieve that leak rate.

Under BHRA sponsorship ${ }^{33-41}$ a design procedure has been developed which relates leak rate to compressive stress on the joint. This method is discussed below.

The joint assembly stress, $S_{A}$, must be chosen so that the gasket stress under working conditions (internal fluid pressure, $p_{\mathrm{i}}$ ) is sufficient to keep leakage at an acceptably low level (specified by the design). The value of $S_{A}$ is greater than $y$ and is determined by the joint dimensions, the fluid pressure, and the relative stiffness of the gasket, the bolts, and the flanges. Several factors need consideration: gasket response, flange distortion, initial bolt-up condition, effects of thermal pressure, and thermal effects.

Since gaskets exhibit nonlinearity and hysteresis in plots of both stress-versus-strain and stress-versus-leakage, ${ }^{34-40}$ these relationships must be used to specify the assembly stress, $\mathrm{S}_{\mathrm{A}}$, needed for a given type of gasket under the expected operating crnditions. Most information on gasket leakage, $L_{R}$, has been presented in the form of $\log / \log$ plots of gasket stress, $S_{G}$, versus tightness, $\mathrm{T}_{\mathrm{p}}$,

$$
T_{p}=p /\left(L_{R}\right)^{a}
$$

Here $T_{p}$ is an inverse leakage parameter defined as the ratio of fluid pressure, $p$, to mass leakage, $L_{R}$, raised to the power $a$. The value for $a$ is in the range 0.5 to 1 depending on the fluid.

Two types of tests are done to determine assembly stress: Part A, which simulates "seating" conditions, and Part B, which simulates "operating" conditions. 
In Part $A$, the bolt load, $S_{G}$, is incrementally increased from $S_{N}$ to $S_{A}$, the assembly gasket stress. At each incremental increase in the bolt load, the gasket deflection, $\mathrm{D}_{\mathrm{GN}}$, is measured, and the leak rate, $L_{R}$, is measured at several internal pressures, $p_{i}=p_{1}, p_{2}$, and $p_{3}\left(S_{1}\right.$ is adjusted to remain constant during these tests.) Before each increase in the bolt load, $p_{i}$ is reduced to zero. For Part A data, a well-defined "knee" exists at $K$, indicating an improved joint performance above a certiain gasket stress level, $S_{K}$. Beyond $S_{K}$, tightness increases more rapidly with increasing stress, indicaling improved seiling perlormance. Simila knees have been secon with metal gaskets. ${ }^{42}$ The $S_{K}$ value is lower when the surface finish of the flanges is rougher.

In Part B, decompression and recompression tests produce hysteresis loops, which involve little variation in the gasket deformation. Since the tests are carried out under stresscontrolled conditions, cyclic creep causes a small increase in the gasket deflection with each cycle. Recompression within the previous maximum load, $S_{A}$, gives rise to an almost linear stress-deflection relationship. The tests start with the gasket bolt load at $S_{A}$ and $p_{i}=p_{\max }$. First, $\mathrm{S}_{\mathrm{G}}$ is decreased at regular intervals, and $\mathrm{D}_{\mathrm{GN}}$ and $\mathrm{L}_{\mathrm{R}}$ are measured until the limits of leak detection are reached. Then, $S_{G}$ is increased at regular intervals to $S_{A}$, with $D_{G N}$ and $L_{R}$ being measured at each interval. This sequence is repeated at each of the internal pressures, $\mathrm{p}_{\mathrm{i}}$.

A generic example of the results of Part A and Part B tests ${ }^{40}$ is shown in Fig. 3, with helium as the internal fluid within an asbestos-filled spiral wound gasket. The "knee" developed in Part A tests is readily seen. In Fig. 4, data for Part A tests are shown for lines of constant gasket stress.

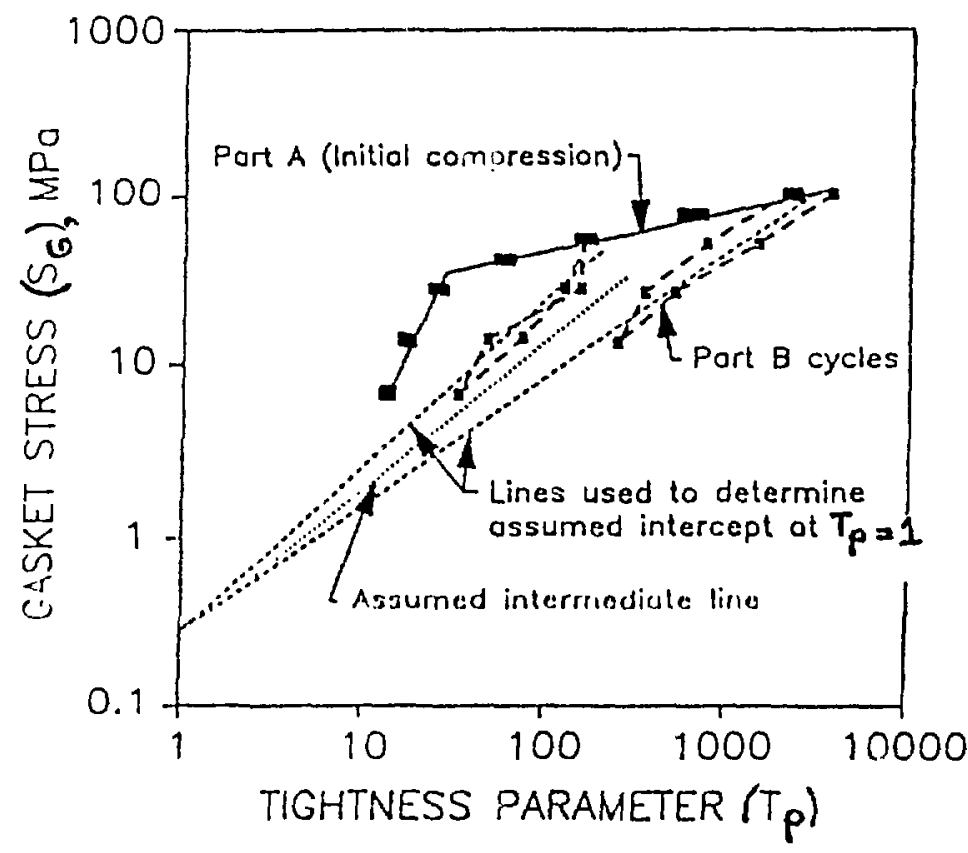

Fig. 3. Generic Example of Rusults of Part A and Part B Tests for Spiral Wound Gaskets ${ }^{40}$

Copyright 1988. Society for Experimental Mechanics, Inc. "Experimental Techniques, Special Supplement on Gaskets and Bolted Joints." Reprinted with permission. 


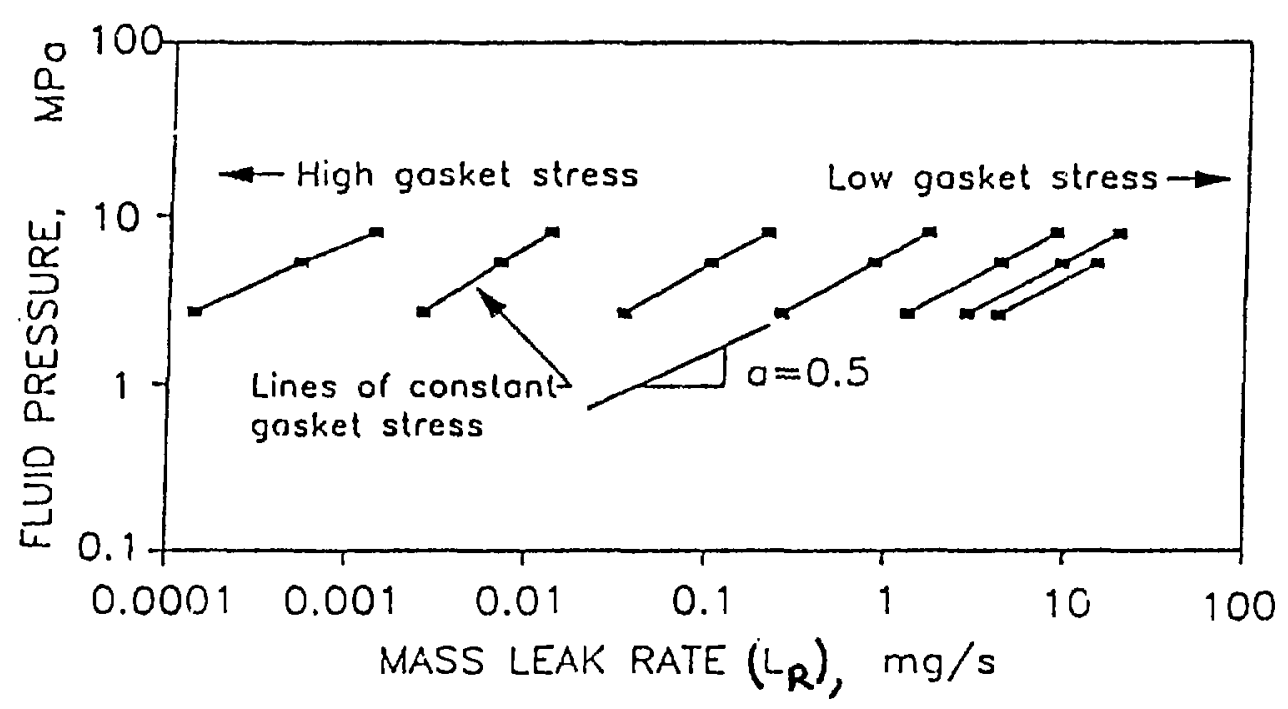

Fig. 4. Data for Part A Tests for Lines of Constant Gasket Stress ${ }^{40}$

Copyright 1988. Society for Experimental Mechanics, Inc. "Experimental Techniques, Special Supplement on Gaskets and Bolted Joints." Reprinted with permission.

One set of Part A and Part B tests was done for 304 stainless steel spiral wound gaskets with graphite filler. ${ }^{34}$ For a rated $272.4 \mathrm{~kg}(600 \mathrm{lb})$ gasket with the dimensions $120.7 \mathrm{~mm} \mathrm{ID} \mathrm{x} 146 \mathrm{~mm}$ OD x $4.37 \mathrm{~mm}$ thick, Fig. 5 gives $\log / \mathrm{log}$ plots of gashet stress versus tightness factor and gasket deflection at room temperature with nitrogen as the test fluid. The value for a is $\mathbf{0 . 5 8}$. These plots indicate the type of tightness possible with these types of gaskets. Qualification tests are needed on representative spiral wound gaskets with expanded graphite filler to provide designers with the characteristics of these gaskets.

The definition of the symbols in Fig. 5 is as follows:

$A_{1}=$ the curve for $S_{G}=S_{1}$, etc.

$B_{2}=$ the curve for $p_{i}=p_{2}$, etc.

$\mathrm{S}_{\mathrm{G}}=$ gasket stress using full gasket area

$\mathrm{S}_{\mathrm{A}}=$ assembly gasket stress $=\mathrm{S}_{\mathrm{G}}$ in Part A

$\mathrm{S}_{\mathrm{K}}=$ Knee stresses in Part A

$\mathrm{S}_{\mathrm{K}}^{\prime}=$ Knee stresses in Part B

$\mathrm{S}_{\mathrm{N}}=$ Intermediate gasket stresses for stress $\mathrm{N}_{\mathrm{N}}$

$D_{\mathrm{GA}^{\prime}}=$ Normalized gasket deflection corresponding to $S_{A}$, etc.

$c, d$, and $f$ are the powers determined from the relationships

$$
\begin{aligned}
& S_{A} / S_{K}=\left(T_{p A} / T_{p K}\right)^{c} \text { for } S_{A} \leq S_{K} \\
& S_{A} / S_{K}=\left(T_{p A} / T_{p K}\right)^{d} \text { for } S_{A} \geq S_{K} \\
& S_{C} / S_{A}=\left(T_{p} / T_{p A}\right)^{d} \text { for Part B data }
\end{aligned}
$$




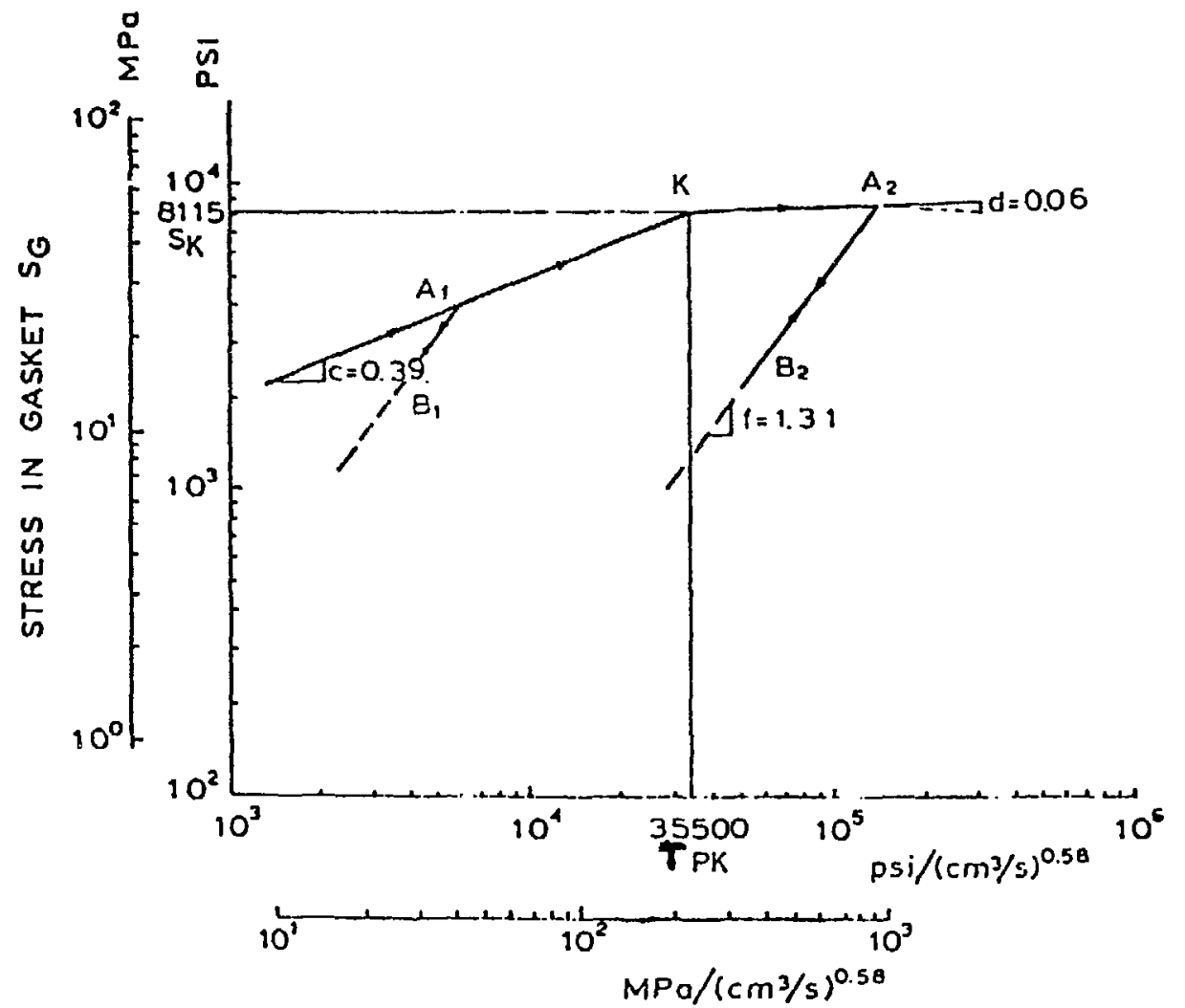

(a)

TIGHTNESS FACTOR $T_{P}=P / L_{R}^{0.50}$

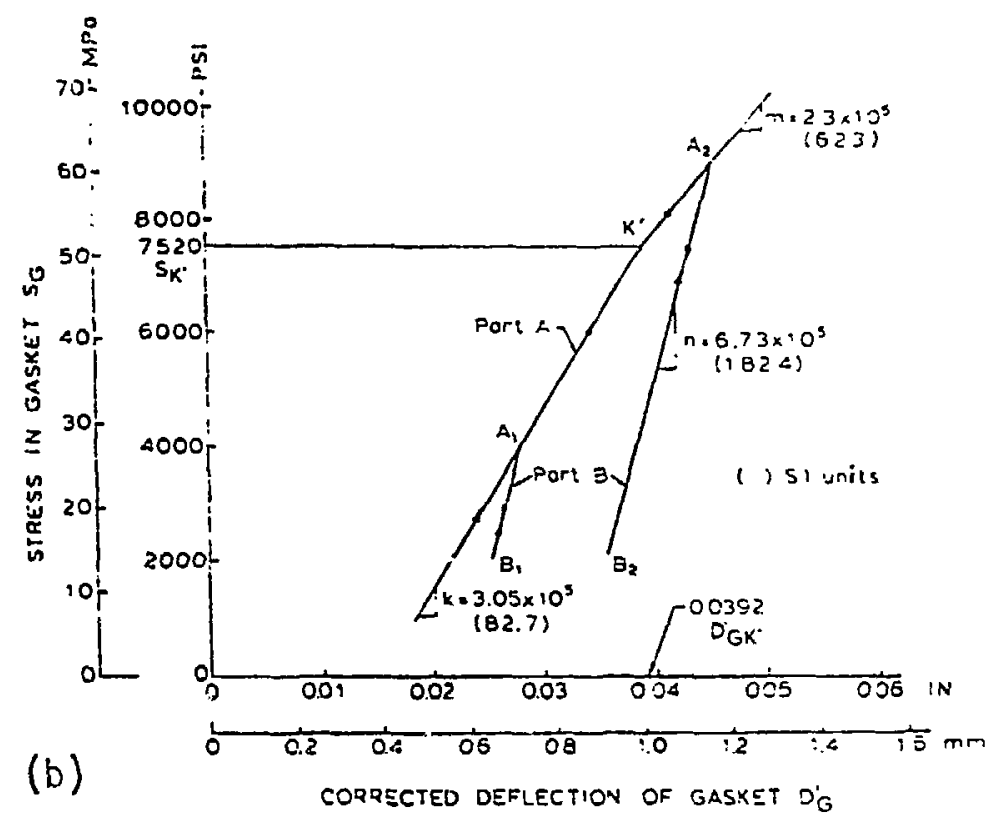

Fig. 5. Stress Versus (a) Leak Tightness and (b) Gasket Deflection for 304 Stainless Steel Spiral Wound Gaskets with Graphite Filler $(272.4 \mathrm{~kg})^{34}$

Copyright 1981. British Hydromechanical Research Association. Proc. of 9th Conf. on Fluid Sealing, April 1-3, 1981, Noordwijkerhout, Netherlands, "Observations and Status of PVRC Gasket Test Program,"

A. Bazergui, G. F. Leon, J. R. Payne. Reprinted with permission. 
$\mathrm{k}, \mathrm{m}$, and $\mathrm{n}$ are constants determined from experimental ratios

$$
\begin{aligned}
& k=\left(S_{A}-S_{K^{\prime}}\right) /\left(D_{G A}-D_{G K}{ }^{\prime}\right) \text { for } S_{A} \leq S_{K}{ }^{\prime} \\
& m=\left(S_{A}-S_{K}{ }^{\prime}\right) /\left(D_{G_{A}}-D_{G K}\right) \text { for } S_{A} \geq S_{K}{ }^{\prime} \\
& n=\left(S_{G}-S_{A}\right) /\left(D_{G}-D_{G_{A}}\right) \text { for Part B data }
\end{aligned}
$$

Because $\log / \log$ plots of $T_{p}$ versus $S_{G}$ are difficult to use for design, $\mathrm{Nau}^{41}$ has suggested that these data be replotted as $\log /$ linear plots of $L_{R} / p^{\alpha}$ versus $S_{G}$, where $\alpha$ is the reciprocal of a. For cases that Nau has examined, the suggested plots show as good a correlation of the variables as do the $\log / \log$ plots. An example of this type of graph is shown in Fig. 6 . In this figure, $S_{M}$ is the required gasket working stress, and GSD is the gasket stress decrement due to bolt load and gasket reaction to the fluid end-load $\left(S_{A}-S_{M}\right)$. For the case of no flange rotation, GSD is represented as

$$
G S D=-\left(k_{g} /\left(k_{b}+k_{b}\right)\right) P / A_{g}
$$

where $k_{g}$ and $k_{b}$ are the stiffness of the gasket and the bolt, respectively; $A_{g}$ is the effective gasket area; and $\mathrm{P}$ is the fluid end-load, defined as

$$
\mathrm{P}=\pi\left(\mathrm{D}_{\mathrm{f}}\right)^{2} \mathrm{p} / 4
$$

where $D_{f}$ is the effective diameter over which the fluid pressure acts. The stiffness of the gasket and the bolt are, respectively,

$$
\begin{aligned}
& k_{g}=E_{g} A_{g} / t_{g} \\
& k_{b}=E_{b} A_{b} / L_{b}
\end{aligned}
$$

where $A_{b}$ is the total effective bolting area; $E_{g}$ and $E_{b}$ are the unloading modulus of the gasket and the Young's modulus for the bolts, respectively; $\mathrm{t}_{\mathrm{g}}$ is the gasket thickness; and $\mathrm{L}_{\mathrm{b}}$ is the effective bolt length.

Flanges are assumed to be rigid, but various deformation modes occur in service. In code-designed flanges, axisymmetric ring-mode rotation is normally the most significant deformation as far as the gasket is concerned, with other bending modes being ignored. The rotational stiffness of the flange, $k_{\phi}$, is computed by finite element analysis,

$$
\mathrm{k}_{\phi}=4 \pi \mathrm{E}_{\mathrm{f}} \mathrm{I}_{\mathrm{f}} / \mathrm{D}_{\mathrm{f}},
$$

where $E_{\mathrm{f}}$ is the Young's modulus of the flange, $I_{\mathrm{f}}$ is the second moment of the area of the flange cross-section about a diametral axis through the centroid, and $\mathrm{D}_{\mathrm{f}}$ is the flange centroid diameter. In addition, rotation produces axial displacement of the bolts and the gasket. The expressions for these parameters are not simple, and they are not dealt with in this report.

For the case of no flange rotation, a logical design procedure is to (1) determine $S_{M}$ for ar acceptable leak rate, $L_{R}{ }^{\prime}$, from test data for the gasket type being used, (2) evaluate the boit 
stiffness, $\mathrm{k}_{\mathrm{b}}$, from bolt data, and (3) evaluate gasket stiffness, $\mathrm{k}_{\mathrm{g}}$, by using stress-strain data for a given gasket type.

If the bolting generates stress $S_{A}$ when the joint is initially assembled, then when the joint is pressurized, the gasket stress will fall to $S_{M}$, and the working leak rate will be $L_{-}{ }^{\prime}$. In practice, correction factors may have to be incorporated to allow for inaccuracies in achieving the target bolt load and the effects of nonuniform gasket stress due to flange rotation.

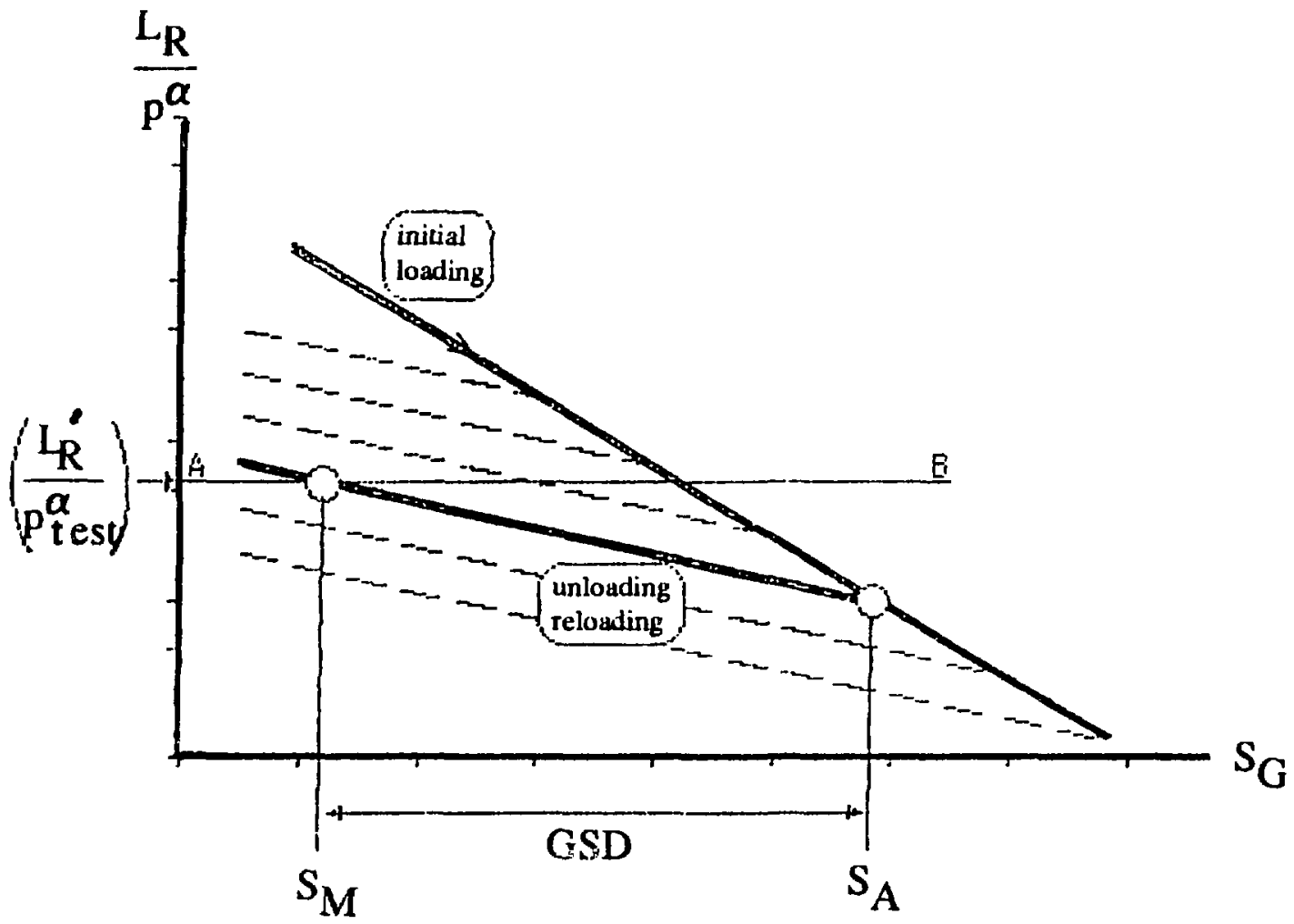

Fig. 6. Gasket Leak Rate Chart for Given Gasket Type ${ }^{41}$

Copyright 1989. British Hydromechanical Research Association. Proc. of 12th Conf. on Fluid Sealing, May 10-12, 1989, Brighton, England, "On the Design of Bolted Gasket Joints," B.S. Nau. Reprinted with permission.

\subsection{Bolt Design}

Bolts behave as springs and hold the joint together. ${ }^{43-49}$ When a bolt is preloaded, a stress is induced in the bolt. Because bolt materials are elastic, a bolt undergoes a slight increase in stress as the working load is increased. As a result, the bolt stretches. If the amount of stretch is greater than the bolt's elastic limit, the bolt yields plastically and takes a permanent set, which results in a loss in the preload stress. Even if the bolt's elastic limits are not exceeded, the induced bolt load changes with time, primarily because a material at constant stress below its 
yield strength undergoes a permanent change in the direction of stress. As a result, the clamping force decreases with time.

An important factor in assuring an adequate preload on a bolt is the effect of manufacturing heat treatments on its relaxation properties. In Fig. 7, relaxation curves are shown for bolts and nuts made lrom AMS 6304 and tested at $482^{\circ} \mathrm{C}$ for 50 h h..$^{43}$ lor bolts which had been heat treated by conventional quench-and-temper methods to a tensile strength of $986 \mathrm{MPa}$ $(145,000 \mathrm{psi})$, the bolt preload decreased from $306 \mathrm{MPa}$ to $184 \mathrm{MPa}(44,000$ to $27,000 \mathrm{psi})$. If the sanne material was heat treated by normalized and tempered methods to $986 \mathrm{MPa}$ (145,000 psi), the bolt preload decreased only to $252 \mathrm{MPa}(36,000 \mathrm{psi})$. If the material was heat treated to a tensile strength of $1360 \mathrm{MPa}(200,000 \mathrm{psi})$, the bolt preload decreased from $420 \mathrm{MPa}$

AMS6304 BOLTS \& NUTS, TESTED $482^{\circ} \mathrm{C}$

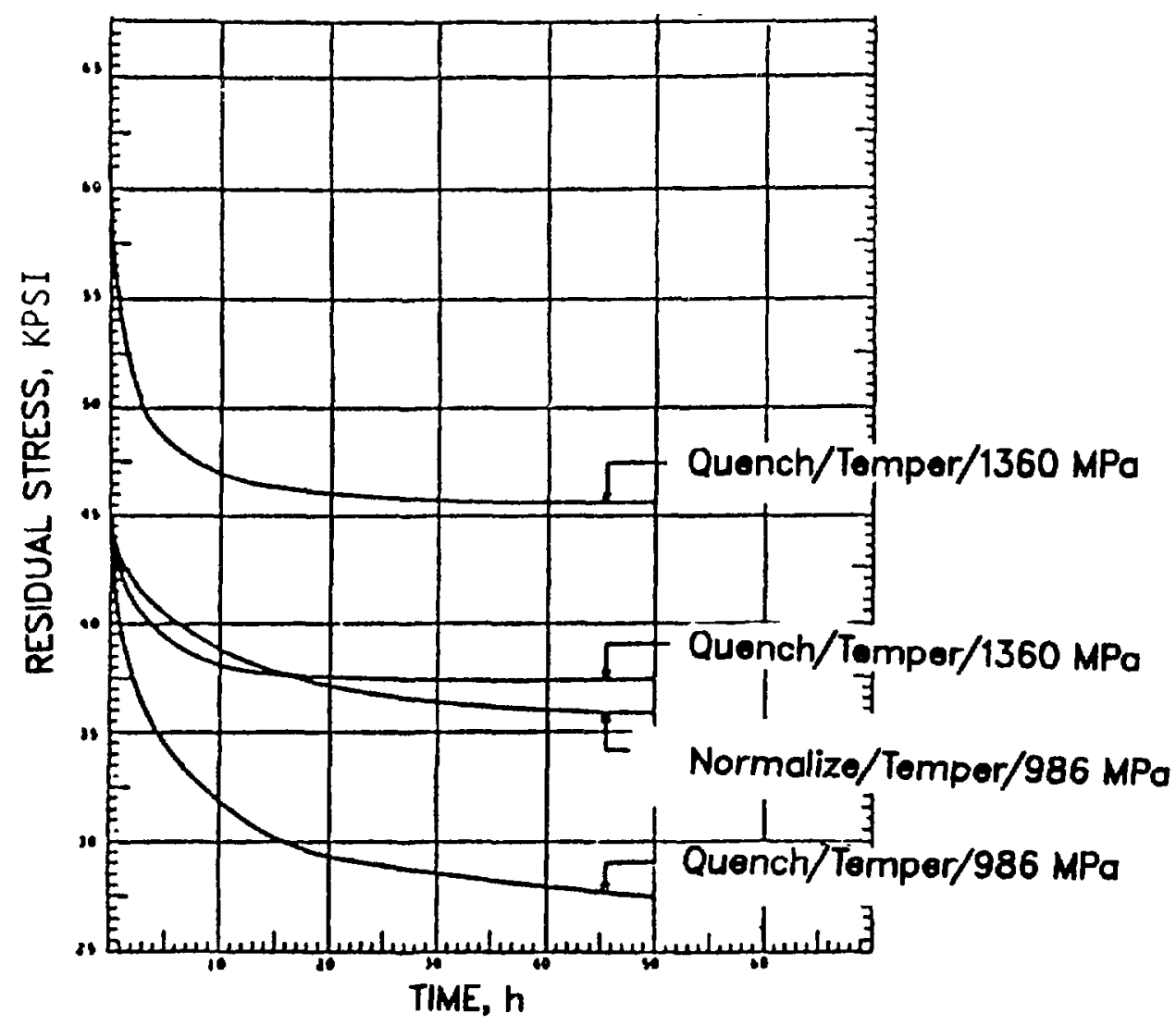

Fig. 7. Bolt Relaxation Curves for Different Pretreatments ${ }^{43}$

Copyright 1976. The American Society of Mechanical

Engineers. Pressure Vessels and Piping: Design and

Analysis, V.4. Reprinted with permission. 
to $320 \mathrm{MPa}(60,000$ to $46,000 \mathrm{psi})$. Thus, with this latter heat treatment of the bolts, a clamping force of $320 \mathrm{MPa}(46,000 \mathrm{psi})$ is left after $50 \mathrm{~h}$ of relaxation. If the joint required this clamping force, one should specify the latter heat treatment for the bolts.

In addition, the design and shape of the bolt thread ${ }^{43}$ have a significant effect on the bolt's relaxation properties. A stud with "square root" threads (threads which descent steeply into the bolt material) lost $50 \%$ of its clamping force in $20 \mathrm{~h}$, with the curve still descending. However, a bolt with a large "radiused root" (threads with a less steep descent) lost only $36 \%$ of the preload after $35 \mathrm{~h}$ and the curve had stopped descending. The residual clamping force for the two cases was 238 and $306 \mathrm{MPa}$ (35,000 and 44,000 psi), respectively.

An additional consideration for bolts and other $f_{a}$ steners is their accreditation. The ASME introduced a fastener accreditation program (FAP) on May 2, $1990^{44}$ because of the magnitude of the problem in counterfeit and substandard fasterers. This program is intended to provide end users a means to rate suppliers and to provide them assurance of quality control and traceability of sources. An ASME document has been prepared that sets forth the requirements for engineering drawings, tooling, production planning and lot control, procurement, raw material control and traceability, personnel training, and other quality control elements. The documentation of companies desiring accreditation will be evaluated against this ASME document. The certificate of accreditation is for three years, during which time there will be at least two unannounced ASME audits.

\section{$5.4 \quad$ Surface Finish}

Surface waviness and tolerances increase with size and result in changes in seal compression and performance. Waviness may also result from post-machining stress relaxation or the influence of other structural components on assembly. When such effects can be quantified, they can be regarded as changes in compression and assessed.

The characteristics of a compressed surface also depend on the machining technique used to finish it. No commercial machining process produces a regular surface; there is always a probability of an occasional large peak-to-valley height forming a communicating path across the seal. It is impossible to distinguish between the effects of damage and large peak-to-valley heights due to machining effects.

The distribution of peak-to-valley heights across a surface can be approximated by a simple model, ${ }^{i 3}$ in which

$$
\mathrm{n}_{\mathrm{h}}=\mathrm{N}_{0} \exp (-\mathrm{h} / \sigma)
$$

where $n_{h l}$ is the number of surface asperities of size $h, N_{0}$ is a constant, $h$ is an equivalent hole dimension, $\sigma$ is a constant in the hole size distribution function. If the flow through holes of size $h$ is assumed to be laminar but compressible, then

$$
\mathrm{Q}_{\mathrm{h}}=\mathrm{n}_{\mathrm{h}} \mathrm{K}\left(\mathrm{h}^{4} / \mathrm{L}\right)
$$


where $\mathrm{K}$ is a constant. The total flow through all holes is

$$
\mathrm{Q}_{1}=k N_{0} \Sigma\left|\exp (-\mathrm{h} / \sigma) \mathrm{h}^{1} / \mathrm{L}\right|
$$

The peak-to-valley distribution of a highly compressed abraded surface is shown in Fig. 8. ${ }^{13}$ Equations 14 and 15 are plotted in Fig. $9^{13}$ in dimensionless form and show that the flow across the seal is dominated by that through a few, large defects. Thus, slight changes in compression can change the leak rate considerably. The variation of seal leakage with an elastomer seal's compression is shown in Fig. $10^{6}$ for seals produced by different machining processes. The term Ra in Fig. 10 is the arithmetic mean deviation of the surface in units of $\mu \mathrm{m}$.

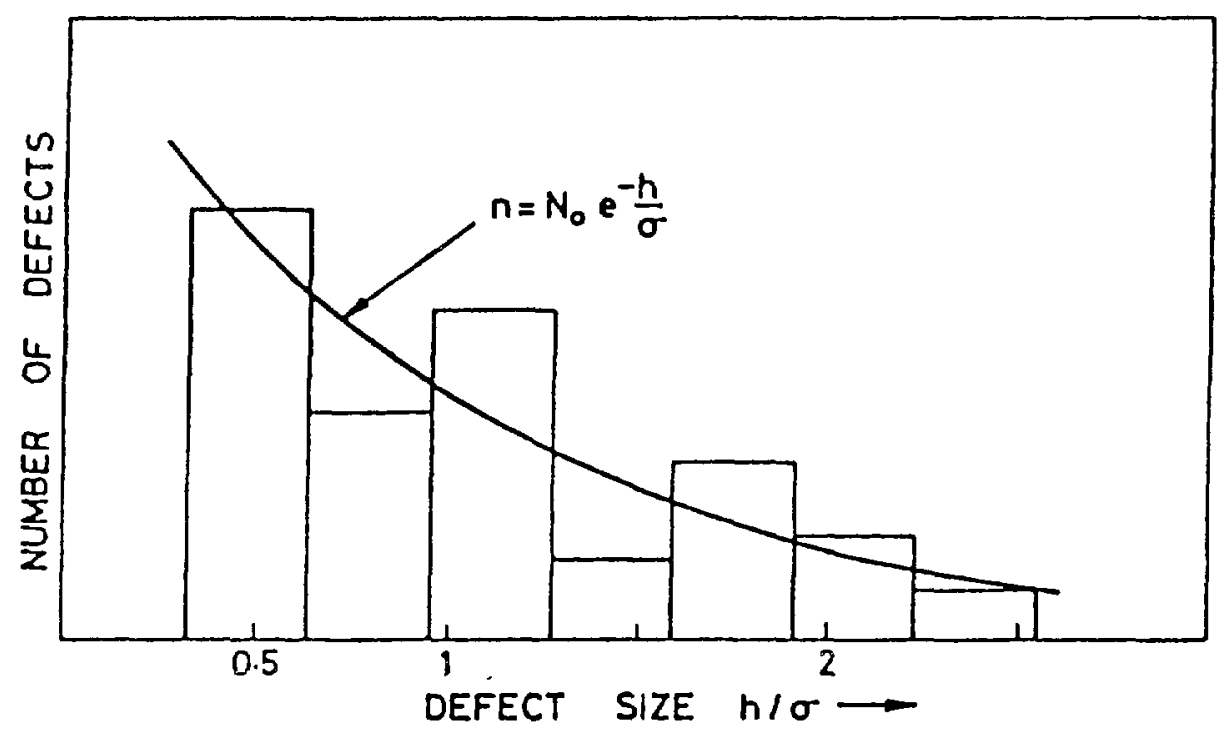

Fig. 8. Peak-to-Valley Distribution of a Highly Compressed Abraded Surface ${ }^{13}$

Copyright 1979. British Hydromechanical Research Association. Proc. of 8th Conf. on Fluid Sealing, Sept. 11-13, 1978, Univ. of Durham, England, "Scaling of Gas Leakage from Static Seals," T.C. Chivers, R. P. Hunt. Reprinted with permission.

Flange surface finishes of 0.5 to $10 \mu \mathrm{m} \mathrm{Ra}$ are used. The smoothest finishes are for precision joints with all-metal gaskets. The mating surfaces of flanges in bolted joints are often distorted and sometimes deeply scored. Flange waviness amplitudes of $0.2 \mathrm{~mm}$ (peak-to-valley) have been measured on commercial flanges. ${ }^{45}$ When these types of flanges are bolted together with a gasket between the faces, the compressive stress on the gasket is not uniform around the circumference. The stress is highest in regions corresponding to the peaks. When the fluid pressure reduces the compressive stress on the gasket, the low stress regions, the valleys, will rapidly approach the condition in which the residual stress is insufficient to prevent leakage. Tightening the bolts will only help if the flanges are rigid enough to transfer the force to the regions of the gasket which require it, and if the mechanical properties of the gasket can allow 
this increase in compression. If these conditions do not apply, then the flanges will be distorted further or the gasket will be over-stressed locally and crushed.
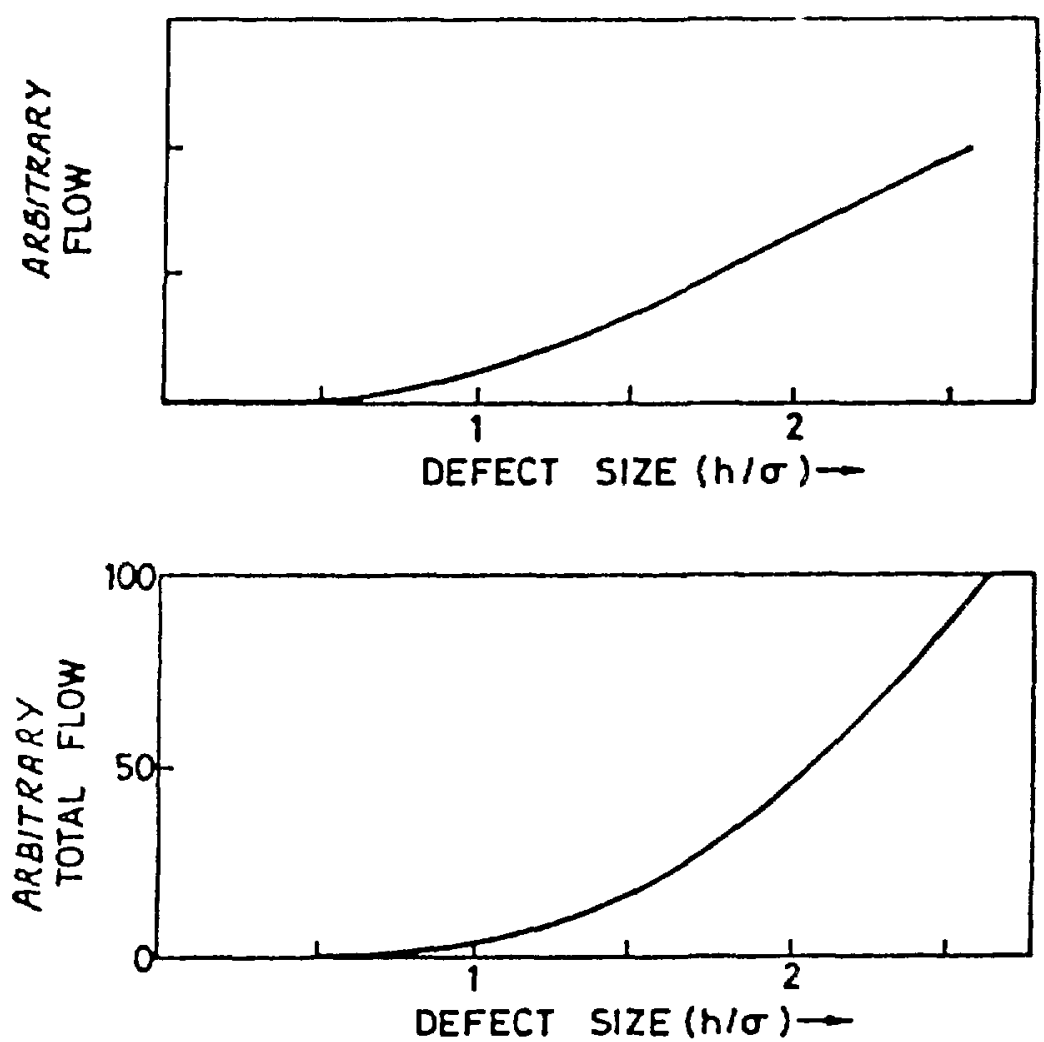

Fig. 9. Effect of Defect Distribution on Flow across Seal ${ }^{13}$

Copyright 1979. British Hydromechanical Research Association. Proc. of 8th Conf. on Fluid Sealing, Sept. 11-13, 1978, Univ. of Durham, England, "Scaling of Gas Leakage from Static Seals," T.C. Chivers, R. P. Hunt Reprinted with permission.

\subsection{Joint Assembly}

Any effort to develop a llinge seal with al low leak rate must lake into consideration joint assembly to ensure that the required clamping force is achieved but does not exceed design specifications. During assembly, most of the applied torque overcomes nut-to-joint friction $(50 \%)$ and thread friction (40\%). Thus, only $10 \%$ of the applied torque is translated into clamping force.

Several new assembly technologies are emerging to reduce problems with bolting. These include ultrasonic control, tension control bolts, and torque-turn control. The advantage of the first technology is shown by the following experience. ${ }^{50}$ 


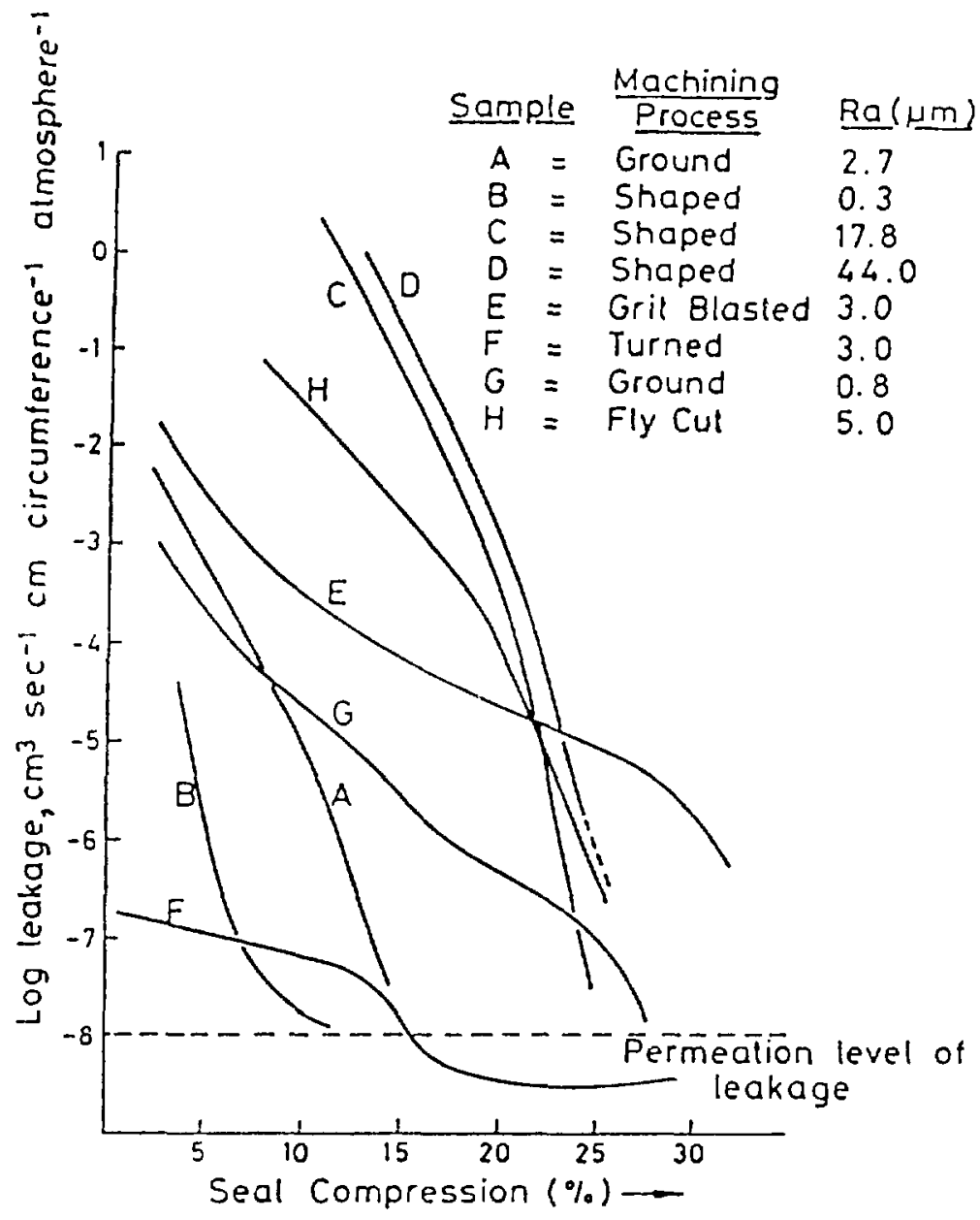

Fig. 10. Variation of Seal Leakage with Seal Compression for Different Machining Processes ${ }^{6}$

\footnotetext{
Copyright 1981. British Hydromechanical Research Association. Proc. of 9th Conf. on Fluid Sealing, April 1-3, 1981, Noordwijkerhout, Netherlands, "High Integrity Static Elastomer ' $O$ ' Ring Seals and Their Performance through Thermal Transients," T.C. Chivers, A.F. George, R.P. Hunt. Reprinted with permission.
}

During assembly of a large diameter flange on a heat exchanger, an ultrasonic extensometer was used to monitor the variation in the bolt loads. The load on individual bolts (Fig. 11a) was random after three tightenings with calibrated torque wrenches. With the input from an extensometer, the required bolt stretch to obtain the desired bolt load was achieved for the flange (Fïg. 11b). When the bolt loads on the joint were examined after two years of operation at elevated temperatures, the mean bolt stretch had decreased about $30 \%$ (Fig. 11c) but the individual load variation was minor. Since no visible leaks had been detected, the joint was not retightened. 


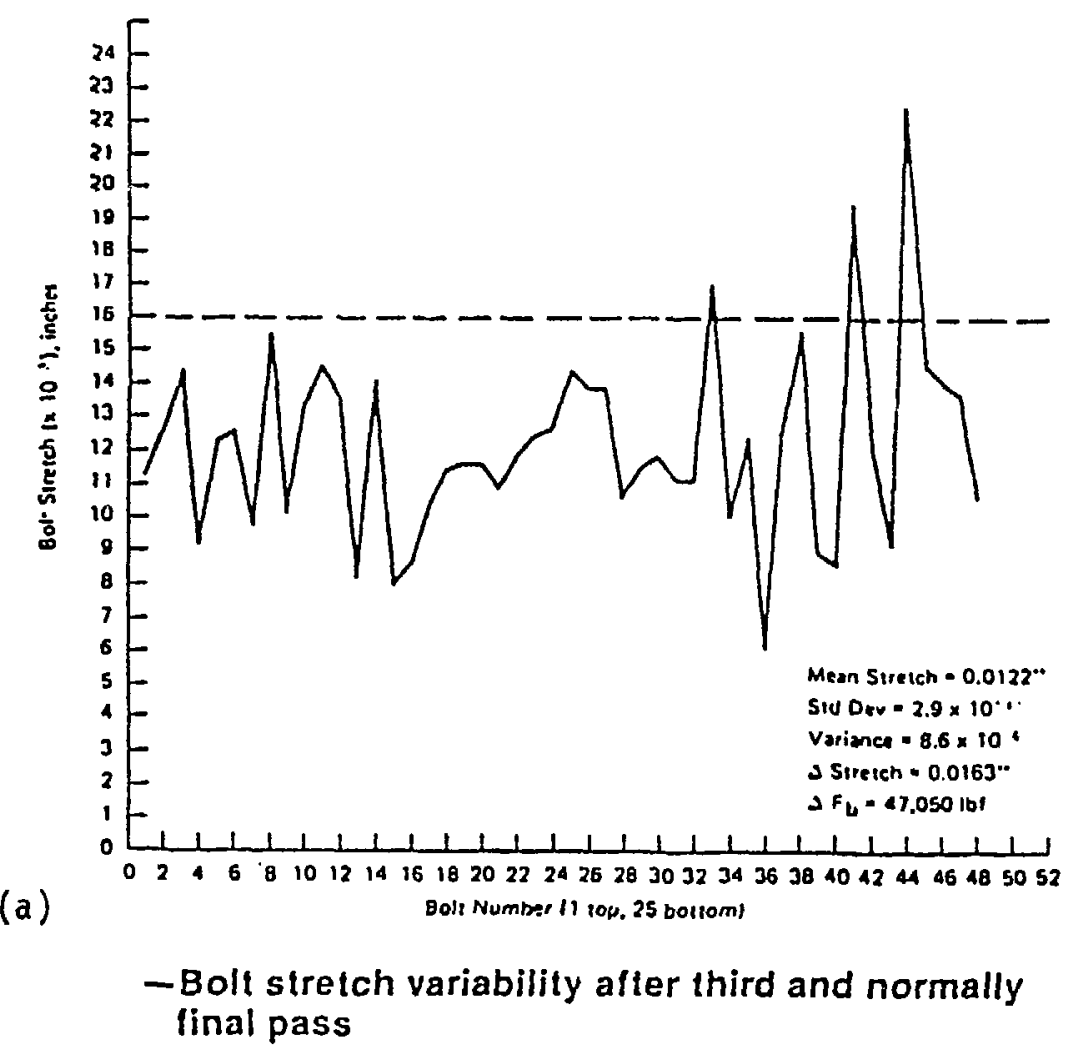

(b)

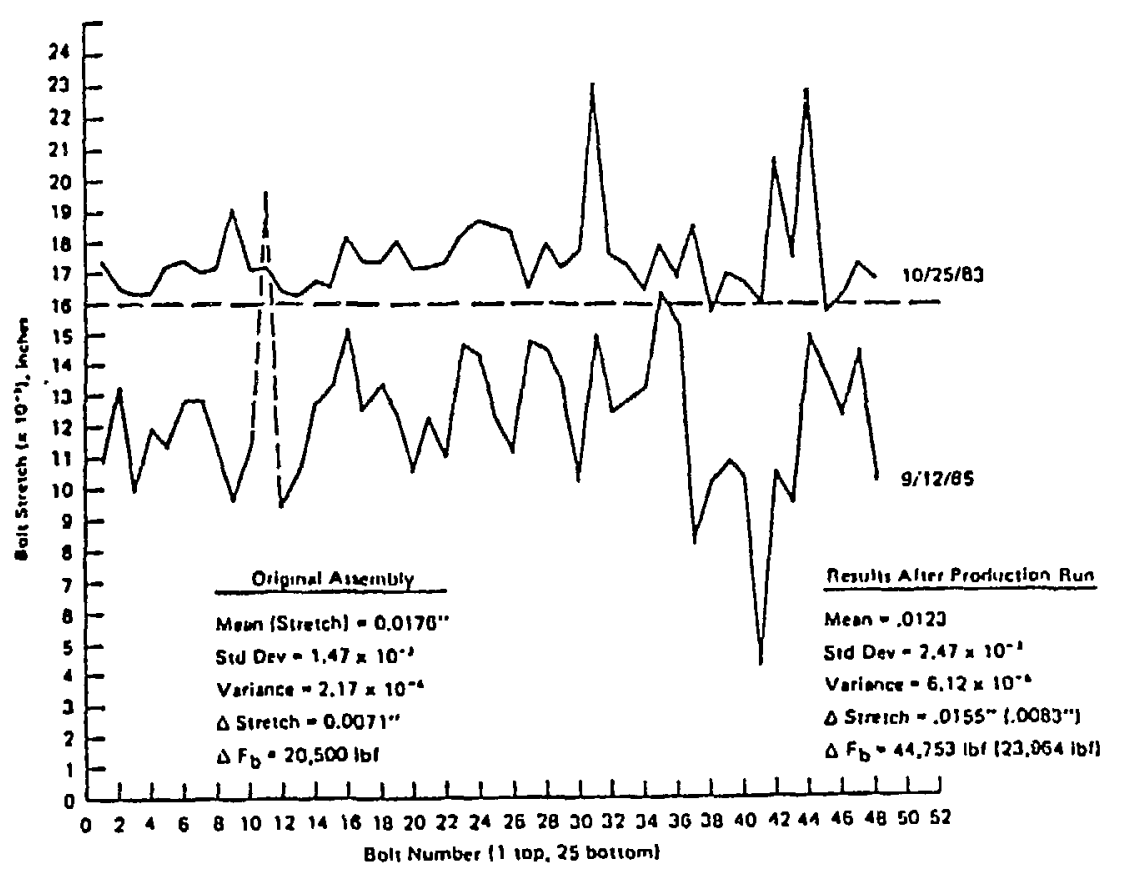

(c)
- Changes in bolt stretch after a two-year production run
-Bolt stretch variability after using the bolt extensometer

Fig. 11. Load on Individual Bolts (a) after Three Tightenings with Calibrated Torque Wrenches, (b) with an Extensometer, and (c) after Two Years Operation ${ }^{50}$

Copyright 1988. Society for Experimental Mechanics, Inc. "Experimental Techniques, Special Supplement on Gaskets and Bolted Joints." Reprinted with permission. 
During this joint's assembly, the load on a given bolt decreased as adjacent bolts were tightened. This was identified as local elastic interaction, and its magnitude is determined by the flexibility of the flange; this interaction could lead to very large variations in each bolt load. For a flexible flange, the elastic interaction is low; thus, the tightness of a bolt three bolts removed from the tightened bolt is not affected. Second, major variations in each bolt's coefficient of friction were also found; these variations correspond to major differences in the torque needed to achieve the required bolt load. Third, galling could be detected with the extensometer; minor galling produced a stick-slip phenomenon, which resulted in a sudden increase in the bolt stretch, producing very high peaks in Fig. 11a. ${ }^{50}$

The designer of seals for the HWR-NPR should remember that (1) a uniform bolt load is as important as the mean bolt load in joint assembly, since for the same quality seal, a flexible flange requires a more uniform bolt load than a stiff flange; (2) the mean bolt load must be achieved to attain the initial gasket compression needed; and (3) the flange stiffness will determine the type of equipment needed to control bolt load during assembly, if the correct gasket is used and the bolt type is adequate. If flange rotation is $<0.12$ degrees, then following good assembly procedures using calibrated torque wrenches is adequate to achieve the required seal. If the flange has a rotation of $\leq 0.15$ degrees, then calibrated torque wrenches and an ultrasonic extensometer are required to achieve the required seal.

Ultrasonic methods to measure bolt tension are still under development. According to Bickford, ${ }^{46}$ some practical problems to be overcome are that accuracy is poor for short bolts and at low stress levels (173 MPa, 25,000 psi). Also, obtaining an accurate measurement is difficult because (1) bolts have a nonuniform tensile stress, residual manufacturing stresses, anisotropy, and nonuniform variations in bolt properties; (2) there are structural changes in the bolt surfaces; (3) the velocity of the ultrasonic shear wave is affected by the bolt's tensile stress; (4) there are problems with the coupling of transducers to a bolt; and (5) measurements can be affected by the position of the transducer. Because of these multiple difficulties, this technique requires additional refinement.

To bolt the joint on a reactor head, the French ${ }^{53-54}$ have a stud bolting robot that can simultaneously bolt several of a reactor's studs. They also use remotely operated grinding/polishing machines that clean the grooves in the closure head and the surface of the reactor vessel flange prior to the bolting operation. These machines automatically travel around the flange and use a vacuum to eliminate dust. Grinding automatically stops if the machine stops.

To achieve the bolt loads required to obtain seals with low leak rates, the designer must specify the bolt tension control strategy to be used in the assembly operation and must also specify that simultaneous bolt tightening is to be used to minimize elastic interactions.

\section{ELASTOMER SEALS}

The degrading effects of both gamma and tritium irradiation on the lifetime of elastomer O-rings is an important parameter since elastomers may be used to provide dynamic seals for fuel tubes, safety rods, and control rods at the reactor head of the HWR-NPR. 
For most elastomers, $10 \mathrm{Mrad}$ of radiation produces insignificant effects but rapid degradation occurs in all elastomers at $1000 \mathrm{Mrad}$. Atomic Energy of Canada, Limited (AECL) ${ }^{55-56}$ UKAEA,${ }^{57}$ Westinghouse at the Savannah River Site (W-SRS) ${ }^{58-59}$ and Los Alamos National Laboratory (LANL) ${ }^{60-63}$ have tested various types of elastomers to determine which has the best performance in tritium service.

Since the early 1960 s, the effect of gamma irradiation on elastomers has been examined. ${ }^{64-68}$ However, because tritium is incorporated into the elastomer structure, the effects of tritium on the elastomer are more crucial in the HWR-NPR environment. Elastomers are bound together by covalent bonds that are easily disrupted by the addition of radiation energy. The effect of irradiation for a given material depends upon the chemical structure of the material. Both radiation-induced cross-linking and bond breaking lead to changes in physical properties. Cross-linking can change a material which is soft or rubbery to one which is a hard glass. Scission produces a greater number of chain ends, which leads to weakening and embrittlement of the elastomer, reducing its impact and tensile strength. Materials which soften after irradiation not only lose tensile strength but also have major gains in their compression set. (The latter denotes the degree of permanent deformation of the elastomer after a given time at a given temperature under a given stress.)

Other parameters which determine the effect of radiation are the degree of crystallinity, dose rate, presence of cross-linking agents and other additives, and $\mathrm{O}_{2}$ concentration. Oxygen produced from radiolysis of water can cause increases in the scission rate.

Besides the effect of radiation, elastomers can have a volume change of $1-10 \%$ when immersed in water, which could change the behavior of seals within the HWR-NPR.

\subsection{Long Term Deformation}

The resistance of elastomer materials to long-term deformation is important for seal design. There are three techniques which have been used to measure this important property: compression set, compression set relaxation, and diametral compression set.

A correlation between these tests was established by British workers ${ }^{69}$ for three elastomer materials: fluorocarbon rubber, low compression set fluorocarbon, and silicone rubber. Deformation data were plotted in a $\log / \log$ relationship to aging time, and a linear region was extrapolated to a $100 \%$ value to give an aging time defined as the failure time, which is not the "true failure time." However, since this extrapolation errs on the side of safety, it is useful for design purposes. Failure times were found to fit an Arrhenius relationship. Arrhenius plots are shown in Fig. 12 for silicone rubber and low compression set fluorocarbon. Materials performance for these three tests can be compared by such figures. Parallel lines for the different tests imply a homogeneous aging mechanism of constant activation energy, regardless of test method.

The compression set test consistently gave a longer time to failure than the other two tests, but the other twe tests are closer to service conditions, one as a face seal and the other as a diametral seal. Factors such as O-ring dimensions, temperature of conditioning before 


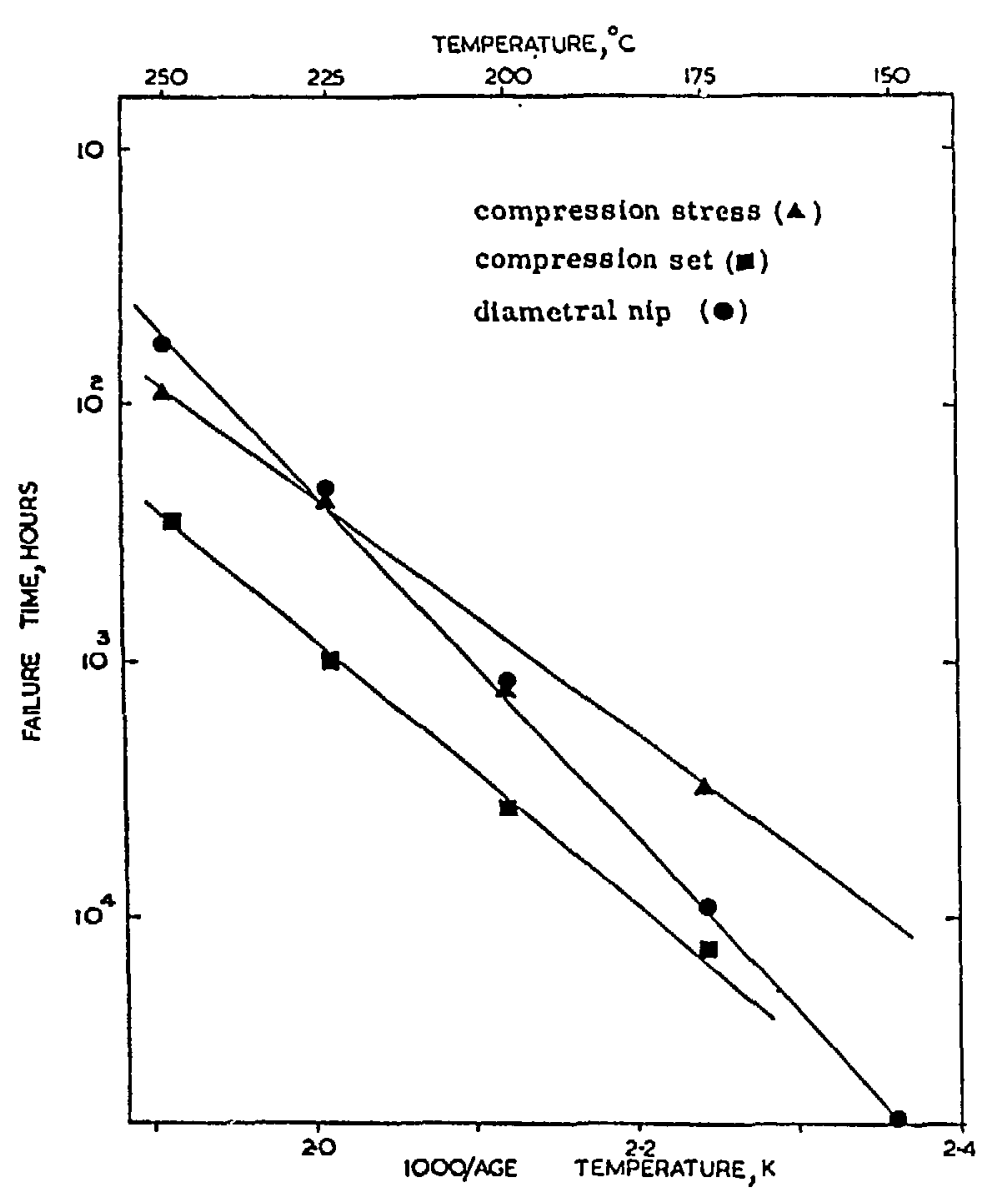

Low compression set fluorocarbon rubber O-rings

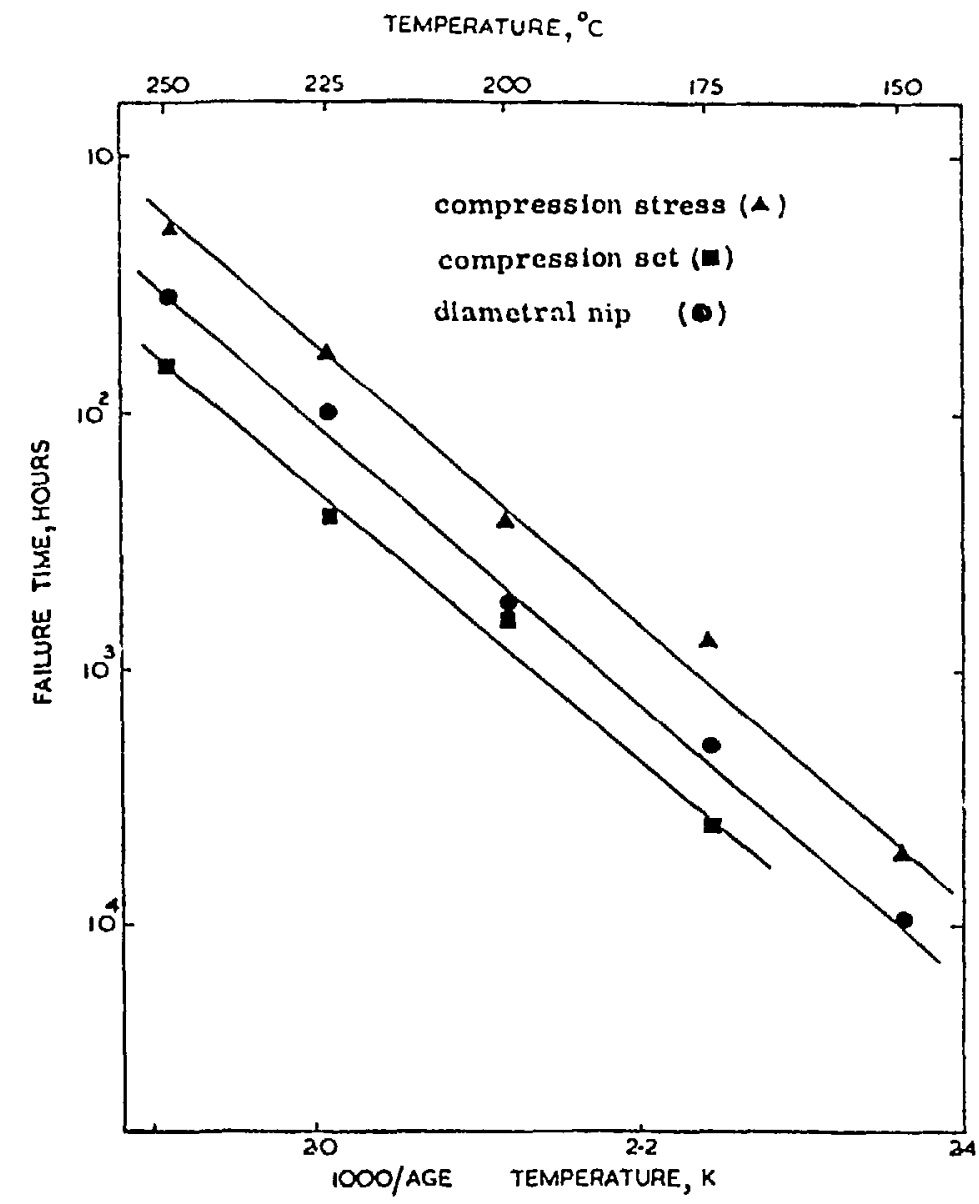

Sillicone rubber O-rings

Fig. 12. Arrhenius Plots Comparing Compression Set to Two Other Techniques for Silicone Rubber and Low Compression Set Fluorocarbon ${ }^{69}$

Copyright 1976. British Hydromechanical Rescarch Association. Proc. of 7th Conf. on Fluid Sealing, Sept. 24-26, 1975, Univ. Nottingham, England, "Laboratory Assessment of O-Ring Sealing Performance," D. W. Southwart. Reprinted with permission. 
measurement, and access of air during aging are all factors which can affect the results of any of the three tests. Thus, relevant aging conditions in service may not be faithfully reproduced by any of these tests.

Compression stress relaxation has been advocated in Europe to replace the compression set. ${ }^{70}$ Compression stress relaxation measures, as a function of time, the decrease in resisting force exerted by an elastomer held under constant compressive strain, usually $25 \%$. Initial strain and counterforce are measured by strain gauges. A cylindrical sample is compressed to the specified $25 \%$ strain within $30 \mathrm{~s}$. The initial compressive measurement is made $30 \mathrm{~min}$ later, and subsequent measurements are taken at specified time intervals over 166-168 h. The compression set relaxation ratio, $R_{t}$, is calculated from

$$
R_{t}=100\left(F_{0}-F_{t}\right) / F_{0}
$$

where $F_{0}$ is the initial counterforce, and $F_{t}$ is the counterforce after 166-168 h. This test has been recognized overseas by ISO Standard 3384 but is not accepted in the U.S. because military specifications and ASTM D-2000 specify the compression set as defined in ASTM D-395. ${ }^{70}$

Compression set is defined as the percentage displacement not recovered $30 \mathrm{~min}$ after removing the compressive load. ${ }^{58}$ Compression set in elastomer seals results in a permanently distorted shape that is associated with stress relaxation. This change leads to an increase in leakage and forms a basis for pessimistic assessments of water leak rates from elastomer seals. Experiments show that it is relative movement, found during thermal cycling, which produces the greatest changes in leakage. If compression set occurs at a high temperature, and relative movements occur as the temperature is reduced, then sufficient elastomer elasticity may not be retained to cope with dimensional changes. Thus, large variations in leak rates could occur. $^{5}$

\subsection{Characterization of Ethylene Propylene}

The material of choice for tritium service is ethylene propylene. ${ }^{55-62}$ However, a variety of materials fall under this name; characterization work has been done with several of them, which all have slightly different properties. Ethylene propylene terpolymer (EPT) ${ }^{*}$ is a copolymer of three monomers; the third monomer allows easier vulcanization than is possible with fully saturated ethylene propylene copolymer (EPR). ${ }^{* *}$ The former is similar to high styrene but has an increased oxygen and ozone resistance and has excellent steam and hot water resistance.

The most extensive tests were done in England by Blakeston et al. ${ }^{57}$ with EPR, including long-term endurance tests with large seals in a reactor. The English requirements for the elastomer were that (1) seals could be made or released via remote operation; (2) seal designs could use two O-rings; (3) the material should be chemically stable in water with a pH 6-7,

\footnotetext{
${ }^{*}$ Also referred to as EPDM.

${ }^{* *}$ Also referred to as EPM.
} 
conductivity $<20 \mu \mathrm{S} / \mathrm{mm}$, and $\mathrm{Cl}<0.1 \mathrm{~g} /$ ton of water; (4) the seal should operate reliably for five years; (5) the seal should survive in a gamma radiation field of $4 \times 10^{5}$ rad at a dose rate of $10 \mathrm{R} / \mathrm{h} ;(6)$ the seal should not adhere to metal surfaces; and (7) the seal material should not release halides to the reactor.

The change in compression set for EPR in air as a function of time and temperature is shown in Fig. 13. The material's compression set increases rapidly at temperatures greater than $100^{\circ} \mathrm{C}$. The change in compression set of EPR in pressurized water $\left(100^{\circ} \mathrm{C}\right.$ and $\left.6.5 \mathrm{MPa}\right)$ as a function of $\mathrm{O}_{2}$ content is shown in Fig. 14. The importance of the need to minimize the $\mathrm{O}_{2}$ content of the water is readily seen. Blakeson et al. alluded to the effect of elastomer formulation on compression set in noting that EPT was the most promising alternative to EPR; however, no definitive information was given.

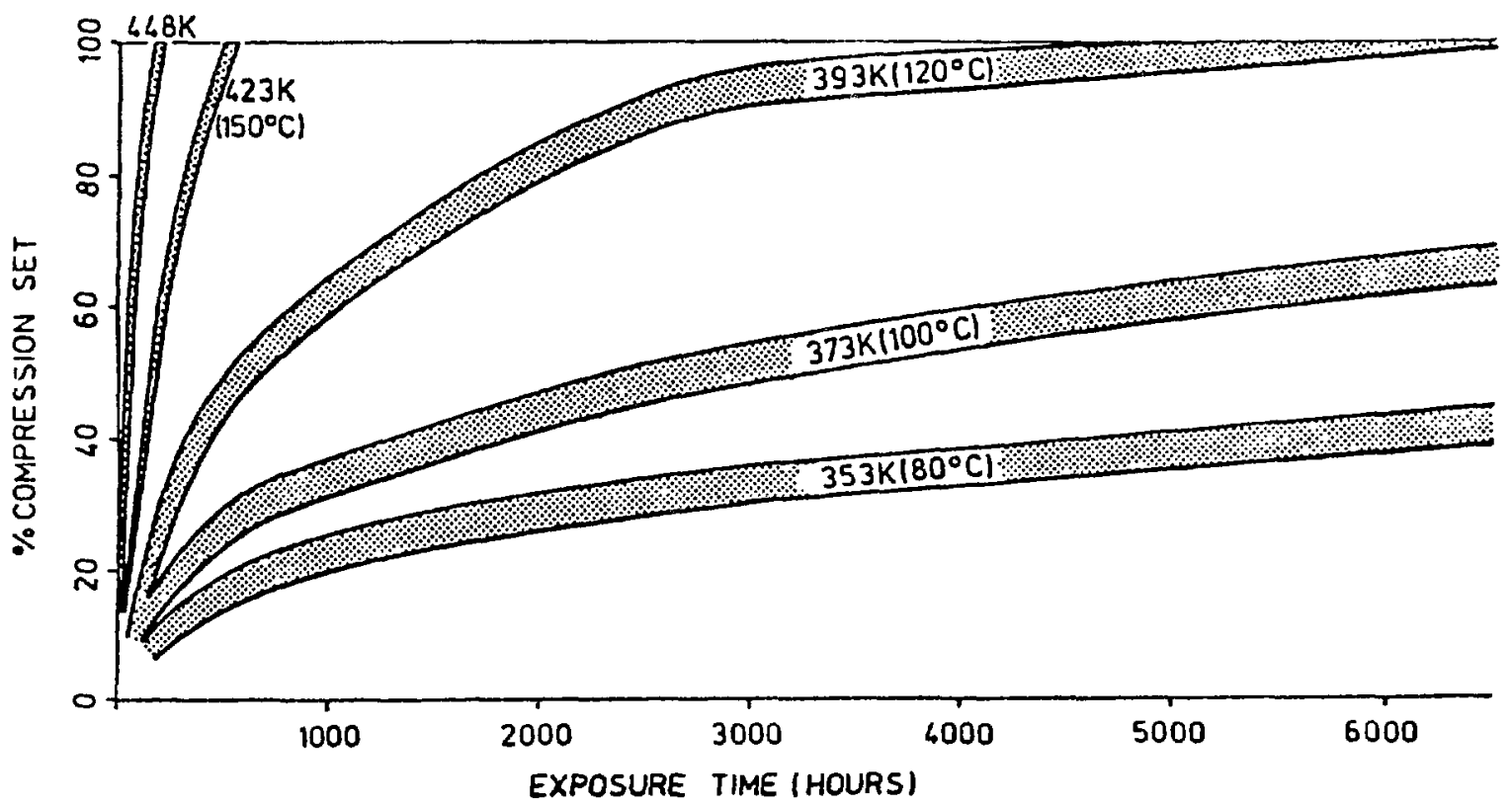

Fig. 13. Change in Compression Set for Ethylene Propylene Copolymer in Air as Function of Time and Temperature ${ }^{57}$

Copyright 1979. British Hydromechanical Research Association. Proc. of 8th Conf. on Fluid Sealing, Sept. 11-13, 1978, Univ. of Durham, England, "The Testing of Elastomers for Channel Sea Plugs in a Steam Generating Heavy Water Nuclear Reactor," M.L. Blakeston, K.A. Tomblin, J. Ward. Reprinted with permission.

At AECL, ${ }^{55,56}$ ethylene propylene O-rings of two different formulations (E515-80 and E692-75) were tested for up to one year as static seals in water with a $\mathrm{pH}$ of 10 at a pressure of $6.9 \mathrm{MPa}$ and temperatures of 177 and $232^{\circ} \mathrm{C}$. In addition, radiation tests were done with a Co-60 source at two different dose rates and three different doses, in water at $\mathrm{pH}=7,10$, and 10 (with dissolved $\mathrm{O}_{2} \leq 10 \mathrm{ppm}$ ). Compression set was used as an indicator of seal deterioration. The compression test results shown in Table 9 for ethylene propylene are for conditions under 
which the other elastomers tested had failed. A comparison between compression set and water leak rate is shown in Table 10.

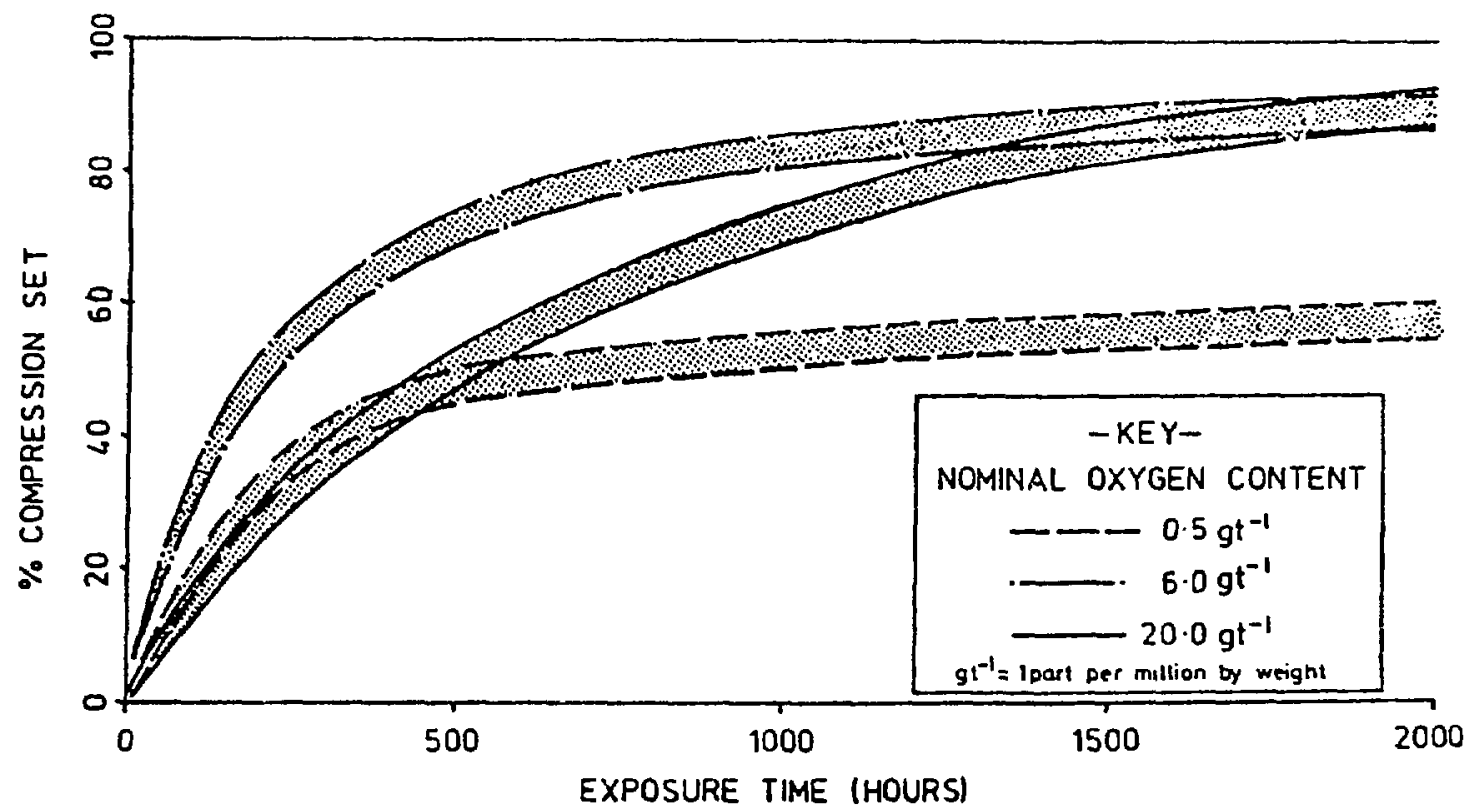

Fig. 14. Change in Compression Set for Ethylene Propylene Copolymer in Pressurized Water $\left(100^{\circ} \mathrm{C}, 6.5 \mathrm{MPa}\right)$ as Funciion of $\mathrm{O}_{2}$ Content and Time ${ }^{57}$

Copyright 1979. British Hydromechanical Research Association. Proc. of 8th Conf. on Fluid Sealing, Sept. 11-13, 1978, Univ. of Durham, England, "The Testing of Elastomers for Channel Seal Plugs in a Stean Generating Heavy Water Nuclear Reactor," M.L. Blakeston, K.A. Tomblin, J. Ward. Reprinted with permission.

The compound with the highest resistance tr deformation in a radiation environment (Table 10) was a Parker Seal (now Norton) ethylene propylene E692-75, having a compression set $\leq 50 \%$ for short-term tests. For E692-75 seals, exposure to $10^{7} \mathrm{rad}$ had more severe compression set effects than exposure to $177^{\circ} \mathrm{C}$ water for $200 \mathrm{~h}$. Also, the effect on compression set of radiation at $121^{\circ} \mathrm{C}$ was more severe th.an the effect at $15^{\circ} \mathrm{C}$.

A radiation-resistant elastomer to replace Buna- $N$ rubber was desired at Savannah River Laboratory; thus, ethylene propylene E740-75 and other elastomers were tested ${ }^{58-59}$ using compression set as an indicator of radiation resistance. The compression test was done two months after exposure of the elastomers to tritium. As shown in Table 11, the compression set for ethylene propylene E740-75 in the presence of 0.07-0.08 $\mathrm{MPa}$ molecular tritium was $52 \%$ at 125 days tritium exposure and decreased to $74 \%$ at 225 days tritium exposure. The "radiationinduced set" is the difference between the total compression set for the irradiated elastomer and that for a control exposed to air. The tritium off-gas rate, also listed? in Table 11, gives a relative indication of the solubility of tritium in each elastomer. 
Table 9. Conditions for which Compression Was $\geq 50 \%$ for Ethylene Propylene (E515-80 and E692-75) in AECL Tests ${ }^{a}$

\begin{tabular}{lccl}
\hline Conditions & $\begin{array}{c}\text { Time, } \\
\mathrm{h}\end{array}$ & $\begin{array}{c}\text { Dose, } \\
\text { rad }\end{array}$ & $\begin{array}{c}\text { Compression Set, } \\
\%\end{array}$ \\
\hline $177^{\circ} \mathrm{C}$ in air & 20 & $\cdots$ & $>50$ (only E515-80) \\
$177^{\circ} \mathrm{C}$ in air & 200 & $\cdots$ & $>75$ \\
$15^{\circ} \mathrm{C}$ in air & $<50$ & $7.4 \times 10^{7}$ & $>50$ \\
$177^{\circ} \mathrm{C}$ in water, all pH's & 200 & $6 \times 10^{7}$ & $>50$ \\
\hline
\end{tabular}

${ }^{3}$ Other materials had failed prior to these conditions.

bEflect was independent of dose rate, i.e., time.

Table 10. Water Leak Rates and Compression Set for Ethylene Propylene Compared to Other Elastomers

\begin{tabular}{lcc}
\hline Scal Material & Leak Rate, $\mathrm{mL} / \mathrm{min}$ & Comp. Set, \% \\
\hline Echylene Prop. E692-75 & 0 at 15 cycles $^{\mathrm{a}}$ & 50 \\
Ethylene Prop. E692-75 & 0 at 10 cycles & 47 \\
Elhylene Prop. E692-75 & 0 at 5 cycles & 42 \\
Echylene Prop. E515-80 & 0 at 5 cycles & 75 \\
Viton 19357 & 0 at 5 cycles & 61 \\
Viton V747-75 & High at 3 cycles & 96 \\
Perfluoro ECD 006 & High at 1 cycle & 97 \\
\hline
\end{tabular}

${ }^{\mathrm{a} C y c l e d}$ from $177^{\circ} \mathrm{C} / 6.9 \mathrm{MPa}$ to ambient conditions.

Table 11. Compression Set and Tritium Orf-gas Rate for Ethylene Propylene and Other Elastomers

\begin{tabular}{|c|c|c|c|c|c|}
\hline \multirow[b]{2}{*}{ Elastomer } & \multicolumn{2}{|c|}{$\begin{array}{c}\text { Total } \\
\text { Compression } \\
\text { Set, \% }\end{array}$} & \multicolumn{2}{|c|}{$\begin{array}{c}\text { Rad. Induced } \\
\text { Set }{ }^{a} \% \\
\end{array}$} & \multirow{2}{*}{$\begin{array}{l}\text { Off-gas Rate } \times 10^{7}, \\
\mathrm{~cm}^{3}(\mathrm{STP}) / \mathrm{s}\end{array}$} \\
\hline & $125 \mathrm{~d}$ & $225 \mathrm{~d}$ & $125 \mathrm{~d}$ & $225 d$ & \\
\hline Ethylene Propylene (E740-75) & 52 & 74 & 44 & 66 & 3.6 \\
\hline Styrene Butadiene (G244-70) & 75 & 97 & 68 & 88 & 9.1 \\
\hline Kalrez Perfluoro 4084 & na & 85 & na & 46 & na \\
\hline Kalrez Perfluoro 1018 & 83 & na & 34 & na & 11 \\
\hline Viton B (V494-70) & 88 & na & 42 & na & 11 \\
\hline Viton E60C (V747-75) & 93 & 97 & 69 & 75 & 20 \\
\hline Ethylene Acrylic (A936-70) & 93 & 97 & 77 & 83 & 39 \\
\hline Nitrile (N741-75) & 97 & 97 & 90 & 88 & 14 \\
\hline Urethane (P642-70) & 98 & 100 & 77 & 71 & 140 \\
\hline Silicone (S604-70) & 99 & na & 90 & na & 120 \\
\hline
\end{tabular}

${ }^{3}$ Difference between irradiated sample and control held in air. 
Since there are different types of ethylene propylene, a non-proprietary formulation of EPDM was prepared at LANL ${ }^{61-62}$ and tested to ensure that a material with reproducible properties and formulation would be available over several years. The desired properties were the following: chemical stability, long shelf-life, minimum $\mathrm{H}_{2}$ permeation, low compression set, durometer hardness of Shore $\mathrm{A} \leq 80$, temperature range of -55 to $75^{\circ} \mathrm{C}$, and minimum elongation (100\%).

Two roll mills were used to attain a compound with the dispersion needed for small diameter seals. High peroxide and high cross-linking co-agent were used to achieve a high crosslink density, which makes the material less sensitive to radiation. A vacuum post cure was used to remove residues, which contribute to further cross-linking when a seal is compressed. An acceptable material was one in which $<2 \%$ of the total material was lost. No plasticizer or sulfur was added. Even with a non-proprietary formulation, the material characteristics could change from year to year since the formulations of the starting ingredients (trade names) could be changed in the future.

The compression set of the EPDM material was $5 \%$ after 400 days exposure to molecular tritium at room temperature. The maximum compression set was $10 \%$ after $70 \mathrm{~h}$ at $125^{\circ} \mathrm{C}$. The hardness was Shore A 78; the tensile strength was $8.2 \mathrm{MPa}$; the minimum elongation was $100 \%$. The tritium permeability was $<10^{-6} \mathrm{~cm}^{3} / \mathrm{s}$ after $10 \mathrm{~min}$. After $270 \mathrm{Mrad}$ gamma irradiation, the permeation decreased $15 \%$. This result could indicate elastomer movement against the gland face and/or EPDM degradation.

Several ASTM methods measure the release of gases from elastomers, depending on the form of the elastomer (films, sheets, thick materials, coatings). However, the results from these methods for the same material from the same company can vary by a factor of three or more. Using one of these methods, Cassidy, Aminabhavi, and Thompson ${ }^{7}$ measured the permeability of water in EPLiM and found it to be $2 \times 10^{-7} \mathrm{~cm}^{3} /(\mathrm{cm} \cdot \mathrm{s} \bullet \mathrm{MPa})$.

The problem associated with the continuous reformulation of elastomers by the polymer industry is highlighted in the case of another elastomer. ${ }^{63}$ To obtain a species with a lower hydrogen permeability than the non-proprietary EPDM, ${ }^{61-62}$ Hydrin 100, unfilled and filled with hydrous $\mathrm{MgSiO}_{3}$, was examined. The deuterium permeation was 5-45 times less than that of EPDM. However, the material is no longer made because the company was su!d. A material known as H-65, made by a different company, may be comparable but this has to be verified by repeating all tests.

\subsection{Engineering Design of Elastomers}

O-rings are designed to be deformed. A designer is interested in how much force is needed for a given deformation, since this affects the achieved leak rate and the assembly procedure for a seal. The Young's modulus varies with the amount of strain and can be related to the hardness of the elastomer material. The general relation ${ }^{45}$ between Young's modulus $\left(\mathrm{N} / \mathrm{mm}^{2}\right)$ and hardness (IRHD = International Rubber Hardness Degrees) is not linear, rather the relation is $1.47 / 40,1.76 / 45,2.14 / 50,3.16 / 55,4.34 / 60,5.72 / 65,7.16 / 70,9.24 / 75$, and $27.6 / 90$ at room temperature. Elastomers for static seals would have a hardness of 90 , those for dynamic 
seals would have a hardness of 70 . The lower hardness results in a lower friction force. Since temperature affects the Young's modulus, stress relaxation, and expansion of an elastomer, the prediction of an elastomer seal's performance depends on a projected time-temperature-squeeze history of a joint.

Even though the hardness properties of an elastomer are well known, an elastomer's use in a design has to be modeled. ${ }^{45,71-73}$ Elastomer O-rings are pressure actuated and should be pressurized in the right direction. Corrc $t$ constraint geometry and pressure direction should be modeled.

The failure to model the operation of the Challenger seals was a root cause of the 1986 accident. Seal design for the O-rings in the space shuttle solid rocket booster was based on conventional practice, limited data from the manufacturer, and previous experience. The interplay of surface finish, friction, squeeze, end constraints, and time-temperature-dependent material properties on reliability was not recognized.

To analyze the behavior of the O-rings in the solid rocket booster after the shuttle accident, Metcalfe et al. ${ }^{73}$ used a large displacement, incompressible, viscoelastic finite element model (MARC code) ${ }^{74}$ and determined the O-ring squeeze during assembly of the booster case, followed by relaxation, recovery, and pressurization of the seal. The results showed the feasibility of predicting an O-ring's dynamic response to conditions, including thermal cycling and deformation and/or movement of the joint. In effect, this study ${ }^{73}$ was a practical demonstration that the viscoelastic response of an O-ring to squeeze, dwell time, gap widening, friction, temperatuic, and pressure can be successfully modeled using the MARC code, combined with a rigorous approach to materials characterization, boundary conditions, and incremental solution procedures. The appendix of Ref. 73 contains a detailed theoretical basis of the approach.

\section{SEALS IN VALVES}

Valve leakage is a major contributor to reactor plant contamination and maintenance. The sources of valve leakage in order of importance are (1) stem packing leakage, (2) seat leakage due to chemical buildup, (3) body-to-bonnet joint leakage, (4) valve damage due to cavitation, and (5) excessive seat closure loading.

Valve stem packing is the most significant source of leakage since packings consolidate and wear with time, resulting in insufficient elasticity to accommodate dimensional variation. The factors which control stem packing leakage are the composition of the packing material and the presence or absence of a dynamic system that provides the needed packing gland pressure. Of secondary importance are the frequency of valve stem movement, the finish on the stem and the stuffing, the quality of the surfaces in the stuffing box, the clearances, and the depth of packing.

Valve stem packing leakage can be handled by providing systems to collect the leakage, replacing the packed valves with bellows valves, eliminating the packed valves, and/or redesigning the packed valves. Since collection systems can become overloaded and leak, and 
bellows valves cannot be used for some applications, one must be able to redesign the packed valve.

The effectiveness of stem packing depends on the stuffing box design, the materials used for packing, the manner in which force is applied to the packing, and the finish on the stem. Workers in Canada, ${ }^{75-87}$ France, ${ }^{88-89}$ England, ${ }^{90}$ Germany, ${ }^{91-92}$ Japan, ${ }^{93}$ and the U.S. ${ }^{94-100}$ have sponsored work to increase the effectiveness of stem packing. Three manufacturers have worked in this area, Velan Manufacturing Co., ${ }^{85,90}$ Latty International, France, ${ }^{88-89}$ and Rockwell International. ${ }^{99}$

Lipton ${ }^{101}$ conducted dimensional checks on valves from different manufacturers and found a lack of standardization. Many firms do not understand what compressive stress is needed to achieve a valve packing seal with a low leak rate. ${ }^{101}$ Except for the data supplied by AECL. ${ }^{75.87}$ for valves with asbestos packing, and recently by EPR ${ }^{94,97-98,100}$ for valves with expanded graphite packing, little to no information is available to manufacturers on ways to optimize the design of the packed stuffing box, which is the basis of a packed valve's seal. Work done by one of Rockwell's divisions is summarized in Ref. 99; however, this expertise appears lost since the division no longer exists.

The following sections address the usefulness of bellows valves and the design of packed valves. Some other valve developments which may be applicable to the HWR-NPR design are also mentioned.

\subsection{Bellows Valves}

A valve which does not have stem packing is a metal bellows valve. Closure is affected by a flexible connection between the traveling valve stem and stationary bonnet. A packing gland and/or a weld is added to provide protection in event of rupture. Failure of the bellows occurs due to fatigue induced by excess vibration at the resonance frequency of the bellows or by excess turbulence in the fluid.

The advantages of bellows valves are that they have indefinite "zero" leakage and low "friction." Their disadvantages are that stroke is limited, pressures in excess of $1 \mathrm{MPa}$ require balancing, fatigue life is limited, failure can be catastrophic with little warning, large exposed surface areas can increase degradation, and age hardening can reduce fatigue life. The limited stroke introduces a practical size limitation. For acceptable fatigue life, a bellows for a $30-\mathrm{cm}$ gate valve would have to be $3-\mathrm{m}$ long because the bellows can only be stroked $10-15 \%$ of its free length. This size bellows valve would be expensive to fabricate. However, bellows valves can be a very useful design solutions since the majority $(80 \%)$ of valves in reactors are under $5 \mathrm{~cm}$ in diameter.

A bellows valve should have a backup stem seal to prevent catastrophic leakage if the bellows fails. In CANDU reactors, bellows valves have redundant packed-stem seals or a weld to back up the bellows. During operation of 600 bellows valves $(2.5-\mathrm{cm}$ diameter) through 1975 at Pickering, ${ }^{75} 11$ bellows failures occurred for a mean time between failures of $560 \mathrm{y}$ $\left(\mathrm{MTBF}=4.9 \times 10^{6} \mathrm{~h}\right)$. 
Bellows valves for the HWR-NPR should be subject to proof tests. The criterion for acceptance should be a value of 5000 for the number of failures versus the number of stem actuations. Other tests should address pressure cycling, functional flexing, vibration, resonance frequency of the bellows, and the adequacy of the shield between the bellows and the fluid.

\section{2 $\quad$ Packed Valves}

During the 1970s, the AECL and the Velan Manufacturing Co. collaborated on a valve development program. ${ }^{75-87}$ Work concentrated on three valve types which cannot be replaced with bellows valves: gate valves which have a large $(25-35 \mathrm{~cm})$ diameter ${ }^{79}$; globe valves which undergo fatigue due to thermal stress; and control valves which undergo fatigue due to constant movement during reactor operation.

The AECL reviewed the theory of leakage through porous media and developed an empirical mathematical framework for relating leakage and packing friction to stuffing box dimensions and compressive stress. ${ }^{84}$ They developed a procedure to modify conventional valves and to develop new valve designs.

The four basic findings of their program were the following. First, leakage can be predicted from the knowledge of the stress applied to a known type of packing. Second, packing materials each consolidate in a predictable manner under sustained load. Third, spring mechanisms consisting of Belleville washers can compensate for packing consolidation yet sustain sufficient load to control leakage. The spring mechanism is designed into the stuffing box to accommodate dimensional variation and maintain the packing gland pressure. Fourth, the applied packing load can be determined from the height of calibrated springs. (A spring-loaded system is designated "live-loaded packing.")

Live-loading of packing glands is used in Canada and France; their valves have been designed to optimize the use of live-loading. Canada has used live-loading with asbestos packing in CANDU reactors since 1976. The mean time between maintenance for their asbestos live-loaded packing for gate valves was 19 y $\left(M T B M=1.7 \times 10^{5} \mathrm{~h}\right)$. For live-loaded globe valves, the MTBF was $4.9 \times 10^{6} \mathrm{~h}$. France uses a combination of graplite stem packing and liveloading for packing glands in PWRs.

The first use of live-loaded valves in U.S. PWRs was sponsored by EPRI. ${ }^{94,98,100}$ Modified valves with wedge-shaped expanded graphite packing and live-loading were retrofitted into some of the Duke plants. ${ }^{100}$ Due to the limited nature of the study, these modified valves were not optimized designs, but they had a significantly reduced amount of leakage. The success of the retrofit program has prompted the suggestion that all valves be redesigned to incorporate this design to achieve valves with very low leak rates. However, live-loading is not in the design specifications of any U.S. power plant.

\subsubsection{Live-Loading}

Live-loading is the use of a stack of disc springs, placed under the gland nuts on either side of the valve stuffing box, to exert a constant and controlled force on thie valve 
packing such that the axial stress remains within narrowly defined minimum and maximum values as the packing consolidates. (The distribution of axial and radial forces within the stuffing box is shown in Fig. 15.) Doubt ${ }^{84}$ defined the minimum and maximum values through calculations in which packing material composition, valve rating, cycling frequency, and service conditions were considered. Once the disc springs are in place and the gland nuts are tightened to the calculated value, the result is a self-adjusting leak-tight seal. No further maintenance or periodic tightening of gland nuts is required.

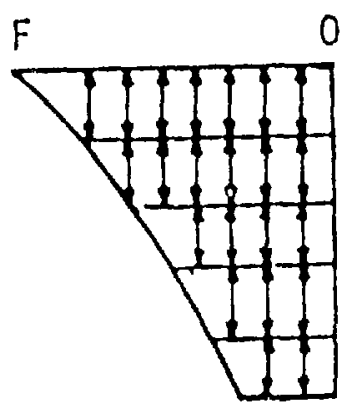

a) AXIAL STRESS
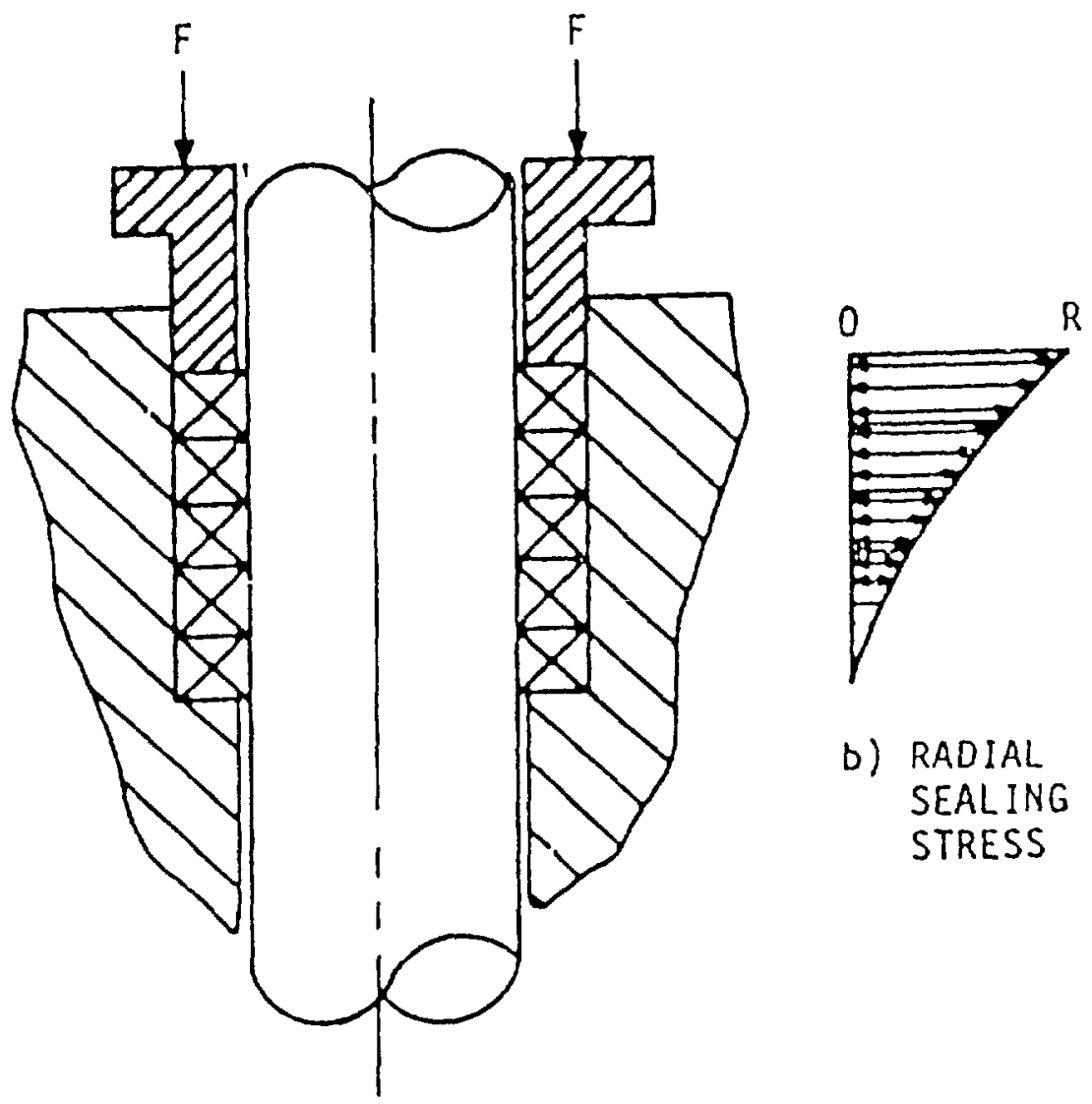

b) RADIAL SEALING STRESS

Fig. 15. Distribution of Axial and Radial Forces within a Valve Stuffing Bc.: 70

Copyright 1988. Electric Power Research Institute. EPRI NP-5697. "Valve Stem Packing Improvements." Reprinted with permission.

As shown in Fig. 16, live-loading reduces the slope of the force-displacement relationship for the gland loading system. Live-loading with disc or Belleville springs provides 20-25 times the energy storage capacity provided by stuffing box (elasticity) and gland follower studs alone. For a disc spring, the gland pressure is constant as the spring deflects. The advantages of springs for live-loading are that they have the capacity to absorb a large amount of energy at high loads and short working stroke, and can be easily stacked in parallel for different stack spring rates. Live-loading with disc or Belleville springs can accommodate thermal expansion, tapered stems, stem wobble, and stem-side loads. 


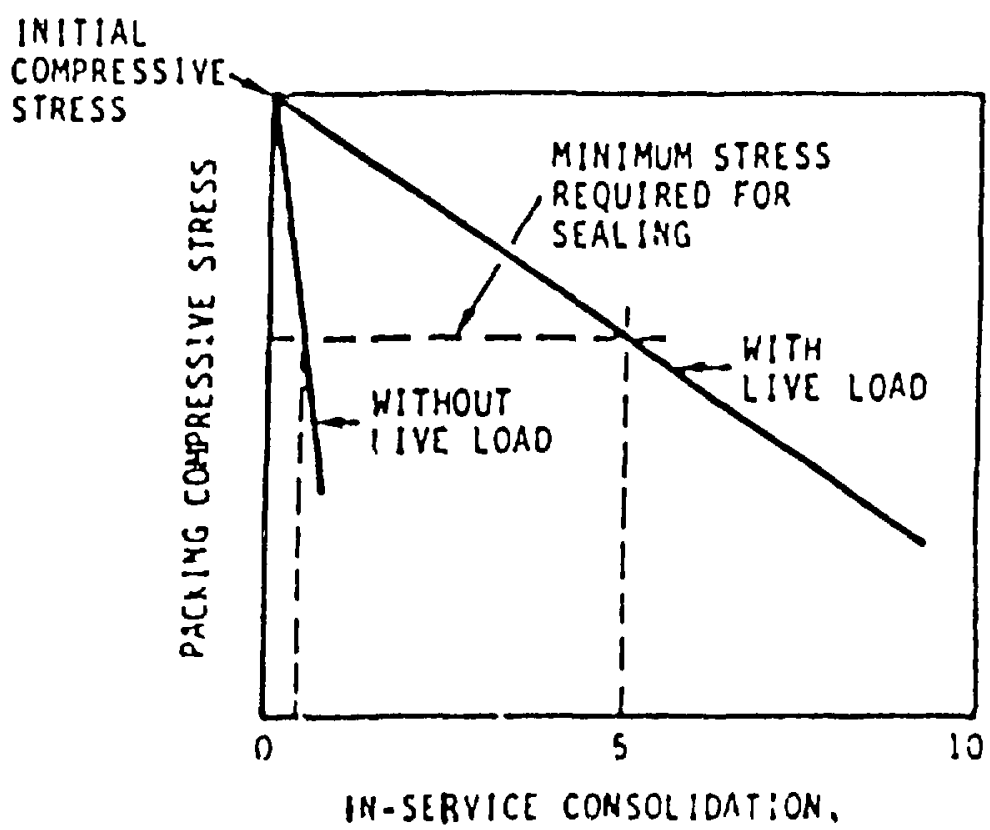

Fig. 16. Force-Displacement Relationship for the Gland Loading System ${ }^{94}$

Copyright 1988. Electric Power Research Institute. EPRI CS/NP-5878-SR. "EPRI Power Plant Valves Symposium." Reprinted with permission.

The theory of load-deflecting characteristics of Belleville springs was reviewed by AECL staff ${ }^{80-81}$ for data from the alloy steels AISI 6150 and AISI 1075, as well as the precipitation hardened stainless steel $17-7 \mathrm{PH}$ in the temperature range 26 to $288^{\circ} \mathrm{C}$. The theoretical load-deflection relationship for a single Belleville spring is:

$$
L=E d d\left[\left(h_{o}-d d\right)\left(h_{o}-d d / 2\right) t+t^{3}\right] /\left[\left(1-\mu^{2}\right) M\left(r_{o}\right)^{2}\right]
$$

where $L$ is the load, $E$ is Young's modulus, dd is the spring deflection, $h_{0}$ is the spring dish height (height of the base of the spring from the horizontal plane), $t$ is the spring thickness, $\mu$ is Poisson's ratio, $r_{0}$ is the spring outside radius, and $M$ is

$$
M=[6 /(\pi \ln (\mathrm{OD} / \mathrm{ID}))][((\mathrm{OD} / \mathrm{ID})-1) /(\mathrm{OD} / \mathrm{ID})]^{2}
$$

In Eq. 18, OD is the outside diameter and $\mathrm{ID}$ is the inside diameter. Based on Eq. 17, the response of a Belleville spring is dependent on the geometry of the spring. By varying the dish height-to-thickness $\left(h_{\delta} / t\right)$ ratio, different characteristic load-deflection curves are obtained, as shown in Fig. 17. The Canadians compared the observed load-deflection curves with the theoretical ones and found that close agreement between tests and theory only occurred if $h_{\mathrm{o}} / t>0.7$. For $h_{\mathrm{d}} / t \leq 0.5$, the stack spring height cannot be closely estimated by theory. For $\mathrm{h}_{\mathrm{o}} / \mathrm{t}>0.5$ and $<1.4$, one can obtain a constant load over a large range of spring deflection. The 


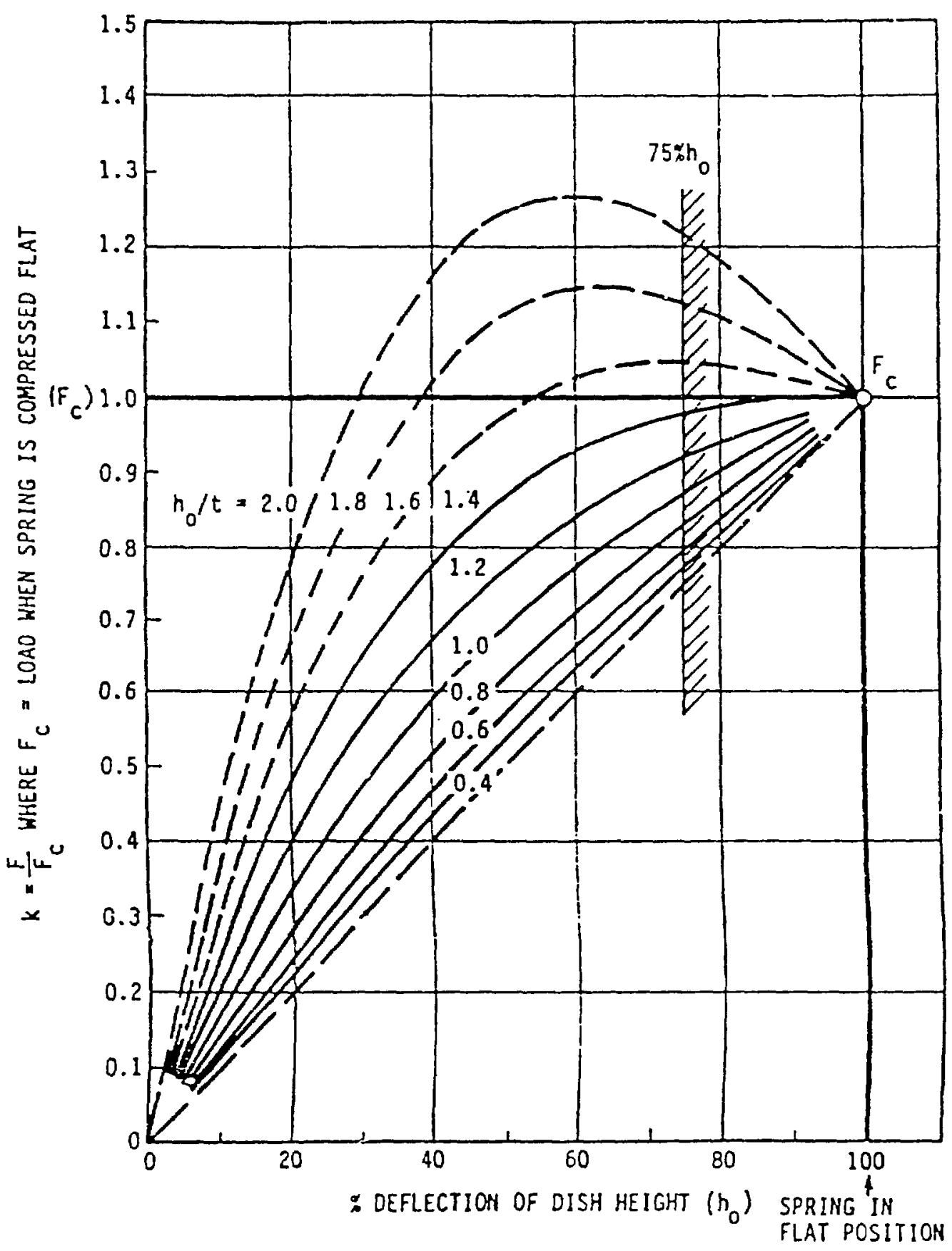

Force Deflection Characteristic for Disc Sirings of Varying $h_{0} / t$ Ratio

Fig. 17. Characteristic Load-Deflection Curves for Belleville Springs ${ }^{100}$

Copyright 1988. Electric Power Research Institute. EPRI NP-5697. "Valve Stem Packing Improvements." Reprinted with permission. 
vertical line in Fig. 17 shows where the spring deflection equals $75 \%$ of the unloaded dish height, $h_{\mathrm{o}}$. This deflection should not be exceeded for live-loading applications.

For the design of spring stacks with specific spring rates, the selection of the stack configuration should be based on observed load-deflection data for a particular spring. Spring deflection must accommodate in-service packing consolidation yet maintain the required force, once initial consolidation is achieved at installation. Two springs stacked in series equals twice the deflection of a single spring. One can stack a maximum of two identical springs in parallel, with the two being nested over each other. Each spring supplies $50 \%$ of the required sealing load. Four types of spring stacking arrangements are shown in Fig. 18. In addition, load relaxation of the springs, which is $<6 \%$ at room temperature but increases linearly with temperature, has to be included in spring design.

\subsubsection{Expanded Graphite Packing}

Most of the work done by the Canadians was done with asbestos packing or a combination of asbestos and graphite. Since expanded graphite has become the packing material of choice, obtaining data on the use of this material in packings is especially important for the HWR-NPR design.

In 1982, valve and valve-packing manufacturers, as well as nuclear plant valve users, recommended the use of graphite packing in valves. ${ }^{97}$ A survey of Licensee Event Reports (LERs) from 1972-1980 using statistical analysi: confirmed that the adoption of graphite packing significantly reduced valve stem leakage. Maintenance experience with expanded graphite as a packing material in reactor valves in Swedish and French plants has been excellent. There was no need for repacking between shut-down periods when the expanded graphite ${ }^{19}$ was correctly specified and installed. Recent development work sponsored by EPRI has been directed at determining if there is an optimum design for graphite packing.

Packing depends on axial compression, initially from a gland follower, then from the applied system pressure. This compression creates a radial loading that produces a seal between the valve shaft and the packing (Fig. 15). Packing rings that are die-formed from expanded graphite tape require $50 \%$ of the gland load of braided asbestos to seal. ${ }^{100}$ Expanded graphite relaxes slightly, 5-6\%, immediately after tightening, then relaxation ceases. ${ }^{89}$ Expanded graphite when formed into a ring of $\geq 80 \%$ theoretical density has very little relaxation, stability over a wide range of temperatures, good behavior in boric acid, and good behavior under irradiation. ${ }^{18}$ The graphite has to be of the highest purity to minimize corrosion, e.g., ash $<0.2 \%$, $\mathrm{Cl}<50 \mathrm{ppm}, \mathrm{S}<600 \mathrm{ppm}$.

In an EPRI study ${ }^{100}$ three expanded graphite ring shapes -- sootblower (a parallelogram), chevron, and wedge -- were compared with a square graphite ring shape to determine which required the lowest gland pressure to achieve a good seal. Sootblower packing was difficult to fabricate and to load because of its shape. Because chevron packing expanded as it was loaded, it too was difficult to load and its edges were prone to damage. Wedge packing had a truncated apex on the outer rings to allow motion between packing rings, making it easy to 
load. Early in the study, studies on sootblower and chevron packing were dropped due to the above problems.

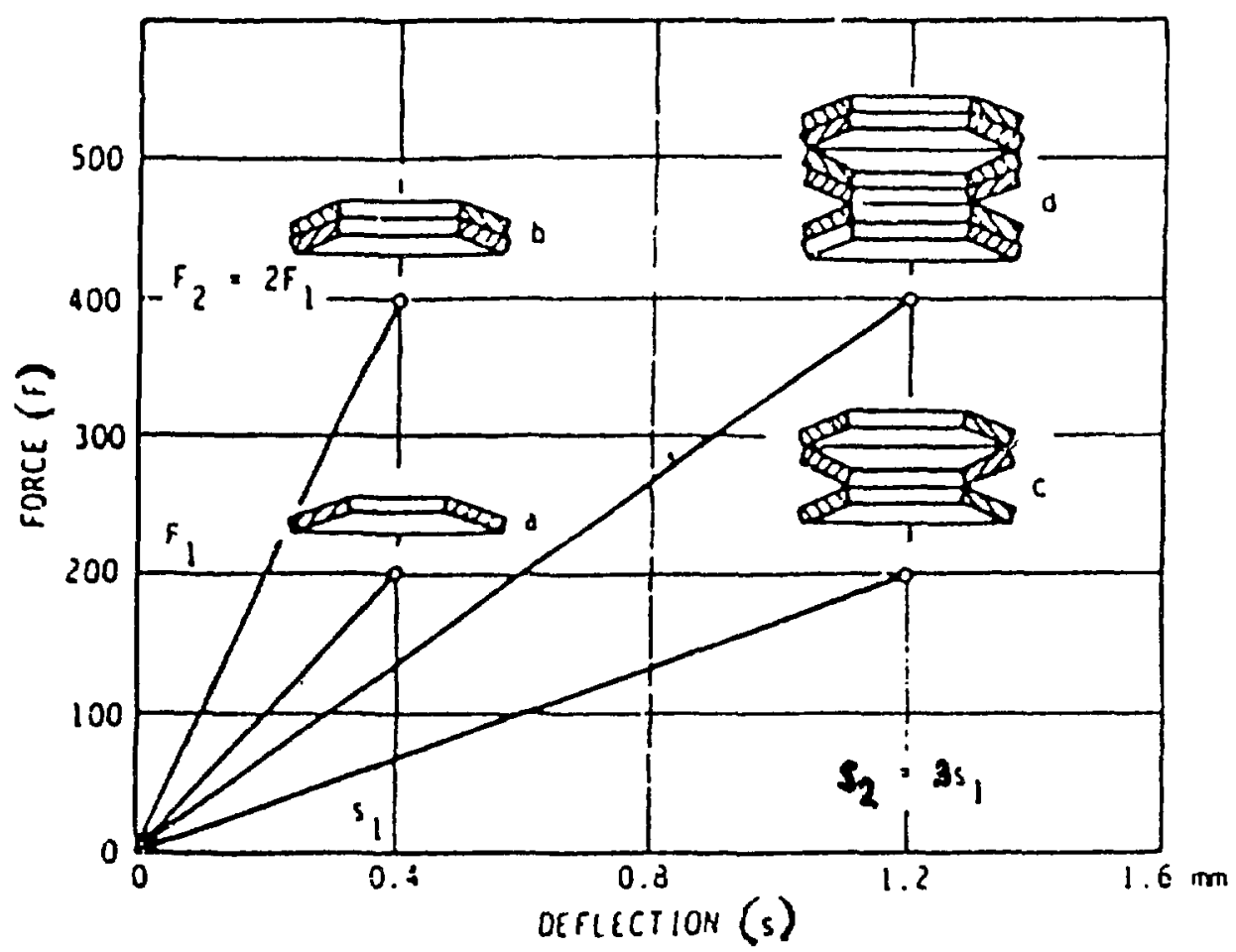

a) Single Spring

b) Two Springs in Parallel (Twice the Force of a Single Spring)

c) Three Springs in Series (Three Times the Deflection and the Same Force as a Single Spring)

d) Three Parallel Pairs (Twice the Force and Three Times the Deflection of a Single Spring)

Fig. 18. Belleville Spring Stacking Arrangements ${ }^{100}$

Copyright 1988. Electric Power Research Institute. EPRI NP-5697. "Valve Stem Packing Improvements." Reprinted with permission.

A full wedge packing set was seven wedge rings (four inner, three outer), and two braided end rings. This set is equivalent to 3.5 square die-formed rings. Braided end rings act as wipers and prevent graphite particle buildup. They have no sealing capability and experience 50\% initial consolidation. The four inner wedges have their bases on the stem while the three outer wedges have their bases on the stuffing box and truncated apex. This arrangement is shown in Fig. 19. 


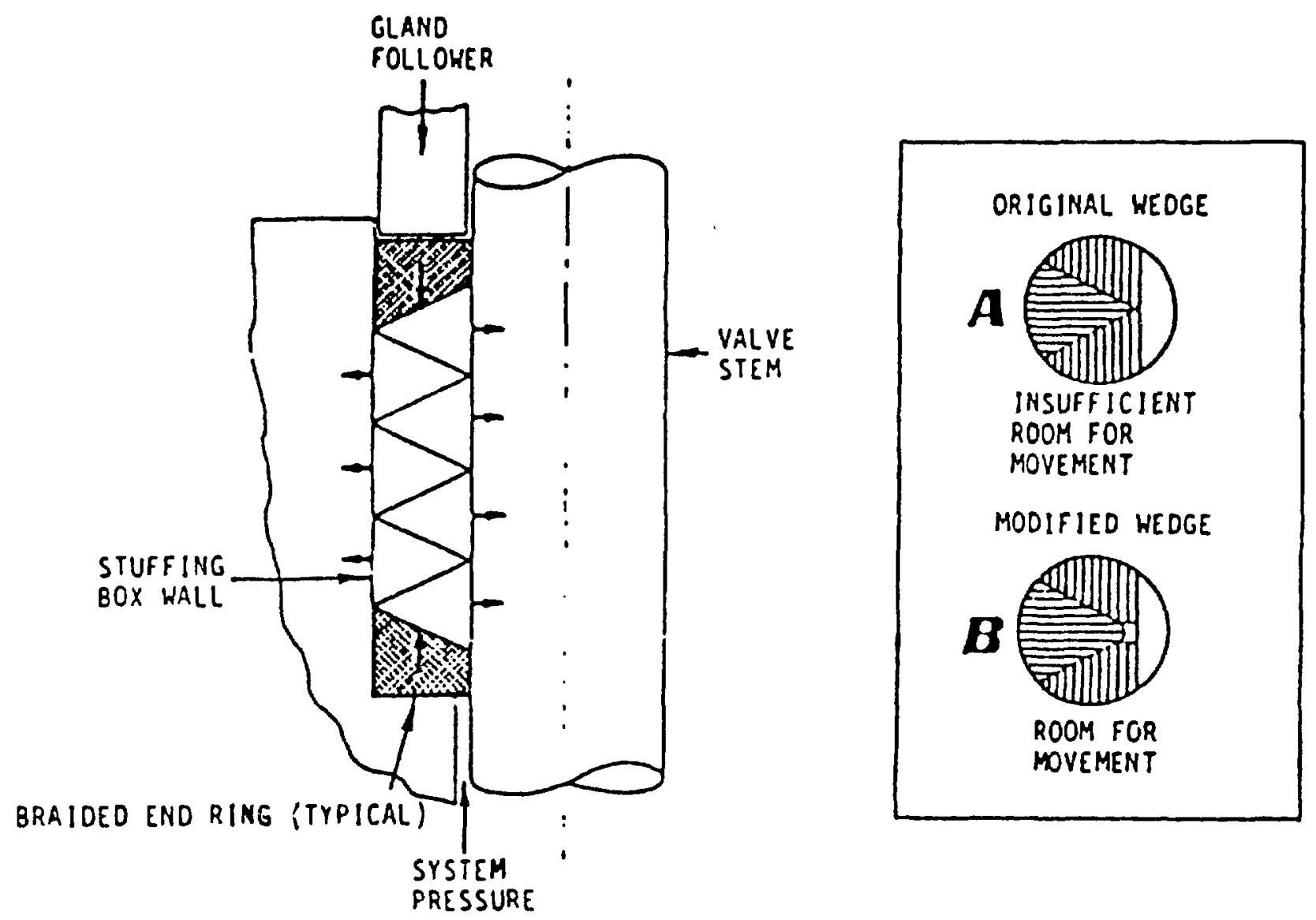

Fig. 19. Graphite Wedge Packing Arrangement in Valves ${ }^{94}$

Copyright 1988. Electric Power Research Institute. EPRI CS/NP-5878-SR. "EPRI Power Plant Valves Symposium." Reprinted with permission.

During initial installation, the valve must be cycled to allow the packing to consolidate, especially the braided graphite. One needs to stroke 10 times when the valve is first installed to account for $20 \%$ consolidation and then retorque the gland nuts before putting the packing into service. The minimum gland pressure is $13.8 \mathrm{MPa}$ (2000 psi) on the graphite rings. The effect on the gland load of the initial consolidation of the packing and later in-service consolidation is shown in Fig. 20 . In-service consolidation is $\leq 2 \%$ of the packing stack height.

For wedge packing the gland load was well below the system pressure to achieve a seal (Fig. 21). This finding implies that wedge packing uses system pressure to load packing and achieve sealing. The compliancy of wedge packing allows it to conform to thermally induced tapers in large-diameter valve stems. Table 12 gives test results in which leak rates for graphite wedge packing with and without live-loading are compared to those for graphite square packing. 


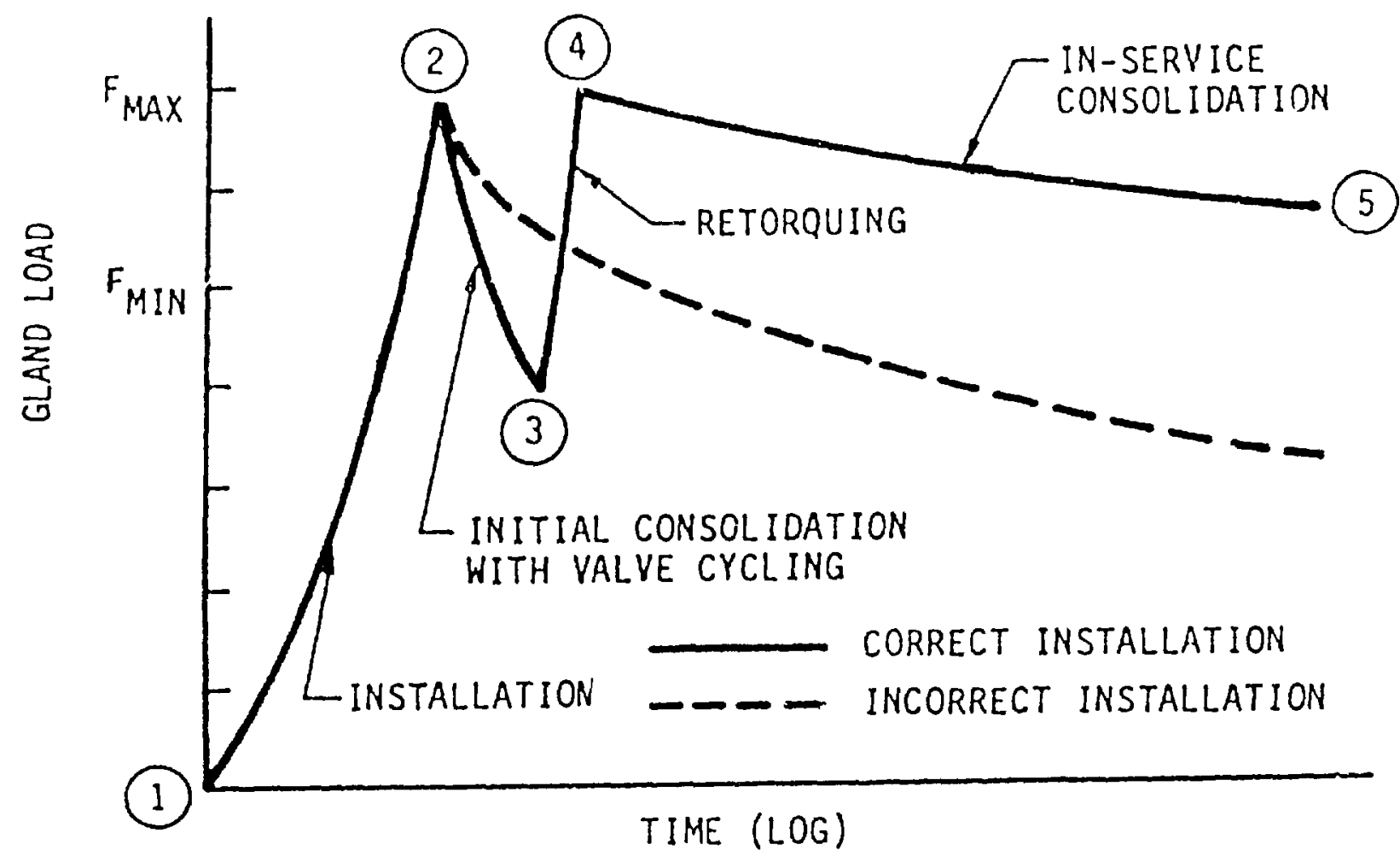

Fig. 20. Initial Consolidation and In-Service Consolidation of Graphite Wedge Packing ${ }^{100}$

Copyright 1988. Electric Power Research Institute. EPRI NP-5697. "Valve Stem Packing Improvements." Reprinted with permission.

1

The use of wedge packing in place of square packing has several advantages. It provides improved leakage control during valve stroking, adjusts to the stem taper to reduce leakage, maintains the radial sealing forces over an extended period, adapts readily to dimensional variation, and is easier to install.

Packing friction is an important consideration in the design and sizing of valve motor actuators. On average, live-loading produced $80 \%$ higher initial in-stroke friction, per unit of gland pressure, than conventional loading. ${ }^{100}$ The higher friction is due to the more uniform gland load that the springs apply to the packing relative to conventional gland loading.

A simple formula for initial friction, $F$, is

$$
F=\pi \mathrm{fdLY} \sigma_{\mathrm{g}}
$$


where $\mathrm{f}$ is the friction coefficient for in-stroke or out-stroke friction, $\mathrm{d}$ is the stem diameter, $\mathrm{L}$ is the packing length, $\mathrm{Y}$ is the ratio of radial to axial stress in the packing, and $\sigma_{\mathrm{g}}$ is the average contact stress between the packing and the gland follower. This formula does not account for the stress gradient in the stuffing box. Over the long term, in-stroke and out-stroke friction is affecled by temperature/diameter variations along the stem, material stress relaxation, and apparent changes in the elastic properties of the packing due to consolidation. These factors substantially reduce the long term friction compared to the initial friction force, with the result that the long-term friction for live-loading and conventional loading is comparable.

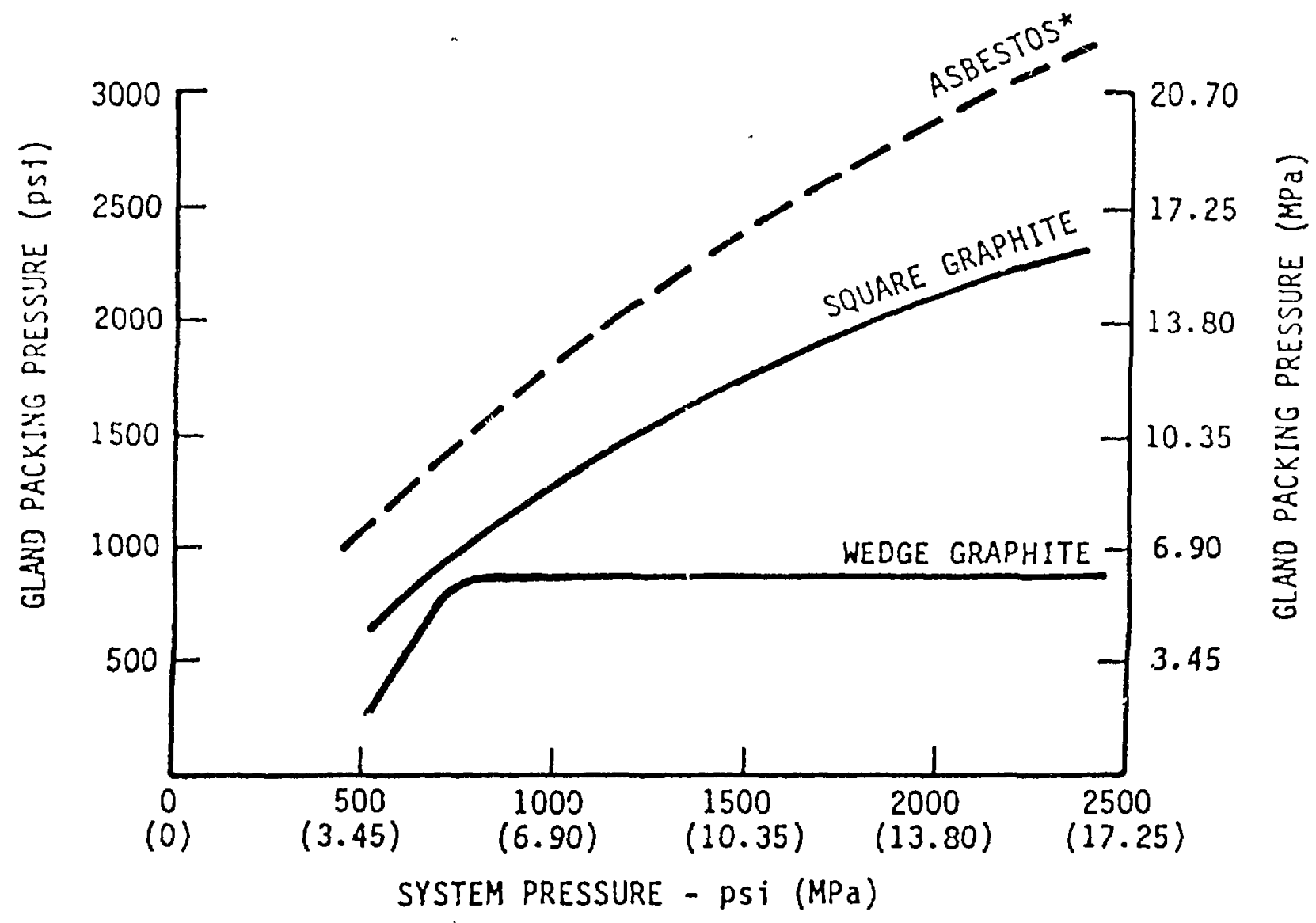

* The results obtained for the asbestos packing were with an acceptable leakage rate. The graphite packings exhibited no leakage during testing.

Fig. 21. Gland Pressure Versus System Pressure for Graphite Wedge Packing. ${ }^{96}$ (Also plotted are results from asbestos and square graphite packing.)

Copyright 1988. Electric Power Research Institute. EPRI NP-5697. "Valve Stem Packing Improvements." Reprinied with permission. 
Table 12. Dynamic Leakage for Graphite Packing in BWR and PWR Modified Valves After 1500 Stroke Cycles

\begin{tabular}{lllll}
\hline & \multicolumn{4}{c}{ Packing Type/Loading Type } \\
\cline { 2 - 6 } & SQ/CON & SQ/L-L & WG/CON & WG/L-L \\
\hline BWR & 155 & 4 & 11 & 3.2 \\
$\quad$ Leak Rate, L & 1.0 & 0.026 & 0.071 & 0.021 \\
$\quad$ Relative Rate $^{\mathrm{b}}$ & & & & \\
PWR & 117 & 25 & $11^{\mathrm{c}}$ & 4 \\
$\quad$ Leak Rate, L & 1.0 & 0.21 & 0.094 & 0.034 \\
$\quad$ Relative Rate $^{\mathrm{b}}$ & & & &
\end{tabular}

a $\mathrm{SQ}=$ graphite square packing, $\mathrm{CON}=$ conventional gland loadings,

$\mathrm{WG}=$ wedge packing, $\mathrm{L}-\mathrm{L}=$ live loading.

${ }^{b}$ Based on 1.0 for square packing with conventional gland loading.

'Initial gland pressure was $10.3 \mathrm{MPa}$ (1500 psi), unlike live-loaded wedge,

which was started at $19 \mathrm{MPa}$. Gland pressure was later increased to $19 \mathrm{MPa}$.

\subsubsection{Valve Redesign}

The design of the stuffing box for a valve has to be modified to incorporate live-loading. To retrofit valves, one has to first know the disc spring characteristics, determine if there is clearance for the spring stack, calculate the maximum and minimum sealing force required, and know the in-service consolidation expected for the packing. Once these factors are taken into consideration, one can modify the valve and add disc springs, disc spring guides, and elongated gland studs.

A correct fit is needed to prevent delamination of the graphite rings and to ensure that the gland load goes to ring deformation and not to radial sealing force. One needs ring tolerances within +0.013 to $-0.000 \mathrm{~cm}$ for the ring $\mathrm{ID},+0.000$ to $-0.025 \mathrm{~cm}$ for the ring $\mathrm{OD}$, and $\pm 0.038 \mathrm{~cm}$ for the ring thickness. For the valve, the stem diameter in three locations is needed to $\pm 0.0025 \mathrm{~cm}$, as is the stuffing box diameter and the stuffing box depth.

Rockwell ${ }^{99}$ attempted to retrofit some of their valves with asbestos packing to valves with graphite packing and live-loading. Their valve stem diameters were $2.5-10 \mathrm{~cm}$, and the stem strokes were $4.27-51 \mathrm{~cm}$. Over 100 packing tests were cycle-tested over 12 months for several types of graphite. The best results were achieved with the Union Carbide form of expanded graphite. A comparison can be made between the dimensions for a valve which uses asbestos packing and one which uses expanded graphite packing. The packing volume is reduced over a factor of two and the packing width a factor of 1.3. In Table 13, the packing cross section is given for valves with $25.4-, 60.3-$, and $101.6-\mathrm{mm}$ stem diameters.

\subsection{Other Valve Developments}

Two types of valves have been developed under EPRI's auspices ${ }^{102}$ as replacements for high-maintenance ( $2.5-\mathrm{cm}$ dia) valves: a rotating-stem, dual-plug valve and a hermetically sealed, actuated, dual-plug valve. The first valve operated well, but the second failed due to 
Table 13. Cross Sections for Graphite Packings Tested by Rockwell

\begin{tabular}{ccc}
\hline $\begin{array}{c}\text { Stem Diam., } \\
\mathrm{mm}\end{array}$ & $\begin{array}{c}\text { Packing Cross Section, } \\
\mathrm{mm}\end{array}$ & $\begin{array}{c}\text { Packing Rings, } \\
\text { No. }\end{array}$ \\
\hline 25.4 & 6.4 & 4 \\
60.3 & 9.5 & 4,5 \\
101.6 & 12.7 & 5 \\
\hline
\end{tabular}

galling of internal parts and/or stem seizure due to a galled bushing. The latter valve was redesigned to eliminate the bushing by replacing it with a ceramic bearing.

Since movement of a valve stem could produce leaks, a microprocessor ${ }^{103}$ can be retrofit on valves to control the movement of the valve stem and the consolidation of the packing. Also, for maintenance convenience, indicators can be designed into valves to detect maximum compression of the packing.

For check valves, which have internal leakage due to wear, several groups have examined their maintenance. ${ }^{104-106}$ The check valve failure rate is $1-2 \%$ and is caused by poor maintenance and inadequate preventive maintenance. To improve this record, the MDVATS ultrasonic diagnostic system ${ }^{105-106}$ has become an integral part of the maintenance program for these motor-operated valves. Dynamic signatures (ultrasonic trace of a valve's response) of critical actuator parameters are obtained and analyzed to identify degradations in check valve performance.

\section{SEALS IN PUMPS}

Two types of pumps are considered in this review, centrifugal pumps ${ }^{107-127}$ and canned motor pumps. ${ }^{128-139}$ Problems with seals, external or internal in these pumps, are reviewed.

\subsection{Centrifugal Pumps}

Frequent seal failures in centrifugal pumps used at CANDU reactors in the 1960 s led the AECL to use custom-designed axial and elliptical seals and improved bearings. This resulted in pumps with seal lives in the Pickering plants of $>2.85 \mathrm{y}$ in 1975 . For later plants, pump testing was used to verify quality control of the seals. ${ }^{108,113}$ At the Bruce power station, 16 primary pump sets were fully loop tested for at least $100 \mathrm{~h}$, while four were proof tested for 1000 $\mathrm{h}$. In addition, seal cartridges accumulated several thousand additional testing hours in test rigs. At the CANDU plants, early seal failure in the pumps was usually due to dirt and improper assembly.

Most reactor coolant pump failures ${ }^{122}$ in the U.S. are attributed to pump seals, followed by pump motors and mechanical components like bearings and flanges. Maintenance and operating data indicate that most seal failures are attributed to improper seal injection; crud in the system, which could be due to seal decomposition or wear; and the fretting of rubber faces in inserts and in the seal housing. 
The shaft seal assembly of reactor coolant pumps in U.S. PWRs and BWRs consists of 3-4 stages of rotating face seals. Each stage includes elastomer O-rings to seal static gaps, an elastomer secondary seal to accommodate small motions between parts, and a small-gap hydraulic primary seal. Each stage operates by maintaining a very small leakage pathway between two seal rings which form the primary seal. The gap is maintained by a balance of forces (hydraulic, spring, and friction), which can be influenced by the fluid conditions in the seal cavity.

Large-diameter, high-pressure elastomer seals, which are used as secondary seals in rotary end-face seal assemblies of the main coolant pumps of PWRs and PHWRs, are susceptible to rapid damage because such seals must accommodate slight cyclic movements caused by misalignments between the inflexibly mounted end-face seals and the rotational axis of the pump shaft. The damage is characterized by a circumferential wear groove in the elastomer seal and later by wear of all areas of the seal in contact with the pump shaft. In plants not plagued with frequent seal replacement from other causes, elastomer damage is a major factor limiting the service life of coolant pump seals.

Wensel ${ }^{112}$ tested three seal forms (curved-back U-cups, flat-back U-cups, and Orings) for thre : elastomer materials (ethylene propylene, neoprene, and nitrile rubber) to determine their behavior during conditions of a power blackout. The damage mechanism was localized fatigue and thermal deterioration of the elastomer material in the area of the seal subjected to greatest flexure from cyclic motion. Abrasion of the seal against the pump shaft sleeve may also have been a factor. Flat-bock U-cups were rapidly damaged, resulting in leakage of $20 \mathrm{~mL} / \mathrm{h}$ in $48 \mathrm{~h}$. The O-rings were damaged and leaked at a rate much lower than the flatback U-cups. The curved-back U-cups, although damaged, did not leak after more than $1000 \mathrm{~h}$ of testing.

In later stages of the tests, ethylene propylene, neoprene, and nitrile rubber were all damaged with equal rapidity when grazed by a water jet, although the damage rate was slightly less for the ethylene propylene curved U-cup. Wensel recommended that the angular misalignment be minimized between the rotational axis of the pump shaft and the face of the inflexibly mounted seal, elastomer seals with the most susceptible shapes (flat-back U-cups and square section rings) be avoided, pump shaft sleeve and seal lip be prelubricated, the shaft be polished to lower its friction, and the sharp edges of the seal gland be polished to a $0.25 \mathrm{~mm}$ radius.

Temperatures of $260^{\circ} \mathrm{C}$ will cause degradation of elastomer seals and will affect the pressure distribution of the flow through the gap between the seal rings. Subudhi et al. ${ }^{122}$ recommended the use of ethylene propylene (E740-75) rather than conventional E515-80, since the former has a better resistance to high temperature. (The E740-75 also has a lower compression set in the presence of tritium.) Increased pressure could cause the hydraulic seal to open to a larger gap (bi-stable seal) or to pop completely open (unstable seal) and allow leakage.

The parameters which had the most influence on seal stability ${ }^{121}$ were inlet fluid conditions, back pressure on the discharge side (inside diameter of the seal rings), and the radial taper in the gap between the seal rings. Analysis showed that stability, although a necessary 
condition for limiting flow through the primary hydraulic seal, is not sufficient to assure acceptable leak rates. ${ }^{121}$ For example, a seal with a gap convergence of $762 \mu \mathrm{m}$ was calculated to leak in excess of $13 \mathrm{~L} / \mathrm{s}$ at $15.3 \mathrm{MPa}$, even though it was operating in a stable manner. The leak rate is highly dependent on the combination of inlet fluid conditions, back pressure, convergence, and closing balance ratio ${ }^{*}$ but is not readily characterized as a function of those parameters.

Other changes recommended in reactor coolant pumps ${ }^{122}$ were to change seal faceplate materials to silicon nitride, to provide chromium carbide clad on stainless steel for all seal rubbing surfaces, and to change from graphite-impregnated Teflon to Tetralon 720 (the former being adversely affected by low levels of radiation $\leq 10^{5} \mathrm{rad}$ ) for double delta (or channel) seals.

\subsection{Canned Pumps}

A canned motor pump $p^{128-134}$ is driven by a magnetic coupling between the pump and an external rotating motor. Electromagnets in the external motor drive the internal rotor, which is sheathed in a metal "can." The pumped fluid lubricates the pump's rotor cavity and the bearings within it. A major problem for a canned motor pump is the buildup of corrosion products arising from iron in the rotor. Corrosion is accelerated in an acid environment, which will be present in the NPR-HWR. The use of stainless steel rotors will lower the corrosion rate but not eliminate the corrosion process.

For a canned motor pump, leakage to the external environment is minimized since seals, which account for the majority of a centrifugal pump's leakage, are eliminated in the pump internals. (There is a gasket seal for the pump housing which can be welded closed or replaced with a spiral wound expanded graphite gasket.) However, internal leakage can occur as a minor breach of the internal "can" or as catastrophic failure. The cause of these "can" failures is the buildup of corrosion particles in the internal lubrication system of the pump or the failure of the bearings and/or the rotor due to wear. Damage to the bearings can result in rubbing of the rotor against the "can," causing failure. Since the external housing of the canned pump can be a high pressure boundary, failure of the "can" can be contained within the housing.

Compared with centrifugal pumps, canned pumps have fewer leaks, need less maintenance and repair ( $80 \%$ of conventional pumps' problems are seal problems), take up less space for a given size, and run quieter. However, canned pumps cost more; their efficiency is lower due to parasitic power losses (20-30\%), which depend on the pump design, its size, and the application; and they can be more easily damaged than seal pumps. The power losses are 5-10\% due to eddy currents in the shell and 15-30\% due to the mechanical gap between the stator and rotor. The canned pumps are more easily damaged for two reasons: pipe scale or bearing wear can block small passages in the internal lubrication system, resulting in major mishap; and

\footnotetext{
"Closing balance ratio is the ratio between the closing load due to the pressure on the back side of the seal rings balanced by the hydraulic opening load due to the pressure between the seal faces. Seals with a low closing balance ratio are most likely to pop open.
} 
running the pumps when they are dry results in worn bearings, internal rotor galling, and rupture of the can.

If canned pumps are used, one needs filters to remove particulates; a detector to signal a dry pump; a thicker can; an outer shell for secondary containment if the can ruptures; a moisture-sensing probe interlocked to an alarm and pump motor; better bearings, preferably expanded graphite bearings rather than the current graphitar bearings in Westinghouse pumps ${ }^{135}$; and a separate clean fluid for the bearings maintained under pressure by a bellows seal.

Canned motor pumps with $3 \mathrm{~L} / \mathrm{s}$ throughput are in use at the Savannah River Site (W-SRS) in the water purification area. These units are discarded if a failure occurs. This practice is not a large expense for pumps of this size ${ }^{139}$ but would not be attractiva for reactor coolant pumps. At W-SRS, the current reactor coolant pumps are large centrifugal Bingham pumps, $1575 \mathrm{~L} / \mathrm{s}$.

\section{DESIGN GUIDELINES}

The need to reassess common practices for the design of bolted flanges, elastomer seals, valves, and pumps has been mentioned. This section highlights some design guidelines which, if used, will result in components for the HWR-NPR coolant system with acceptable leak rates.

\section{$9.1 \quad$ Flange Seals}

For large diameter seals in critical locations, a finite element analysis is required to determine the rotation in the joint, which is a function of the internal pressure and the structural stiffness of the flange. The seal should be modeled full size, since deformation characteristics and contact stress are influenced by a seal's cross section and scaling from data at $0.1 \mathrm{MPa}$ differential pressure could be misleading.

The ASME formulas used to compute the sealing load for a flange are not justified in view of existing data. An alternative system (BHRA development) should be used to specify compression loads for flange seals that contain a spiral wound gasket with an expanded graphite filler.

\section{$9.2 \quad$ Valve Seals}

The valve designer has several choices for the HWR-NPR plant. First, the number of valves can be minimized within the constraints of system maintenance. Second, bellows valves or welds can be used if fatigue is not a problem or if loss of access is allowed. Third, valves using die-formed expanded graphite packing with live-loading can be incorporated. For the latter, packing and spring combinations have to be tested so that spring stacks can be designed to assure a sustained, high gland load on the packing. This option probably will require the design of new valves. The general actions that the designer must take to design packed valves with low leak rates are summarized in Table 14. 
Table 14. Designer Actions to Achieve Valves with Low Leak Rates

Fact

1. Packing materials change properties with time at operating conditions.

2. Packing materials consolidate under sustained load in predictable manner.

3. Leakage must be controlled.

4. Valve industry has no strict standard for stem seal design.
Action

1. Choose material which remains stable a long time.

2. Provide spring-loaded device for packing which is capable of maintaining load at an acceptable level.

3. Control applied packing stress.

4. Issue detailed stuffing box specification.

Four more guidelines arise from Ruggieri and Kelly. ${ }^{96}$ First, since a maximum spring OD gives the greatest load capability over the largest amount of deflection, fewer springs are required to accommodate in-service consolidation. The radial clearance of the valve studs governs the maximum OD. Second, the minimum sealing force for graphite packing is 1.0 to 1.25 times the system pressure times the packing area. Third, elongated gland studs are needed to provide axial clearance for the stacked springs. Fourth, the use of disc spring guides prevents hang-up on the stud threads. The preferred location of these guides is internal to the stack and installed over the gland stud. The advantages of the internal location are larger OD for the springs, thus minimizing the required height of the spring stack.

Designers can incorporate into the design of large valves or high maintenance valves a means for hydraulic packing removal to simplify maintenance. This would be most appropriate for control valves, which experience the most severe sealing service since their stems are continuously modulating and have a short seal and/or stem life.

\subsection{Pump Seals}

The shaft seal of centrifugal pumps should be designed with curved back U-cup ethylene propylene elastomers, since these seals have minimal leakage during off-normal events.

Canned motor pumps may have one external seal, which would be a flange seal for the pump housing. This seal, if present, should incorporate the guidelines given under flange seals. The greatest danger for a canned pump is catastrophic failure. To prevent this, the corrosion behavior of the bearings in large pumps should be examined under conditions representative of the chemistry of the heavy water environment.

\subsection{Manufacturing Requirements}

Two factors are important in manufacturing, the consistent availability of a qualified component and the consistent production of that component to specification. The unavailability of specified formulations of elastomers has been discussed. For valves, there is little 
documentation on their manufacture within many companies, i.e., the tolerances needed for a given leak rate or the loading stress required as a function of the packing material properties. The Canadians found that they required much tighter manufacturing tolerances than most companies could supply.

Our manufacturing guidelines are the following. First, certificates of conformance or compliance would be advisable to ensure that the required material is supplied. These certificates would include the manufacturing history, especially important for bolts, and would document the exclusion of deleterious materials (chloride or sulfur containing). Second, the effects of post-machining stress relaxation or the influence of other structural components need to be considered in a flange design to achieve a seal with a low leak rate. Surface waviness and changes in tolerances increase with physical size, and distortions can occur due to the weightcarrying capacity of a component like a flange.

\subsection{Assembly Requirements}

Special tools may be required for assembly or disassembly of flanges, valves, and/or pumps. These tools need to be specified and designed if so required. For example, an ultrasonic extensometer should be specified for the assembly of bolted flanges.

\subsection{Maintenance Requirements}

Achieving seals that are reliable and maintainable requires considerable effort, including the collection of failure rate data for each component and the determination of failure modes, corrective maintenance times, and preventive maintenance times. ${ }^{140}$ Design decisions based on analysis of failure modes can improve reliability and maintainability. Physical changes in equipment, systems, or procedures can improve reliability, as can clearly stated specifications for the equipment and factual evidence that the specifications are met.

The failure rate for seals depends on the seal's environment and human action. Failures due to human action can result from improper procedures during field construction. For example, during assembly, flange gaskets which are not properly restrained in grooves can be pinched, thus leaving gaps in the seal. Thus, contract specifications for components should contain clauses on assembly procedures, repair times, and repair procedures. Repair times can be substantially reduced by designers if they provide easy access to components, specify correct maintenance procedures, and specify special assembly/disassembly tools.

Maintenance should include the compilation of maintenance records on each component throughout its lifetime. For example, plant data sheets should be maintained for valves. This data sheet would include the number and type of packing rings; the size of the packing rings; the length of a stuffing box spacer, if needed; the number, size, and stacking arrangement of the disc springs; the maximum and minimum sealing loads; the amount of inservice consolidation accommodated; and the uncompressed spring stack height. 


\section{RECOMMENDED RESEARCH AND DEVELOPMENT}

\subsection{Material Tests}

A rigorous characterization of the properties of spiral wound graphite filled gaskets, elastomers, expanded-graphite packing materials, bolts, and springs is needed since these properties serve as a basis for designer's calculations.

For spiral-wound gaskets, the leak behavior has to be measured using the technique developed under the sponsorship of BHRA. The properties of the elastomer, EPDM, have to be well characterized if it is chosen as the material of choice to achieve flexible, dynamic seals for safety and control rods. The response to load of graphite packing and Belleville springs, as a function of time, needs to be determined so that the lifetime of these components can be estimated.

\subsection{Quality Control Tests}

A quality control program is needed for the design, manufacture, installation, and assembly of all coolant component seals and/or joints. ${ }^{141}$ First, the needed components must be defined. Then, specifications must be set for the components to ensure that they achieve the minimal leak rate. Last, the components have to be qualified in defined tests to ensure acceptable long-term leakage performance. In addition, procedures for the installation and assembly of these components within containment have to be documented.

Four types of tests may be necessary for quality control: qualification tests, validation tests, compliance tests, and development tests. Qualification tests would be done on a prototype component and on a series of identical components under the maximum allowable conditions, regardless of actual service conditions. Validation tests would be done on components that would be subjected to special service conditions. Compliance tests on seriesproduced components would be carried out under the maximum service conditions observed by all identical components in the plant. These tests would answer two questions: Is the performance in conformity with that of the initially qualified component? Is this component identical to the qualified component as to geometry and its capability to perform the specified functions? Development tests would be done in collaboration with a manufacturer.

Detailed safety analyses may require the demonstration of both operability and leaktightness under various load conditions that occur in accidents, earthquakes, or high-energy pipe breaks. The condition of equipment in the post-accident environment would be important for future operability of the reactor. 


\section{ACKNOWLEDGMENTS}

This work was supported by the Office of the New Production Reactor, U.S. Department of Energy. The author also wishes to acknowledge the assistance given by the Technical Information Services at Argonne National Laboratory, especially Sharon Clark in collecting the available information, and by Janet Stratton, who helped organize the references and typed the report. 


\section{REFERENCES}

1. S. J. Server et al., Analysis of Refueling Outages in PWRs of Westinghouse Design, Electric Power Research Institute Report EPRI NP-3942 (1985).

2. H. A. Baker and C. W. Carr, Procedures and Equipment for Shortening Refueling Outages in Babcock and Wilcox PWRs, Electric Power Research Institute Report EPRI NP-3947 (1985).

3. I. Bernstein and D. D. Miller, Equipment for Removing Seized Closure Studs from Reactor Pressure Vessels, Electric Power Research Institute Report EPRI NP-3950 (1985).

4. N. C. Howard et al., Improvements to Critical Path Time for BWR Refueling Outages, Electric Power Research Institute Report EPRI NP-4010 (1985).

5. T. C. Chivers and $:$ P. Hunt, "The Achievement of Minimum Leakage from Elastomer Seals," Proc. of 8th Int. Conf. on Fluid Sealing, September 11-13, 1978, Univ. of Durham, England, pp. F3:31-40 (1979).

6. T. C. Chivers, A. F. George, and R. P. Hunt, "High Integrity Static Elastomer 'O' Ring Seals and Their Performance through Thermal Transients," Proc. of 9th Int. Conf. on Fluid Sealing, April 1-3, 1981, Noordwijkerhout, Netherlands, pp. 37-54 (1981).

7. P. E. Cassidy, T. M. Aminabhavi and C. M. Thompson, "Water Permeation Through Elastomers and Plastics," Rubber Chem. Tech. 56, 594-618 (1983).

8. R. G. Carbonell and G. C. Sarti, "Coupled Deformation and Mass-Transport Processes in Solid Polymers," Ind. Eng. Chem. Res. 29, 1194-1204 (1990).

9. J. Amesz, Conversion of Leak Flow-Rates for Various Fluids and Different Pressure Conditions, Euratom Report EUR 2982.e (1966).

10. L. Kohler, Measurements of the Penetrations of Water through Small Leaks, Bundesministerium fur Forschung und Technologie Report BMFT-FB K 77-16 (1978).

11. T. C. Chivers, R. P. Hunt, W. J. Rogers, and M. E. Williams, "On the Relationships between Gas Properties, Surface Roughness, and Leakage Flow Regimes," Proc. of 7th Int. Conf. on Fluid Sealing, September 24-26, 1975, Univ. of Nottingham, England, pp. D3:13-24 (1976).

12. T. C. Chivers, W. J. Rogers, and M. E. Williams, "On Load Measurement of Gas Leakage from Static Seals," Proc. of 7th Int. Conf. on Fluid Sealing, September 24-26, 1975, Univ. of Nottingham, England, pp. D2:5-12 (1976). 
13. T. C. Chivers and R. P. Hunt, "Scaling of Gas Leakage from Static Seals," Proc. of 8th Int. Conf. on Fluid Sealing, September 11-13, 1978, Univ. of Durham, England, pp. G3:33-46 (1979).

14. A. F. George and D. Williams, "An Investigation of Leakage Past Static Elastomer Seals," Proc. of 10th Int. Conf. on Fluid Sealing, April 3-5, 1983, Innsbruck, Austria, pp. 43-53 (1984).

15. P. T. Spaminato et al., INTOR Critical Issue D: Maintainability, Tritium Containment and Personnel Access, Oak Ridge National Laboratory Report ETR/INTOR/CDF/6 (1984).

16. B. M. Meale, D. G. Satterwhite, and P. E. McDonald, "Results of an Aging-Related Failure Survey of Light-Water Safety Systems and Components," Nucl. Safety $\underline{30}$, 543-553 (1989).

17. E. Staaf, "A Review of the Properties of Expanded Graphite and Selected Forms of PTFE as Alternatives to Asbestos in a Sealing Role," Proc. of 8th Int. Conf. on Fluid Sealing, September 11-13, 1978, Univ. of Durham, England, pp. D1:1-20 (1979).

18. R. A. Howard, Graphoil Engineering Design Manual, Vol. 1, Union Carbide Corp., Cleveland, Ohio (1987).

19. J. M. Lancaster, "Graphite Seals: An Expanding Technology," in 11th International Conference on Fluid Sealing. B. S. Nau, Ed., Elsevier Applied Science Publishers, New York, pp. 631-641 (1987).

20. Gerry Lastovica, Flexitallic, Inc., Deer Park, TX, personal communication (June 26, 1990).

21. John Easterbrook, Sealing Devices, Inc., Buffalo, NY, personal communication (June 27, 1990).

22. T. Oku, M. Eto, and S. Ishiyama, "Irradiation Creep Properties and Strength of Fine Grained Isotropic Graphite," J. Nucl. Mat. 172, 77-84 (1990).

23. J. Neumann, "Spiral-Wound Gasket with Specific Sealing Zone," Proc. of 7th Int. Conf. on Fluid Sealing, September 24-26, 1975, Univ. of Nottingham, England, pp. D1:1-4 (1976).

24. C. X. Latty, "The Sealing of High Performance Flanges," Proc. of 12th Int. Conf. on Fivid Sealing, May 10-12, 1989, Brighton, England, pp. 231-242 (1989).

25. J. C. Vignaud, H. Nowak and P. Digat, "Sealing Test of Gaskets with Expanded Graphite for French Nuclear Power Plants," Proc. of 12th Int. Conf. on Fluid Sealing, May 10-12, 1989, Brighton, England, pp. 243-256 (1989).

26. "Avoiding Leaks in High Performance Bolted Joints," Nucl. Eng. Int. 35 (426), 46 (1990). 
27. J. Morrison, Westinghouse Savannah River Site, personal communication (June 8, 1990).

28. Static Seals and Their Application in Water-Cooled Nuclear Reactor Systems, Oak Ridge National Laboratory Report ORNL-TM-3308 (1971).

29. H. T. Lin, Simulation of the Welding of Irradiated Materials, Ph.D Thesis, Auburn University (1989).

30. J. J. Whalen, "How to Select the Right Gasket Material," Pressure Vessels and Piping, Vol. 4, Design and Analysis, H. H. Waite, Ed., Am. Soc. Mech. Eng., New York, pp. 166-171 (1976).

31. R. T. Brown, "Static Seals for Pressure-Vessel and Piping Systems," Pressure Vessels and Piping, Vol. 4, Design and Analysis, H. H. Waite, Ed., Am. Soc. Mech. Eng., New York, pp. 159-165 (1976).

32. R. E. Latham and R. T. Brown, "Evaluation of Metal Seal Criteria for Spent Fuel Cask Closure," Pressure Vessels and Piping, Vol. 4, Design and Analysis, H. H. Waite, Ed., Am. Soc. Mech. Eng., New York, pp. 203-210 (1976).

33. B. Nau, "Research Aims to Improve Performance of Gasketed Joints," Nucl. Fng. Int. $\underline{33}$ (412), 40-42 (1988).

34. A. Bazergui, G. F. Leon, and J. R. Payne, "Observations and Status of PVRC Gasket Test Program," Proc. of 9th Int. Conf. on Fluid Sealing, April 1-3, 1981, Noordwijkerhout, Netherlands, pp. B2:1-35 (1981).

35. A. Bazergui and L. Marchand, PVRC Milestone Gasket Tests - First Results, Welding Research Council Bulletin No. 292 (1984).

36. A. Bazergui and J. R. Payne, "Progress in Gasket Testing - Milestone Results," J. Press. Ves. Tech. 106, 93-103 (1984).

37. A. Bazergui, L. Marchand, and J. R. Payne, "Effect of Fluid on Sealing Behavior of Gaskets," Proc. of 10th Int. Conf. on Fluid Sealing, April 3-5, 1983, Innsbruck, Austria, pp. 365-385 (1984).

38. J. R. Payne, A. Bazergui, and G. F. Leon, "A New Look at Gasket Factors," Proc. of 10th Int. Conf. on Fluid Sealing, April 3-5, 1983, Innsbruck, Austria, pp. 345-364 (1984).

39. A. Bazergui and G. Louis, "Tests with Various Gases in Gasketed Joints," Exp. Tech., Special Supplement on Gaskets and Bolted Joints, 12 (11), 17s-21s (1988).

40. J. R. Payne, A. Bazergui, and G. F. Leon, "Getting New Gasket Design Constants from Gasket Tightness Data," Exp. Tech., Special Supplement on Gaskets and Bolted Joints, 12 (11), 22s-27s (1988). 
41. B. S. Nau, "On the Design of Bolteri Gasket Joints," Proc. of 12th Int. Conf. on Fluid Sealing, May 10-12, 1989, Brighton, England, pp. 199-215 (1989).

42. J. E. Kalasky, "Characteristics of Metal O-Rings and Relationship to Sealing Capabilities," Pressure Vessels and Piping, Vol. 4, Design and Analysis, H. H. Waite, Ed., Am. Soc. Mech. Eng., New York, pp. $211-214$ (1976).

43. T. C. Baumgartner, "Fastener Performance at Elevated Temperatures," Pressure Vessels and Piping, Vol. 4, Design and Analysis, H. H. Waite, Ed., Am. Soc. Mech. Eng., New York, pp. 225-234 (1976).

44. "ASME Announces Fastener Accreditation Program," Assembly Engineering, pp. 9-10 (Aug. 1990).

45. R. K. Flitney, B. S. Nau, and D. Reddy, The Seal Users Handbook, 3rd Ed., BHRA, The Fluid Engineering Centre, Cranfield, Bedford, England (1984).

46. J. H. Bickford, "Using Ultrasonics to Measure the Residual Tension in Bolts," Exp. Tech., Special Supplement on Gaskets and Bolted Joints, $\underline{12}$ (11), 1s-5s (1988).

47. Dale A. Barsness, "Unlocking the Secrets of Threadlocking," Assembly Engineering, pp. 21-23 (Jan. 1990).

48. P. Bennett, "Selecting Fastener Locking Elements," Machine Design, p. 107 (July 26, 1990).

49. J. Bickford, "Bolting Flanged Joints," Proc. of 12th Int. Conf. Fluid Sealing, May 10-12, 1989, Brighton, England, pp. 187-197 (1989).

50. J. R. Winter, "Use of an Ultrasonic Extensometer to Determine the Variation in the Assembly Bolt Loads of a Problem Industrial Flange," Exp. Tech., Special Supplement on Gaskets and Bolted Joints, 12 (11), 6s-11s (1988).

51. P. Holland, "Tightening Up on Performance With New Equipment," Nucl. Eng. Int. $\underline{3}$ (412), 43 (1988).

52. "Advanced Multi-Stud Tensioners for Convoy Plants," Nucl. Eng. Int. $\underline{33}$ (412), 38-39 (1989).

53. "Maintaining Leak-Free Vessels Seals at French PWRs," Nucl. Eng. Int. $\underline{35}$ (426), 48-49 (1990).

54. "Framatome Robots Aid Opening and Closing of Reactor Pressure Vessels," Nucl. Eng. Int. $\underline{3}$ (412), 36-38 (1988). 
55. R. G. Wensel, Resistance of O-Ring Seal Compounds to Heat and lonizing Radiation in Air and in Water, Atomic Energy of Canada, Ltd. Report AECL-5697 (1977).

56. R. G. Wensel and B. M. Cotnam, Evaluation of O-Rings of Various Elastomer Compounds for Service in Hot Water, Atomic Energy of Canada, Ltd. Report AECL-6214 (1978).

57. M. L. Blakeston, K. A. Tomblin, and J. Ward, "The Testing of Elastomers for Channel Sea Plugs in a Steam Generating Heavy Water Nuclear Reactor," Proc. of 8th Int. Conf. on Fluid Sealing, September 11-13, 1978, Univ. of Durham, England, pp. G1:1-22 (1979).

58. P. E. Zapp, Effects of Tritium in Elastomers, Savannah River Laboratory Report DP-MS-82-54 (1982).

59. P. E. Zapp and G. L. Tuer, Jr., Degradation of Elastomers by Tritium Beta Radiation, Savannah River Laboratory Report DP-MS-84-103 (1983).

60. D. O. Coffin, S. P. Cole, and R. C. Wilheim, "A Tritium-Compatible Piezoelectric Valve for the Tokamak Fusion Test Reactor," Fus. Tech. 14, 972-976 (1988).

61. K. F. Wylie, Los Alamos National Laboratory, personal communication (May 31, 1990).

62. K. F. Wylie, "Anatomy of an Elastomer Selection for a Gas Seal," Proc. of 11 th SUBWOG-12B, May 21-25, 1990, Savannah River Site, Aiken, South Carolina (1990).

63. J. R. Carnes, Tritium Compatible Barrier Materials, M. S. Thesis, University of Texas at Austin (May 1990).

64. R. W. King, N. J. Broadway, R. A. Mayer, and S. Palinchak, "Polymers," Effects of Radiation on Materials and Components, J. F. Kircher and R. E. Bowman, Eds., Reinhold Publishing, New York, pp. 84-166 (1964).

65. W. W. Parkinson and O. Sisman, "The Use of Plastics and Elastomers in Nuclear Radiation," Nucl. Eng. Des. 17, 247-280 (1971).

66. L. N. Koenig and C. V. Subramanian, "Leaking Potential of LWR Containment Penetrations Under Severe Accident Conditions," Nucl. Eng. Des. 100, 121-128 (1987).

67. L. W. Dickson, "A Preliminary Assessment of the Effects of Radiation on Polymer Properties," Atomic Energy of Canada, Ltd. Report AECL-9556 (1988).

68. W. H. Buckalew and J. Chenion, "U.S./French Joint Research Program Regarding the Behavior of Polymer Base Materials Subjected to Beta Radiation," Sandia National Laboratory Report SAND-86-0366/3, NUREG/CR-4530/3 (1989). 
69. D. W. Southwart, "Laboratory Assessment of the O-Ring Sealing Performance," Proc. of 7th Int. Conf. on Fluid Sealing, September 24-26, 1975, Univ. of Nottingham, England, pp. E1:1-10 (1976).

70. G. L. Strouse, "Better Way to Measure Sealing Capacity," Nachine Design, p. 50 (July 12, 1990).

71. D. H. Weitzel, P. R. Ludtke, and R. F. Robbins, "Design of Static Elastomer Seals for Cryogenic Temperatures," Pressure Vessels and Piping, Vol. 4, Design and Analysis, H. H. Waite, Ed., Am. Soc. Mech. Eng., New York, pp. 215-224 (1976).

72. C. DeSmedt, J. L. Kosrnala, and A. M. Sohlo, "Fluorocarbon Performance and Applications," Proc. of 10th Int. Conf. on Fluid Sealing, April 3-5, 1983, Innsbruck, Austria, pp. 157-171 (1984).

73. R. Metcalfe, S. B. Baset, R. Lesco, and W. N. Selander, "Modelling of Space Shuttle Solid Rocket O-Rings," Proc. of 12th Int. Conf. on Fluid Sealing, May 10-12, 1989, Brighton, England, pp. 3-25 (1989).

74. MARC General Purpose Finite Element Program - Revision K.3," Vols. 1-4, MARC Analysis Research Corp., Palo Alto (1988).

75. P. A. Ross-Ross, E. J. Adams, D. F. Dixon, and R. Metcalfe, "Performance and Reliability of Primary Circuit Components in CANDU Reactors," in Nuclear Energy Maturity, Proceedings of European Nuclear Conference, Vol. 6, Nuclear Quality, Assurance and Reliability, R. Sher, M. Mantega, J. Gueron, and M. M. R. Williams, Eds., Pergamon Press, Oxford (1975).

76. D. F. Dixon, Valves for Primary Heat Transport Systems for Canadian Power Reactors, Atomic Energy of Canada, Ltd. Report AECL-3858 (1971).

77. W. A. Wolfe and G. W. E. Nieu whof, AECL's Reliability and Maintainability Program, Atomic Energy of Canada, Ltd. Report AECL-5504 (1975).

78. N. Issid, "Excellent Performance Record with Live Load Stem Packing," Nucl. Eng. Int. $\underline{32}$ (390), 46 (1987).

79. N. E. Pothier, "Performance Testing of Prototype Live Loaded Packed Stem Seals for Large Gate Valves in Pressurized Hot Water," Proc. of 7th Int. Conf. on Fluid Sealing, September 24-26, 1975, Univ. of Nottingham, England, pp. G1:1-16 (1976).

80. N. E. Pothier, Application of Belleville Springs as Energy Storage Devices on Packed Valve Stem Seals in CANDU Power Reactor Service, Atomic Energy of Canada, Ltd. Report AECL-5555 (i976). 
81. N. E. Pothier, Observed Load Deflection Characteristics of Belleville Springs Under Static Loads at Room and Elevated Temperatures, Atomic Energy of Canada, Ltd. Report AECL-5505 (1976).

82. D. F. Dixon, Solving the Problem of a Valve Stem Leak, Atomic Energy of Canada, Ltd. Report AECL-5550 pp. 3-7 (1976).

83. W. A. Crago, Low Leakage Mechanical Joint Development, Atomic Energy of Canada, Ltd. Report AECL-5550 pp. 21-25 (1976).

84. G. L. Doubt, Reference Book for Design of Valve Packings, Sealing High Temperature Water, Atomic Energy of Canada, Ltd. Report AECL-5120 (1976).

85. D. F. Dixon, J. M. Farr, and R. F. Coutinho, Valve Stem Packing Seal Test Results for Primary Heat Transport System Conditions in Canadian Nuclear Generating Stations, Atomic Energy of Canada, Ltd. Report AECL-6183 (1978).

86. H. Tamm, V. S. Krishnan, H. E. Rosinger, A. C. Vikis, J. C. Wood, and D. J. Wren, Overview of the Technical Basis for the Safety of CANDU Reactors, Atomic Energy of Canada, Ltd. Report AECL-9559 (1988).

87. K. R. Hedges and E. M. Hinchley, "CANDU3 Aims to Provide a Smaller, Cheaper, More Reliable Alternative," Nucl. Eng. Int. 35 (430), 22-25 (1990).

88. "EdF Reports Good Experience with Improved Stem Seals," Nucl. Eng. Int. $\underline{33}$ (410), 48 (1988).

89. C. X. Latty, "Valve Stem Sealing in Nuclear Plants," in 11th Int. Conf. on Fluid Sealing, B. S. Nau, Ed., Elsevier Applied Science Publishers, New York, pp. 189-210 (1987).

90. M. Sivers, "New Live Loading Design Improves Gland Sealing," Nucl. Eng. Int. $\underline{33}$ (411), 44-45 (1988).

91. E. Koch, W. Muser, and N. Schauki, "How the Germans are Benefiting from a Rigorous Approach to Quality," Nucl. Eng. Int. 32 (390), 44-45 (1987).

92. K. Bohner, H. Blenke, and R. Hinkel, "Lateral Stress Ratio, Deformation, and Relaxation of Stuffing Box Soft Packings," Proc. of 7th Int. Conf. on Fluid Sealing, September 24-26, 1975, Univ. of Nottingham, England, pp. E3:25-42 (1976).

93. K. Hayashi and K. Hirasata, "Experimental Derivations of Basic Characteristics of Asbestoid and Graphitic Packings in Mounted Conditions," Proc. of 12th Int. Conf. on Fluid Sealing, May 10-12, 1989, Brighton, England, pp. $59-74$ (1989). 
94. S. K. Ruggieri and J. Kelly, "Valve Stem Packing Improvements," in EPRI Power Plant Valves Symposium, B. Brooks, T. H. McCloskey, and S. E. Pace, Eds., Electric Power Research Institute Report EPRI CS/NP-5878-SR, pp. 2-15 to 2-28 (1988).

95. S. K. Ruggierei, Foster-Miller, Inc., personal communication (March 9, 1990).

96. J. U. Derby, E. G. \& G. Sealol, personal communication (March 6, 1990).

97. C. W. Adey and J. J. Klein, Valve Stem Packing Improvement Study, Electric Power Research Institute Report EPRI NP-2560 (1982).

98. S. K. Ruggierei, Valve Stem Packing Improvements, Electric Power Research Institute Report EPRI NP-4255 (1986).

99. E. A. Bake and R. J. Gradle, "Tests of Asbestos-Free Stem Packings for Valves for Elevated Temperature Service," Rockwell Technical Article V-Rep 86-2 (1986).

100. S. K. Ruggieri and J. S. Kelly, Valve Stem Packing Improvements, Electric Power Research Institute Report EPRI NP-5697 (1988).

101. S. Lipton, "Fugitive Emission Control in Packed Valves," Chem. Eng. Prog. $\underline{86}$, 70-76 (1990).

102. J. Blanco, Field Test Report on Manually Operated 1" Nuclear Valves, Electric Power Research Institute Report EPRI NP-3646 (1984).

103. R. A. S. Lee, Improvements in Motor-Operated Valves, Electric Power Research Institute Report EPRI NP-4254 (1984).

104. Application Guidelines for Check Valves in Nuclear Power Plants, Electric Power Research Institute Report EPRI NP-5479 (1988).

105. A. G. Charbonneau, "Movats Signature Analysis Helps Prevent Malfunctions," Nucl. Eng. Int. 31 (386), 40-41 (1986).

106. D. M. Ciesielsi, "Using Ultrasonics to Avoid Check Valve Disassembly," Nucl. Eng. Int. 33 (410), 42-44 (1988).

107. J. M. Heald, "The Seal's Environment - Its Housing," Proc. of 7th Int. Conf. on Fluid Sealing, September 24-26, 1975, Univ. of Nottingham, England, pp. X17-X24 (1976).

108. R. Metcalfe, N. E. Pothier, and B. H. Rod, "Diametral Tilt and Leakage of End Face Seals with Convergent Sealing Gaps," Proc. of 8th Int. Conf. on Fluid Sealing, September 11-13, 1978, Univ. of Durham, Ergland, pp. A1:1-14 (1979). 
109. J. Phillips and C. M. Johnson, "Quality Control and Its Place in Shaft Sealing," Proc. of 8th Int. Conf. on Fluid Sealing, September 11-13, 1978, Univ. of Durham, England, pp. E1:1-12 (1979).

110. E. Makay and O. Szamody, Recommended Design Guidelines for Feedwater Pumps in Large Power Generating Units, Electric Power Research Institute Report EPRI CS-1512 (1980).

111. R. G. Wensel and R. Metcalfe, The Significance of Eccentric Mountings and Elastomer Resistance in Main Coolant Pump Face Seals, Electric Power Research Institute Report EPRI NP-3714 (1984).

112. R. G. Wensel, Factors Affecting Wear Damage to Elastomer Seals in Main Coolant Pump Face Seals, Electric Power Research Institute Report EPRI NP-4245 (1985).

113. R. Wensel, B. Cotnam, H. Gentili, and I. Constantinescu, "Friction and Axial Force/Displacement Characteristics of Elastomer Seals in Water," Iubrication Eng. 41, 550-555 (1985).

114. R. Metcalfe, Sensitivity of Reactor Coolant Pump Seal to Changes in Operating Conditions, Electric Power Research Institute Report EPRI NP-4244 (1985).

115. C. A. Kittmer et al., "Reactor Coolant Pump Shaft Seal Behavior During Station Blackout," Nuclear Regulatory Commission Report NUREG/CR-4077, EGG-2365, AECL-MISC-305 (1985).

116. T. Boardman, N. Jeanmougin, R. Lofaro, and J. Prevost, Leak Rate Analysis of the Westinghouse Reactor Coolant Pump, Nuclear Regulatory Commission Report NUREG/CR-4294 (1985).

117. S. Mitra and R. Youngblood, Evaluation of Core Damage Sequences Initiated by Loss of Reactor Coolant Pump Seal Cooling, Brookhaven National Laboratory Report BNL-NUREG-52003 (1986).

118. I. J. Karassik, W. C. Krutzsch, W. H. Fraser, and J. P. Messina, Pump Handbook, 2nd Ed., McGraw-Hill, New York (1986).

119. P. Wilm Wernecke, "Analysis of the Reciprocating Sealing Process," in 11 th International Conference on Fluid Sealing, B. S. Nau, Ed., Elsevier Applied Science Publishers, New York, pp. 249-277 (1987).

120. "Review of Design and Development of High Performance Gas Compressor Seals," in 11th International Conference on Fluid Sealing, B. S. Nau, Ed., Elsevier Applied Science Publishers, New York, pp. 533-547 (1987). 
121. D. B. Rhodes, R. C. Hill, and R. G. Wensel, Reactor Coolant Shaft Seal Stability During Station Blackout, Nuclear Regulatory Commission Report NUREG/CR-4821 , EGG-2492 or AECL-9342 (1987).

122. M. Subudhi, J. H. Taylor, J. H. Clinton, C. J. Czajkowski, and J. R. Weeks, Indian Point 2 Reactor Coolant Pump Seal Evaluations, Brookhaven National Laboratory Report BNL-NUREG-52095 (1987).

123. J. Jackson, "Current Status of Generic Issue 23: Reactor Coolant Pump Seal Failures," in Proceedings: Main Coolant Pump Diagnostics, Electric Power Research Institute Report EPRI NP-6116 (1988).

124. R. Metcalfe, "Canadians Solve Seal Problenıs," Nucl. Eng. Int. $\underline{35}$ (420), 46-50 (1989).

125. "Longer Life Pump Seals for German Plants," Nucl. Eng. Int. 34 (420), $50-51$ (1989).

126. G. A. Green and F. J. Tribe, "Carbon-Carbon Composite Materials for Submarine Propeller Shaft Seals," in 11th International Conference on Fluid Sealing, B. S. Nau, Ed., Elsevier Applied Science Publishers, New York, pp. 611-630 (1987).

127. "Liquid Ring Seal for Rotating Shafts," Machine Design, p. 26 (Jan. 1, 1990).

128. H. D. Muller and W. Schneider, "An Internal Canned-Motor Unit for the Advanced BWR," Nucl. Eng. Int. 32 (390), 50-51 (1987).

129. "How the 'Wet Motor' Can Help Eliminate RWCU Leaks," Nucl. Eng. Int. 33 (410), 51-52 (1988).

130. D. R. Nixon, "The Role of Canned Motor Pumps in Upgrading Power Plants," in Symposium Proceedings: Power Plant Pumps, Electric Power Research Institute Report EPRI CS-5857, pp. 2-133 to 2-144 (1988).

131. H. Dittmer, A. Reymann, and H. Reinecker, "Advanced Development and Operating Experience with a Canned Motor Pump under Pressurized Water Reactor Conditions," Pump Congress, Karlsruhe, Germany, p. 3 (1988).

132. S. M. Englund, "Opportunities in the Design of Inherently Safer Chemical Plants," in Advances in Chemical Engineering, J. Wei, J. L. Anderson, K. B. Bischoff, and J. H. Seinfeld, Eds., Vol. 15, Academic Press, New York, pp. 73-135 (1990).

133. Westinghouse Canned Motor Pumps data sheets.

134. John Lepitsch, KSB (Klein, Schanlin, Becker), Germany, personal communication (May 4, 1990).

135. A. E. Goldman, U.S. Graphite, Saginaw, MI, personal communication (July 10, 1990). 
67

136. Steven Tower, Westinghouse Corp., personal communication (July 1990).

137. A. Cruickshank, "Westinghouse Simplifies the PWR," Nucl. Eng. Int. $\underline{35}$ (426), 56-58 (1990).

138. S. S. Grossel, "Highly Toxic Fluids, Moving Them Around the Plant," Chem. Eng., pp. 110-115 (Apr. 1990).

139. W. Gondi, Westinghouse Savannah River Site, personal communication (June 6, 1990).

140. J. G. Melvin and R. B. Maxwell, Reliability and Maintainability Manual Process Systems, Atomic Energy of Canada, Ltd. Report AECL-4607 (1974).

141. "Nuclear Research in France," French Nuclear Newsletter, pp. 8-10 (May 1986). 